\title{
JUSTIZBEHÖRDEN UND GERICHTE
}

\section{$3.1 \quad$ Justizverwaltung}

Mit dem 1. und 2. Gesetz zur Überleitung der Rechtspflege auf das Reich vom 16. Februar 1934 (RGBI. I, S. 91) und vom 5. Dezember 1934 (ebda, S. 1214) wurde die gesamte Justiz vom Reich übernommen. Die Justizministerien der Länder wurden im Laufe des Jahres 1935 beseitigt. Die Einheitlichkeit kam auch darin zum Ausdruck, daB für alle Einrichtungen der Justiz vom Reichsjustizministerium bis zum letzten Amtsgericht gültige Vorschriften für die Schriftgutverwaltung eingefuihrt wurden, nach denen deren archivalische Überlieferung in der Regel geordnet ist. Sie unterschieden zwischen General- (=Verwaltungs-) Akten und den nur bei den Gerichten und Staatsanwaltschaften geführten Verfahrensakten. Der Generalaktenplan von 1935 schrieb folgende neun Hauptgebiete mit jeweils bis zu neun Gruppen vor, die wiederum bis zu neun Untergruppen zu je 9 Einzelaktentiteln umfassen konnten:

1 Verfassung und Verwaltung

2 Rechts- und Dienstverhältnisse der Staatsbediensteten

3 Zivilrecht und Zivilrechtsgang einschl. Gerichtsverfassung

4 Strafrecht und Strafrechtsgang einschl. Strafvollzug, Polizei

5 Finanzwesen

6 Kultur- und Wohlfahrtspflege

7 Wirtschaftsangelegenheiten

8 Land- und Forstwirtschaft

9 Wehrmacht und auswärtige Angelegenheiten.

In den entsprechenden Beständen aller Archive sind daher aus der Zeit ab 1935

z. B. Akten über das Verhältmis der Justiz zur NSDAP unter den Aktenzeichen der Untergruppe 105 zu suchen, über Gestapo und Schutzhaft unter 4606 bzw. 4611, uber Militärstrafrecht in Untergruppe 902.

Lit.: ANWEISUNG für die Verwaltung des Schriftguts in Justizverwaltungsangelegenheiten. 1936. - HANDBUCH der Justizverwaltung.(1942). - Die DEUTSCHE JUSTIZ und der Nationalsozialismus. 1968. 1970. M. HIRSCH, D. MAJER. J. MEINCK: Recht, Verwaltung und Justiz im Nationalsozialismus. 1984.

\subsubsection{Reichsministerium der Justiz}

BA, Best. R 22

ZStA, Best. 30.01

Während sich Akten aus den Jahren 1933/34 fast ausschlieBlich im ZStA befinden, ist die trotz Kriegsverlusten umfangreiche Überlieferung aus der Zeit ab der Vereinigung mit dem preuBischen Justizministerium zwischen Koblenz und Potsdam geteilt; dabei ist noch zu unterscheiden zwischen Generalakten (überwiegend BA) und Einzelfallakten (überwiegend ZStA).

Der Koblenzer Bestand, der zum Teil auch Vorgänge aus den Büros der Minister Franz Gürtner (1932-1941, dabei Korrespondenzen und Kopie des von Hans v. Dohnanyi von Oktober 1934 bis Dezember 1938 geführte dienstlichen Tagebuchs) und Otto Thierack (ab 1942), der Staatssekretäre Franz Schlegelberger (1931-1942, 1941/42 mit der Führung der Geschäfte des Ministers beauftragt), Curt Rothenberger (1942-1943) und Herbert Klemm (ab 1944), nicht jedoch Roland Freisler (1934/35-1942) enthält, ist nach dem Aktenplan unabhängig von den Organisationseinheiten geordnet: 
Von den Akten des Hauptgebiets 1 (ca. 150 Bde) betreffen die meisten Geschäftsverteilung und Geschäftsgang (ca. 50). Ferner gehören dazu die Vorgänge über NSDAP und Gliederungen (6 Bde), Protektorat Böhmen und Mähren (11 Bde), Nürnberger Rassegesetze (4 Bde), Justizpressewesen und Gerichtsberichterstattung (15 Bde).

Im Hauptgebiet 2 (ca. $350 \mathrm{Bde}$ ) haben die Akten über die Dienstverhältnisse der Richter und Staatsanwälte den gröBten Anteil (ca. 70 Bde). Von mehr als 15000 bis 1945 in diesen Ämtern, im Strafvollzug und im Ministerium tätigen oder ausgeschiedenen Juristen und Beamten sind Personalakten überliefert (weiterer Teil im ZStA). Dazu kommen die Akten über die personelle Besetzung der einzelnen Gerichte aller Instanzen einschlieBlich der Erbhof- und Erbgesundheitsgerichtsbarkeit (ca. 900 Bde).

$\mathrm{Zu}$ den Generalakten des Hauptgebiets 3 (ca. 750 Bde, überwiegend betr. Gerichtsverfassung im allgemeinen, materielles bürgerliches Recht und Verfahrensrecht der freiwilligen Gerichtsbarkeit) gehören Aufzeichnungen und Protokolle über die Konferenzen der Chefpräsidenten der Gerichte und anderen Behördenleiter (14 Bde) und Besprechungen Thieracks (1942-1944), Lageberichte der Oberlandesgerichtspräsidenten und Generalstaatsanwälte (35 Bde, überwiegend ab 1940), die „Führerinformationen“, mit denen Hitler über wichtige Vorgänge informiert wurde (187 Nrn, 1942-1945), die ,Richterbriefe“ zur Lenkung der Rechtsprechung und Material zu der von Rothenberger betriebenen Justizreform für eine „Rechtsprechung durch das Volk“ und ein „Volksgesetzbuch“ (ca. 45 Bde). Ferner liegen Akten über die Rechtsanwaltschaft (ca. 70 Bde) und über Gerichtsorganisation vor (ca. 75 Bde, dabei Volksgerichtshof 3, Sondergerichte 2 Bde, Standgerichte 1945), Entscheidungen des Reichsgerichts in Zivilsachen (14 Bde, 1939 . 1945) und des Reichsarbeitsgerichts (1943/44). Einzelfallakten belegen die Befreiung von der Beibringung ausländischer Ehefähigkeitszeugnisse (6 Bde), die Anerkennung ausländischer Ehescheidungen (30 Bde) und die Befreiung von handelsrechtlichen Vorschriften nach der VO vom 15. 1. 1940 (ca. 900 Vorgänge über einzelne Firmen insbes. der Rüstungswirtschaft). Außerdem sind Eingaben in Zivilprozessen vorhanden (58 Bde).

Die Akten über Strafrechtspflege und Strafvollzug (ca. I 000 Bde) bieten u. a. Material zu einzelnen Deliktsarten, z. T. mit Vorgängen über einzelne Verfahren, z. B. Hochund Landesverrat (13 Bde) und über Maßnahmen in eingegliederten und besetzten $\mathrm{Ge}$ bieten (9 Bde), Kritik von NSDAP und SS an Urteilen (4 Bde, 1939-1944), Behandlung „Gemeinschaftsfremder“ (4 Bde), Tötung von Geisteskranken (3 Bde, 1939-1941), Kriminalstatistik (14 Bde), Jugendstrafrecht (27 Bde), Ausübung des Gnadenrechts, auch in Einzelfällen (10 Bde), Vollzug der Todesstrafe (14 Bde und Mikrofilm von 38 Bden des Vollstreckungs- (sog. „Mord“-) Registers 1939-1945), Arbeitseinsatz von Strafgefangenen (ca. 50 Bde). Umfangreich sind die Akten über die Strafrechtsreform, die teilweise (136 Bde) von den dafür 1933-1936 bzw. 1938 eingesetzten Strafrechts- und Strafprozeßkommissionen stammen. Außerdem ist eine alphabetische Kartei über den Arbeitseinsatz von Häftlingen (vor allem Ausländern) der Justizvollzugsanstalten (ca. 26000 Karten) vorhanden; sie bietet Angaben aus der Zeit von 1942-1945 u. a. über Anstalt, Straftat, Strafzeit und -art, Strafende, Werdegang und Beruf, Anlernfähigkeit als Metallarbeiter oder Feinmechaniker, Arbeitsbetrieb. Ein vom Reichsjustizministerium veranlaBter Film "Arbeit und Strafvollzug im Zuchthaus Brandenburg-Görden“ von 1942 befindet sich im Bundesarchiv-Filmarchiv.

Relativ wenig Akten sind aus den Hauptgebieten 5 (ca. 200 Bde, vor allem betr. gerichtliches Kostenwesen), 6 (ca. 50 Bde, dabei Kirchen 9, Erbgesundheitspflege 5 
Bde), 7 (ca. 120 Bde, dabei Versicherungswesen 24, Verkehr 29, Arbeitsrecht 26 Bde) und 8 (ca. 250 Bde, dabei ca. 100 Erbhofrecht mit Entscheidungen des Reichserbhofgerichts und einzelner Erbhofgerichte, auBerdem 166 Einzelfallakten über Fideikommisse 1942-1945 und 550 über Abweichungen von der gesetzlichen Anerbenfolge 1937-1944) überliefert.

Von den Akten des Hauptgebiets 9 überschneiden sich diejenigen der Gruppe 913, Kriege gegen Deutschland, z. T. mit solchen der anderen Hauptgebiete. Sie enthalten die Unterlagen über die in Rechtsprechung und Verwaltung seit 1939 vor allem zur Verkürzung und Vereinfachung des Verfahrens, zur Verschärfung des Strafrechts und gegen Angehörige von Feindstaaten erlassenen Vorschriften und deren Durchführung (ca. 200 Bde) und über die Einführung und Anwendung deutschen Rechts in eingegliederten und besetzten Gebieten (ca. $60 \mathrm{Bde}$ ). Den gröBten Anteil an dieser Hauptgruppe haben allerdings die Serien über Gesetzgebung und Verwaltung in ausländischen Staaten (ca. 430 Bde nach Länderalphabet), über Abkommen mit einzelnen Ländern (ca. 280 Bde) und über Kollektivvereinbarungen und internationale Interessengemeinschaften auf verschiedenen Rechtsgebieten (ca 100 Bde). Die Anzahl der Akten über Wehrmachtsangelegenheiten einschließlich Luftschutz (ca. $60 \mathrm{Bde}$ ), über auswärtige Angelegenheiten und Völkerrecht im allgemeinen (ca. 50 bzw. 6 Bde) und über Kriegsrecht (22 Bde, vor allem Prisenrecht) ist dagegen geringer.

Der Potsdamer Teilbestand ist nach Organisationseinheiten wie folgt gegliedert: Abteilung 1, Personal- und Organisationsangelegenheiten: Allgemeine Organisations- und Personalsachen (115 Bde, 1934-1944/45); Besetzung der Amtsgerichte, Landgerichte, der Staatsanwalt- sowie der Amtsanwaltschaften (ca.1200 Bde, 1934-1944); Aufbau der Justizverwaltung in Lothringen (2 Bde, 1940-1942); Einzelangelegenheiten der Rechtsanwälte und Notare (60 Bde, 1943-1945).

Abteilung $\Pi$, Ausbildung und Fortbildung: Akten im Bestand Reichsjustizprüfungsamt (unten 3.1.3.5).

Abteilung III, Strafgesetz und Jugendrecht (bis 1941): u. a. Listen über Gnadenentscheidungen (1937-1939), von Todesurteilen gegen Volksschädlinge und Gewaltverbrecher (1940-1941), Generalakten und Tätigkeitsberichte über Sondergerichte in den eingegliederten Ostgebieten (3 Bde, 1939-1941), Übersicht über Strafverfahren gegen Geistliche (1936-1938); Verzeichnisse geschichtlich wervoller Akten aus den OLGBezirken (35 Bde, u. a. über Ritualmorde 1900-1940).

Abteilung IV, Strafrechtspflege (30 Bde, 1934-1944, u. a. betr. Konferenzen der Strafvollzugsreferenten, Listen beantragter Todesurteile, 1942-1943, Abgabe von Urteilen und Anklageschriften an das Reichsministerium für Volksaufklörung und Propaganda, 1941-1942).

Abteilung V, Strafvollzug (ca. 300 Bde, 1934-1945, dabei Akten über land- und forstwirtschaftliche Arbeitsbetriebe, Gefangenenfürsorge im allgemeinen und durch einzelne Vereine, Reichsvollzugsstatistik 1936-1942, Belegungs- und Beschäftigungsübersichten der einzelnen Vollzugsanstalten 1934-1943), Vorgänge über die Strafgefangenenlager im Emsland 1934-1939 und Zuchthaus Berlin-Plötzensee 1922-1939).

Eine eigene Teilüberlieferung bilden die Akten der Geschäftsstellen der Strafrechtsabteilung (III bis 1942, dann IV) über einzelne Strafverfahren mit Berichten, Anklageschriften und Urteilen der erkennenden Gerichte und zugeordneten Staatsanwaltschaften. Zu den ursprünglich neun Geschäftsstellen (IIIg I - IIIg) mit Zuständigkeit für Volksgerichtshof (g1), preuBische ( $g 2-g 8)$ und nichtpreuBische OLG-Bezirke kamen bis 
Kriegsende 16 weitere mit regionaler (gll - g 14 nichtpreuBische Bezirke im Altreich. g19 - g22 Bezirke in Österreich, Sudetenland, Protektorat, Ostgebiete) oder sachlicher Zuständigkeit (u. a. g16 - g18 für kirchenpolitische Strafsachen, g23 und g24 für Verfahren gegen ausländische Arbeiter).

Aus diesen Registraturen enthält der Bestand im ZStA ca. 75000 Einzelfallakten aus dem Zeitraum 1934-1945. Sie betreffen neben den Verfahren wegen unpolitischer Delikte Hoch- und Landesverratssachen, andere politische Straftaten, Vorwürfe gegen Geistliche, deretwegen zu einem großen Teil vor Sondergerichten verhandelt wurde. Außerdem ist ein kleiner Teil der vom Reichsjustizministerium (Abt. IIIw) als ,geschichtlich wertvoll" ausgesonderten Einzelfallakten des Reichsgerichts und der Oberreichsanwaltschafi beim Reichsgericht sowie von Länderbehörden vorhanden.

Im Bestand befinden sich jetzt auch die bisher im ehem. Zentralen Parteiarchiv der SED aufbewahrten Justizakten (Bestand St l, 154 Bde, und Bestand NJ 24943 Bde). Der Teilbestand NJ wurde aus Einzelfallakten von Volksgerichtshof, Oberreichsamwalt beim Reichsgericht sowie Oberreichsanwalt beim Volksgerichtshof, Reichsjustizministerium und verschiedenen Feldgerichten zusammengefaBt, die künftig nach der Provenienz geordnet werden sollen. Dasselbe gilt für eine beträchtliche Anzahl von Einzelfallakten vor allem der Abteilungen III/TV, die im Zusammenhang mit der Auflösung ehemaliger Ministerien der DDR übernommen wurden. Alle Einzelfallakten sind durch vielfältige, im Reichsjustizministerium, im ehem. ZPA oder im ZStA erstellte Karteien, Register, Übersichten usw. erschlossen.

Abteilung VI Bürgerliches Recht und Rechtspflege, bäuerliches Recht: u. a. Akten zur Grundbuchordnung (15 Bde, 1935-1943), zur Erbgesundheitspflege (18 Bde, 1934 1938), zum Reichsjagd- und Reichsforstgesetz (7 Bde, 1934-1942), zum FideikommiBund Erbhofrecht (11 Bde, 1934-1941), Kollektivvereinbarungen zum internationalen Privatrecht mit Arbeitsschutzrecht für Kinder, Jugendliche und Frauen, Sozialversicherungsrecht (12 Bde, 1934-1941), Unterlagen über die Konvention zum Schutz von Werken der Literatur und Kunst (3 Bde, 1934-1942).

Abteilung VII, Handels-, Verkehrs- und Wirtschaftsrecht, Vereinsrecht, Öffentliches Recht und Völkerrecht: Relativ umfangreiche Überlieferung zum Aktienrecht, dabei insbesondere Einzelfälle (250 Bde, 1936-1943), ferner Akten über See-, Seehandelsund Seeversicherungsrecht, insbesondere Arbeiten des Seerechtsausschusses der Akademie für Deutsches Recht (15 Bde, 1935-1941), über Aufbau von Staat und Wirtschaft, wirtschaftliche Zusammenschlüsse, Industrie- und Handelsabkommen (78 Bde, 1934 1943), andere Abkommen mit einzelnen Staaten (10 Bde, 1934-1942), über Luft- und andere Verkehrsrechtsfragen (18 Bde, 1934-1941), über Abwesenheitspflegschaften bei der Verwaltung feindlichen Vermögens (ca. 2000 Bde Einzelfallakten, ca. 60 Bde Generalakten), schließlich über Ansprüche auf Kolonien (2 Bde, 1936-1943).

Abteilung VIII, Haushaltssachen (ca. 560 Bde, 1934-1943, vor allem zum Haushalt der Reichsjustizverwaitung und zu Bauangelegenheiten in den Oberlandesgerichtsbezirken). Eine spezielle Überlieferung (1893-1943) liegt über die Strafanstalten (ca. 300 Bde) und Haushaits- und Personalangelegenheiten (ca. 180 Bde) in Bayern vor.

Aus der Tätigkeit der zeitweilig für die Einführung des Reichsrechts gebildeten Abteilung Österreich sind u. a. Unterlagen über den Brand des Wiener Justizpalastes (10 Bde, 1927-1938), Justiz- und Kriminalstatistik (6 Bde, 1934-1936) sowie Personalakten von Beamten der Abteilung überliefert. 
Eine bedeutende Ergänzung für die aktenmäßige Überlieferung bilden die amtlichen Druckschriften des Reichsjustizministeriums (ZStA und BA), darunter das Amtsblatt: Deutsche Justiz, Rechtspflege und Rechtspolitik (1934-1945). - Handbuch der Justizverwaltung. - Deutsches Jugendrecht. Beiträge für die Praxis und Neugestaltung des Jugendrechts (1941-1944).

Die Akten werden weiterhin wesentlich ergänzt durch die im Nürnberger JuristenprozeB vor dem amerikanischen Militärgericht 1947 vorgelegten Dokumente und die Protokolle der Hauptverhandlung (BA, Best. All. Proz. 1; IfZ). Angeklagt waren die Staatssekretäre Schlegelberger, Rothenberger und Klemm, der Leiter der Zivilrechtsabteilung Altstötter und aus den Strafrechts- und -vollzugsabteilungen der Ministerialdirigent Mettgenberg und die Ministerialräte v. Ammon und Engert. Vor dem Landgericht Wiesbaden wurde 1952 der Leiter der Strafvollzugsabteilung, Ministerialdirektor Marx, zusammen mit drei Referenten vor allem wegen der Auslieferung von Strafgefangenen in Konzentrationslager angeklagt und freigesprochen (JUSTIZ UND NATIONALSOZIALISMUS, Nr. 310).

Lit: SCHRIFTEN ZUM STAATSAUFBAU 36/37. 1939. - TRIALS of WAR CRIMINALS. vol. 3. - QUELLEN zur Reform des Straf- und StrafprozeBrechts. Hrsg. von W. Schubert u. a Abt. 2: NS-Zeit (1933-1939) - Strafgesetzbuch. 1988. - H. HATTENHAUER: Das NS-Volksgesetzbuch. 1983. - E. REITTER: Franz Gürtner. 1976. - H. BOBERACH: Richterbriefe. 1975. - C. STROHM: Das von Hans v. Dohnanyi geführte Dienstagebuch des Reichsjustizministers. 1988. - VOM REICHSJUSTIZAMT zum Bundesministerium der Justiz. 1977. - G. GRIBBOHM: Die Führerinformationen des Reichsministers der Justiz. - L. GRUCHMANN: Ein unbequemer Amtsrichter im Dritten Reich. 1984. - Ders.: Justiz im Dritten Reich 1933-1940. 1987.

\subsubsection{Justizministerien der Länder}

Die Überlieferung der 1934 aufgehobenen obersten Landesjustizbehörden aus den beiden ersten Jahren der NS-Herrschaft ist teilweise in deren fortgeführten älteren Akten enthalten, soweit diese nicht im Krieg vernichtet wurden; sie fehlt völlig für Braunschweig, und in Lippe und Schaumburg-Lippe gab es keine spezielle Justizverwaltung (vgl. Abschnitte 1.2.8 und 1.2.9). Die Überlieferung der Bremer Justizverwaltung, für die 1933 erstmals mit Th. Laue ein Senator für Inneres und Justiz berufen wurde, befindet sich in den Aktenbeständen der Senatskanzlei und der inneren Verwaltung (Abschnitte 1.2.1.1 und 2.1.2.1.7).

Nur in wenigen Fällen wurden, z. B. über die unmittelbaren Auswirkungen der „Machtergreifung“, neue Akten angelegt, die 2. T. auch nach 1934 in den Staatsministerien fortgeführt wurden. Bei den nachstehend nachgewiesenen Beständen handelt es sich jeweils nur um einzelne Aktenbände.

\subsubsection{Preußisches Justizministerium}

GStA, Rep. 84 a

Nachdem der Reichsjustizminister gegen den Widerstand des preußischen Justizministers Kerrl, unter dem Freisler als Staatssekretär wirkte, bereits im Juni 1934 die Leitung auch von dessen Ministerium übernommen hatte, wurden beide Ministerien im Oktober 1934 vereinigt. Die bis dahin entstandenen preußischen Akten wurden nicht fortgeführt, jedoch gemeinsam mit der älteren Überlieferung seit dem Ende des 18. Jahrhunderts nach den Sachgebieten und Aktenzeichen des Generalaktenplans geordnet. So sind aus den Hauptgebieten 1 und 2 Akten über die Gleichschaltung der Länder und das Verhältnis zur NSDAP bzw. Vorgänge über das Berufsbeamtengesetz überliefert. Vorhanden sind ferner Unterlagen über die Einrichtung der Sondergerichte und die Beschleunigung 
des Strafverfahrens, Bemühungen um die Strafrechtsreform und vor allem über die Anordnung über den "Rechtsschutz des Volkes". Bei den Akten der Gruppen 46 und 47 , Polizei, fehlen solche über Gestapo und Schutzhaft. Relativ umfangreich ist die Überlieferung zum Reichserbhofgesetz (20 Bde), weniger zum Erbgesundheitsgesetz und zu den neuen arbeitsrechtlichen Vorschriften (u. a. betr. soziale Ehrengerichtsbarkeit). Neben den Generalakten sind die bis 1934 geführten Akten über die Besetzung der Gerichte und Staatsanwaltschaften in den einzelnen Oberlandesgerichtsbezirken vorhanden. Sie belegen für alle Bezirke die Entfernung politischer Gegner des Nationalsozialismus und von Juden aus ihren Ämtern bei Gerichten und Staatsanwaltschaften, aus der Anwaltschaft und dem Notariat und die Errichtung der Erbgesundheitsgerichte sowie der Erbgesundheitsobergerichte Berlin. Celle. Frankfurt/Main. Hannover, Kassel und Kiel. ferner der Erbhofgerichte Breslau und Kiel.

\subsubsection{Bayerisches Staatsministerium der Justiz}

M, Best. MJu

Aus dem vom Führer des NS-Juristenbundes Hans Frank geleiteten Ministerium sind Akten folgender Sachgebiete überliefert:

Bau- und Grundstückswesen (bis 1936). - Aufsicht über Gerichte und Notare (bis 1935). - Allgemeine Personalangelegenheiten (bis 1936, Gerichtsvollzieher bis 1938). - Rechtsanwaltschaft (bis 1935). - Saargebiet (bis 1935). - Kostenwesen (bis 1936). Reichs- und Staatsrecht (bis 1939, dabei „Nationale Erhebung“ 1933-1941). - Erbgesundheitsgesetz (bis 1936, dabei Statistiken). - Kommunalrecht (bis 1935). - Polizei (bis 1934). - Sozialpolitik, Versicherungswesen (bis 1936, z. T. bis 1942). - Strafrecht (bis 1938, dabei 5 Gnadenverfahren nach Todesurteilen 1933/34). - Kirchenrecht (bis 1934). - Vereinsrecht (bis 1935). - Gerichtsorganisation (bis 1934). - Gesundheitswesen (bis 1938). - Landwirtschaft, Erbhofgesetz (bis 1935). - Arbeitsrecht (bis 1936). - Gewerberecht (bis 1939). - Bankwesen, Devisenbewirtschaftung (bis 1936). - Verkehrsrecht (bis 1935). - Handelsrecht (bis 1935). - Presse- und Urheberrecht (bis 1936). - Schulund Hochschulangelegenheiten (bis 1934).

Lit:: H. RUMSCHÖTTEL: Das Bayerische Staatsministerium der Justiz 1799-1966. 1984.

\subsubsection{Württembergisches Justizministerium}

S, Bestand E 303 b

Mit Ausnahme der Handakten eines Justizverwaltungsrats über Personalangelegenheiten des gehobenen und mittleren Dienstes (13 Bde, 1928-1945, u. a. betr. KdF, Auszeichnungen, Dienststrafverfahren) und einiger im Innenministerium fortgeführter Akten über Personenstandsrecht ist die gesamte Überlieferung aus der Amtszeit des Justizministers Jonathan Schmid im Krieg vernichtet worden.

\subsubsection{Badisches Justizministerium}

KA, Best. 234

In der Amtszeit des Justizministers Otto Wacker wurden u. a. Akten folgender Betreffe geführt:

Banken (1927-1940). - Gerichtsberichterstattung (1927-1935). - Erbgesundheitsgesetz (bis 1936). - Verhältnis Partei und Staat (bis 1936). - Gleichschaltung der Länder. - Beamtenrecht (dabei Ausführung des Berufsbeamtengesetzes). - Handels- und Arbeitsrecht (17 Bde, 1924-1936). - Kirchenrecht. - Polizei (bis 1935, dabei Maßnahmen gegen Kommunisten und Sozialdemokraten, Einstellung ,alter Kämpfer“ der NSDAP). - Strafrecht (bis 1936, dabei Gewohnheitsverbrechergesetz, Vollzug der Todesstrafe, 
Selbstmorde im Landesgefängnis Mannheim 1930-1936). Einzelne vom Justizministerum Südbadens nach 1945 fortgeführte Vorgänge und Personalakten von Richtern befinden sich im StA Freiburg (Best. A 4).

\subsubsection{Oldenburgisches Ministerium der Justiz}

OL, Best. 133

In Oldenburg hatte bereits im Juni 1932 der Nationalsozialist Heinz Spangemacher in der ersten NSDAP-Regierung die Leitung des Justizministeriums übernommen; ihm folgte 1933 Julius Pauly. Im Bestand liegen Lageberichte des Landgerichtspräsidenten (1936-1945) und Akten aus folgenden Sachgebieten vor:

Strafrecht (bis 1936, dabei wichtige politische Strafverfahren, Beleidigung der NSDAP, Einrichtung der Sondergerichte, Beschleunigung der Verfahren, Beschlagnahme kommunistischer Schriften). - Beamtenrecht (bis 1936, dabei Berufsbeamtengesetz, Disziplinarrecht, Förderung von Nationalsozialisten, „Schönheit der Arbeit"). Zusammenarbeit mit der NSDAP (bis 1936). - Rechtsanwaltsordnung (dabei Zulassung von Juden, bis 1937). - Strafvollzug, einzelne Anstalten (bis 1936).

\subsubsection{Hessisches Ministerium der Justiz DA, Best. G 21}

Das von Ministerpräsident Ferdinand Werner geleitete Ministerium wurde wie alle anderen hessischen Ministerien bereits am 22. Juni 1933 aufgehoben, und seine Aufgaben übernahm die Abteilung Ic des Staatsministeriums; die dort bis 1936 geführten Akten folgender Sachgebiete (ca. 70 Bde) befinden sich jedoch in der überlieferten Ministerialregistratur:

Staatsverwaltung (dabei Gleichschaltung, Verhältnis zur NSDAP). - Strafrecht (dabei einzelne Verfahren, Gnadengesuche). - Bevölkerungspolitik. - Sozialversicherung und Wohlfahrtsangelegenheiten. - Gesundheitswesen. - Gewerbepolizei. - Hochschul- und kulturelle Angelegenheiten.

Vorhanden sind außerdem Personalakten und Personalbögen bis 1936 ausgeschiedener Beamter und Rechtsanwälte.

\subsubsection{Hamburgische Senatskommission für die Justizverwaltung}

HH, Best. 241-1 I

Die unter der Aufsicht des Justizsenators Kurt Rothenberger geführten Akten betreffen überwiegend die Dienststellenverwaltung und allgemeine wie einzelne Personalangelegenheiten, außerdem Prozesse des hamburgischen Staates und enthalten Eingaben und Beschwerden sowie Unterlagen über das Gerichtsvollzieheramt (bis 1936). Davon getrennt sind die Akten der Gefängnisverwaltung (Best. 242-1 II), die über 1934 hinausgehen. Sie enthalten Jahresberichte (bis 1941), Erhebungen über die Entwicklung der Kriminalität (bis 1935), Unterlagen über Dienststellenverwaltung, Behandlung der Gefangenen, FürsorgemaBnahmen (1933-1938). In Akten des Staatsamtes (vgl. Abschnitt 1.2.10) ist die Hamburger Justizverwaltung ebenfalls dokumentiert.

\subsubsection{Oberste Reichsbehörden und Einrichtungen}

Nur von folgenden Behörden und Körperschaften, die wie die Gerichte und Justizvollzugsanstalten zum Geschäftsbereich des Reichsministers der Justiz gehörten oder seiner Aufsicht unterstanden, ist Schriftgut aus der NS-Zeit überliefert: 


\subsubsection{Akademie für Deutsches Recht}

BA, Best. R 61

ZStA, Best. 30.13

Der bayerische Justizminister, Reichskommissar für die Gleichschaltung der Justiz in den Ländern und ab 1934 Reichsminister ohne Geschäftsbereich und zugleich Reichsrechtsführer Hans Frank wollte mit der von ihm Juli 1933 zunächst in München errichteten und als Präsident geleiteten Akademie „das nationalsozialistische Programm auf dem gesamten Gebiet des Rechts" verwirklichen.

Der Bestand im BA (500 Bde, 1935-1944) dokumentiert vor allem die Tätigkeit der Abteilung für Rechtsgestaltung und von 53 ihrer insgesamt 87 Aussschüsse und Unterausschüsse durch deren Protokolle und Denkschriften (36 Bde von 20 Ausschüssen, meist vor 1937, ZStA); sie befaBten sich auBer mit den Hauptgebieten des Straf- und Zivilrechts u. a. mit Rechtsfragen der Bevölkerungspolitik (22 Bde), Filmrecht (6 Bde). Kolonialrecht (2 Bde, 1938/39), Luftrecht (17 Bde), Nationalitätenrecht (15 Bde), Religionsrecht (20 Bde), Sozialversicherungsrecht (15 Bde) und der Vorbereitung des „Volksgesetzbuches" (11 Bde, 1938-1944).

Von der Abteilung für Rechtsforschung sind allgemeine Unterlagen und Niederschriften und Korrespondenzen der Klassen für Geschichte und Grundsatzfragen des Rechts (7 Bde), Recht von Volk und Reich (16 Bde), Volksgenössisches Rechtsleben (13 Bde) und Völkische Wirtschaft (4 Bde) überliefert.

Im Potsdamer Bestand bilden einen Schwerpunkt Akten der Auslandsabteilung über die Beziehungen zum Ausland und zur Auslandsorganisation der NSDAP (34 Bde, 1934-1942, vornehmlich bis 1938/39), internationale Gesellschaften und Kongresse (16 Bde, 1935-1942 (weitere 9 Bde über Auslandsbeziehungen BA). Von den Akten über Strafvollzug enthalten die meisten ebenfalls Schriftwechsel mit Justiz-, Gefängnis- und Polizeibehörden des Auslands (24 Bde, 1934-1942), die übrigen u. a. die Zeitschrift „Deutsche Gesellschaft für Gefängniskunde “ (5 Bde, 1937-1939) und Unterlagen über Organisation und Tätigkeit dieser Gesellschaft (6 Bde, 1937-1939).

Während einige Akten der Bibliothek ( $u$. a. eine Kartei juristischer Autoren mit biographischen und bibliographischen Angaben) in Koblenz liegen, ist die Tätigkeit der Redaktion der Zeitschrift der Akademie in Potsdam dokumentiert (10 Bde, 1935-1939), im BA (Best. RD 44) deren Jahrgänge 1934-1944, ferner Arbeitsberichte 1934-1942, Jahrbücher 1933-1940, 33 Bde verschiedener Schriftenreihen.

Aus der Dienststellenverwaltung stammen einige Akten (BA, 26 Bde) u. a. über Rechtsgrundlagen und Organisation, Vollsitzungen (1934-1941), Errichtung des „Hauses des Deutschen Rechts" in München und (ZStA, 1935-1939) über die Vorbereitung und Durchführung von Sitzungen, Zusammenarbeit mit dem Volksbund für das Deutschtum im Ausland.

Ergänzende Unterlagen (Tagebücher und Korrespondenz) enthalten der Nachlaß Franks (BA, NL 110) und die Protokolle des Nürnberger IMT-Verfahrens, in dem er vornehmlich als Generalgouverneur Polens verureilt wurde.

Lit.: FINDBÜCHER zu Beständen des Bundesarchivs. Bd. 9. - W. SCHUBERT u. a.: Akademie für Deutsches Recht 1933-1945. Protokolle der Ausschüsse. Bisher 5 Bde. 1986 ff. - H. FRANK: Im Angesicht des Galgens. 1955. - D. Le Roy ANDERSON: The Academy for German Law. 1982. - H. R. PICHINOT: Die Akademie für Deutsches Recht. 1981. - C. KLEBMANN: Hans Frank. 1989. 


\subsubsection{Reichspatentamt}

BA, Best. R 131

Der größte Teil des Schriftguts des 1877 errichteten Amtes, u. a. die Prüfungsunterlagen von 18 seiner 21 Abteilungen, wurde durch Kriegsereignisse vernichtet. Im Bundesarchiv befinden sich:

- Generalakten (ca. 700 Bde, überwiegend in fortgeführten Serien und Einzelakten aus der Zeit vor 1933, z. T. mit Fortsetzung über 1945 hinaus) über Anwendung des Patent-, des Gebrauchs- und Geschmacksmuster- und des Warenzeichenrechts im allgemeinen und in Einzelfällen (ca. 180 Bde), über gewerblichen Rechtsschutz im Ausland (240 Bde) und in eingegliederten und besetzten Gebieten (12 Bde), internationales Patentrecht (14 Bde), Patentanwälte (75 Bde, auch Einzelfälle).

- Aus dem Hauptbüro bzw. der Präsidialabteilung u. a. Entscheidungssammlungen, Rechtsauskünfte, Präsidialverfügungen und allgemeine Anweisungen, Statistiken, Sitzungsprotokolle und Akten über kriegsbedingte MaBnahmen (16 Bde) und die $\mathrm{Zu}$ sammenarbeit mit Ingenieur- und Erfinderverbänden.

- Vergeltungsakten über die Erteilung (18 Einzelfälle) und Versagung (58 Einzelfälle) von Auswertungsrechten an Patenten und anderen geschützten Rechten von englischen und amerikanischen Firmen an Deutsche als Vergeltung für die Beschlagnahme deutscher Patente in Feindstaaten (1940-1944).

- Mikrofilme von Akten über Patentanmeldungen ab 1945, deren Prüfung bei Kriegsende noch nicht abgeschlossen war (ca. 1000 Rollen); die Originale verblieben in der National Lending Library for Science and Technology der British Library in Boston Spa (England). Darin sind am stärksten vertreten die Patentklassen

21: Elektrotechnik (mit 11 Unterklassen) - 12: Chemische Verfahren und Apparate - 19: Eisenbahn-, Straßen- und Brückenbau - 37: Hochbauwesen - 42: Instrumente - 46: Kraftmaschinen - 47: Maschinenelemente - 49: Mechanische Metallbearbeitung - 57: Fotografie, Kinematografie - 62: Luftfahrt - 63: Kraftfahrzeuge - 72: Waffen, Geschosse.

Das Deutsche Patentamt in München hat einen Teil der von den USA an die Bundesrepublik Deutschland zurückgegebenen Unterlagen des Reichspatentamtes in seine Registraturen übernommen; bei seiner Dienststelle Berlin wird die Patentrolle und die Sammlung aller Patentschriften vor 1945 aufbewahrt.

Lit.: EINHUNDERT JAHRE Patentamt. 1977.

\subsubsection{Reichskommissar für die Behandlung feindlichen Vermögens}

Die Behörde war ab 1940 zuständig für die Beschlagnahme und Verwaltung des beweglichen und unbeweglichen Vermögens der Feindstaaten und ihrer Staatsangehörigen im ganzen Reichsgebiet, dem Protektorat Böhmen und Mähren und in Luxemburg. Überliefert sind in Koblenz Handakten des Leiters, Staatssekretär Johannes Krohn, und Generalakten über Dienststellenverwaltung (ca. 120 Bde), die Maßnahmen gegen Vermögen aus GroBbritannien mit Dominien und Kolonien, Frankreich, Belgien, den Niederlanden, Norwegen, Griechenland, Jugoslawien, den USA und der Sowjetunion (zus. ca. 100 Bde) und über die Bestellung von Verwaltern (ca. 50 Bde, auch Einzelfälle). Den Hauptbestandteil bilden die Akten über ca. 10000 einzelne Vermögensobjekte, vorwiegend Grundstücke, aber auch Kapitalgesellschaften, z. B. General Motors (Opel), Dunlop. 
Dillinger Hütte, Standard Oil. Nicht selten betreffen Akten das Eigentum jüdischer und anderer Emigranten, die in einem der Feindstaaten eingebürgert worden waren.

Der Potsdamer Bestand enthält nur Akten über die Bestellung von Verwaltern für Vermögenswerte (178 Bde, 1942-1946), er wird jedoch ergänzt durch Unterlagen und Berichte über die Anmeldung und Verwertung von Vermögenswerten und die Prüfungs der wirtschaftlichen und rechtlichen Verhältnisse einzelner Firmen, die von den Zweigniederlassungen Wien (504 Bde, 1938-1944), Brüssel (181 Bde, 1942-1944), Danzig (3 Bde, 1940-1941). den Haag (265 Bde. 1939-1942), Kattowitz (3 Bde, 1941-1942), Prag (2 Bde, 1942), Riga (1 Bd, 1942) und für die Ukraine, Rowno (1 Bd, 1942) der Deutschen Revisions- und Treuhand A.G. stammen (Best. $80 \mathrm{Re}$ ).

In Koblenz sind ergänzend Akten der Dienststelle für Feindvermögensverwaltung beim Generalkommissar für Finanz und Wirtschaft beim Reichskommissar für die Niederlande (ca. 2000 Einzelfälle, Best. R 177) und des Kommissars für die Verwaltung feindlichen Vermögens im Generalgouvernement (14 Bde, 1944, Best. R 52 I) vorhanden.

Lit.: A. KUGLER: Die Behandlung des feindlichen Vermögens in Deutschland. 1988.

\subsubsection{Reichsrechtsanwaltskammer}

BArch, Best. R 66

Von den Akten der 1933 als Dachorganisation der Anwaltskammern mit Justizrat Dr. Reinhard Neubert als Präsidenten errichteten Körperschaft blieben nur Unterlagen der Steuerstelle über die Tätigkeit von Anwälten als Steuerberater (14 Bde, 1943-1945) und des Fortbildungsamtes mit Rundschreiben an Anwälte im Wehrdienst und in Kriegsgefangenenschaft (3 Bde, 1943/44) erhalten. Von den „Mitteilungen der Reichsrechtsanwaltskammer" sind die Jahrgänge 1937 und 1939 vollständig, aus 1936, 1938, 1941 und 1942 einzelne Nummern vorhanden, ferner ihre Richtlinien für die Ausübung des Anwaltsberufs in der Ausgabe von 1938 (BA, ADS-RD 45).

\subsubsection{Reichsjustizprüfungsamt}

ZStA, Best. 30.12

1934 wurden die Landesjustizprüfungsämter, von denen Akten in den Staatsarchiven der außerpreußischen Länder liegen (z. B. DA. Best. G 22 mit Nachakten bis 1944), aufgehoben und die Abhaltung der GroBen Juristischen Staatsprüfung (Assessorexamen) dem Reichsjustizprifungsamt beim Reichsjustizministerium übertragen, das die erste Staatsprüfung durch Prüfungsstellen u. a. in Berlin, Düsseldorf, Hamburg, München und Stuttgar abnehmen ließ. Überliefert sind von verschiedenen Amts-, Land- und Oberlandesgerichten für Prüfungszwecke eingereichte Akten aus abgeschlossenen Prozessen und einzelne Prüfungsakten von Referendaren und Assessoren (ca. 600 Bde, 1934-1945; Unterlagen, die von Gerichten im späteren Gebiet der Bundesrepublik stammten, wurden 1987 den zuständigen Landesarchivverwaltungen übergeben), ferner Generalakten (34 Bde, 1926/33-1944, u. a. über das „Gemeinschafislager Hanns Kerrl “ 1934-1941). Die Akten der Prüfungsstelle Düsseldorf für die Oberlandesgerichtsbezirke Düsseldorf, Frankfurt, Hamm und Köln wurden vom Bundesarchiv an das Hauptstaatsarchiv Düsseldorf abgegeben.

Keine Überlieferung ist von folgenden Einrichtungen erhalten:

\section{Reichsnotarkammer}

Patentanwaltskammer (Jahresberichte 1934-1942 BA, Best. R 131)

Gemeinschaftslager Hanns Kerrl (für Referendare), Jüterbog. 


\subsubsection{Justizvollzugsanstalten}

Nach dem Stand von 1942 gab es in den Oberlandesgerichtsbezirken des späteren Bundesgebiets und in Berlin 89 hauptamtlich geleitete Justizvollzugsanstalten (ohne Untersuchungsgefängnisse) und 472 Richtern oder Staatsanwälten unterstehende Gerichtsgefängnisse und ähnliche Einrichtungen (ohne Jugendarrestanstalten); unterschieden wurde zwischen Zuchthäusern, Strafgefängnissen, Sicherungsanstalten, Gefangenenlagern, Haftanstalten und Arbeitslagern. Ein großer Teil der 1944 im ganzen Reichsgebiet gezählten rund 152000 Strafgefangenen sollte dort nach den Vorschriften der Strafvollzugsordnung von 1934/40 die Strafe als „ein empfindliches Übel“ ertragen und „an harte, nützliche Arbeit“ gewöhnt werden.

Von der schriftlichen Überlieferung dieser Anstalten ist nur ein Teil von den Archiven übernommen und bis jetzt meist nur unzureichend erschlossen worden; anderes wurde durch Kriegsereignisse oder unkontrolliert vernichtet oder befindet sich noch bei bestehenden Anstalten. Der Internationale Suchdienst verwahrt in erheblichem Umfang Kopien von Listen und personenbezogenen Akten, insbesondere aus der Kriegszeit. über Straf- und Untersuchungsgefangene, die aus politischen oder rassischen Gründen einsaßen, und über Ausländer.

Der Quellenwert der Häftlingspersonalakten liegt darin, daB sie vielfach Urteilsausfertigungen enthalten und daB gerade von den Zuchthausgefangenen ein groBer Teil von Gerichten aus weiter entfernten Gebieten des Reichs oder dem besetzten Ausland verurteilt wurde. Für die Erforschung von Widerstand und Verfolgung sind sie daher von erheblicher Bedeutung, wie die Angaben zu den bereits eingehend verzeichneten Beständen der Anstalten Emden und Kassel-Wehlheiden erkennen lassen. Die häufig vorhandenen Gutachten von Geistlichen, Lehrern und Ärten geben Aufschluß über sozialpädagogische Vorstellungen, Selbstzeugnisse der Gefangenen (Lebensläufe, kurze Aufsätze, einzelne beschlagnahmte Briefe) über Bildungsstand und Milieu. Die knappen Eintragungen in den Gefangenenbüchem belegen Einweisungen und Auslieferungen an die Gestapo oder Überführungen in Konzentrationslager.

Ergänzend zu den Verwaltungsakten sind jeweils Akten der Generalstaatsanwaltschaften heranzuziehen, denen der Strafvollzug in der Mittelinstanz unterstand, ferner die Überlieferung aus nach 1945 vor alliierten und deutschen Gerichten wegen Tötung und Mißhandlung von Häftlingen geführten Strafverfahren. Erlebnisberichte von politischen Gefangenen aus zahlreichen Haftanstalten enthält die Sammlung Walter Hammer (IfZ, ED 153), weitere befinden sich im Dokumentationsarchiv des Widerstandes in Frankfurt.

Von folgenden - überwiegend von Beamten des höheren Dienstes hauptamtlich geleiteten - größeren Justizvollzugsanstalten sind Bestände in staatlichen Archiven vorhanden:

Strafgefangenenlager im Emsland

ZStA, Best.30.24

OS, Rep. 947 Lingen

Die 1933 im Emsland vom preußischen Staat eingerichteten Konzentrationslager (vgl. Abschnitt 2.2.2.2 zu KL Esterwegen) wurden 1934 von der Justizverwaltung übernommen. Sie bestanden bis Kriegsende unter der Leitung eines Kommandeurs in Papenburg an mehreren Orten, u. a. in Börgermoor, Aschendorfer Moor, Rhederfeld, Walchum, Neusustrum und Esterwegen; dazu gehörten AuBenlager, in denen Häftlinge für die OT eingesetzt waren, in Nordnorwegen und Nordfrankreich. Untergebracht waren zeitweise 
bis zu 15000 deutsche und ausländische (u. a. sog. "Nacht-und-Nebel“-Gefangene aus Belgien und Frankreich) Häftlinge, darunter ab 1939 sehr viele von Wehrmachtgerichten Verurteilte, die bei der Moor- und Ödlandkultivierung beschäftigt wurden.

Der Potsdamer Teilbestand enthält wenige Generalakten (16 Bde, 1934-1945) über Wachmannschaften und Gefangene, eine alphabetische Kartei mit Daten über 1700 Häftlinge und 290 Akten mit Urteilen, die gegen einzelne Gefangene in den Lagern Börgermoor I, Aschendorfer Moor II, Brual-Rhede III, Walchum IV, Neusustrum V und Esterwegen VI ergangen und zusätzlich durch eine Kartei der am Verfahren beteiligten Richter und Anklagevertreter erschlossen sind.

In Osnabrück sind etwa 3500 Gefangenenpersonalakten ab 1938 vor allem aus den Lagern VII Esterwegen und Börgermoor, eine Kartei mit Daten über 23836 Gefangene und einzelne Transport-, Effekten- und Krankenlisten sowie einzelne Unterlagen aus den Lagern in Norwegen und Frankreich überliefert. Die 1948 noch beim Landgericht Oldenburg vorhandenen Verwaltungsakten (244 Bde) sind nicht mehr aufzufinden. An den ISD gelangten Veränderungsmeldungen 1934-1944 und Kopien von Listen mit „Nacht-und-Nebel“-Gefangenen in Esterwegen 1943/44 (1 477 Namen).

Als Ergänzungsüberlieferung sind heranzuziehen Akten der Stadtverwaltung Papenburg (OS, Dep. 76 b) u. a. über Zwischenfälle mit dem Wachpersonal (2 Bde, 19331940) und über den Transport von Strafgefangenen und Schutzhäftlingen (29 Bde mit ca. 900 Namen, 1933-1940) sowie des Staatsbauamtes Lingen über BaumaBnahmen (OS, Rep. 660 Lingen, 4 Bde, 1938-1944). Vor englischen Militärgerichten wurden zwei Strafverfahren wegen Verbrechen gegen die Menschlichkeit in den Emslandlagern durchgeführ, deutsche Verfahren u. a. vor den Landgerichten Oldenburg 1949, 1950 und 1952, Osnabrück (gegen SA-Oberführer Regierungsdirektor Werner Schäfer, Kommandeur 1934-1942) 1950 und 1953, Aurich 1948, Berlin 1950 und 1959, Bonn 1959 (Ureile in JUSTIZ UND NATIONALSOZIALISMUS, Nr. 178, 253, 320, 340, 473. 484).

Lit: E. KOSTHORST, B. WALTER: Konzentrations- und Strafgefangenenlager im Dritten Reich. 3 Bde (mit Urteilen und mit zahlreichen Dokumenten aus den Nachkriegsprozessen). 1983. - H. FRESE: BremskJötze am Siegeswagen der Nation. 1989.

Aachen, Haftanstalt

$\mathrm{D}-\mathrm{K}$ Häftlingspersonalakten (76 Bde, dabei einige von Belgiern, Verurteilungen wegen Hochund Landesverrat, 1938-1945).

Aichach, Frauenzuchthaus

MSt Häftlingspersonalakten (ca. 12350 Bde, 1933-1945, dabei 74 Bde, 1933-1939, betr. weibliche Schutzhäftlinge), Gefangenenlisten (5 Bde, 1933-1939, auch des Frauengefängnisses Rothenfeld 1938/39), Kopien von Listen und Karteien mit ca. 13000 Namen 1933-1945 ISD.

Amberg, Zuchthaus

AM, Best. O VII,9 Verwaltungsakten (51 Bde, dabei Erlasse 1933-1938, Arbeitseinsatz, Seelsorge, Strafvollzug an Juden 1933-1936, Aufsicht über entlassene politische Gefangene 1936/37) und Gefangenenlisten 1938/39 (Kopien mit 5943 Namen 1937-1945 beim ISD).

Anrath, Frauenzuchthaus und Gefängnis

$\mathrm{D}-\mathrm{K}$

Häftlingspersonalakten (1 264 Bde, 1933-1944, dabei 71 Franzosen, 1933-1935 überwiegend Schutzhaftfälle, sonst Verurteilungen u. a. wegen Kriegswirtschaftsverbrechen, 
Entfernung von der Truppe). Unterlagen über Verfahren vor englischem Militärgericht wegen MiBhandlung von Gefangenen (BArch, Best. All. Proz. 8).

Bayreuth-St. Georgen, Gefängnis und Arbeitshaus

BAM, Best.K 100/VI und K 190 Verwaltungsakten (48 Bde, 1933-1944, u. a. Schutzhaft 1933/34, Beschwerden, Fluchtund Todesfälle, Seelsorge, Statistik). Kopien mit 8993 Namen 1937-1947 beim ISD.

Berlin-Plötzensee, Gefängnis

B, Rep. 69

Häftlingspersonalakten ( 898 Bde, ca. 1200 weitere und Kartei bei der Senatsverwaltung für Justiz), ferner Erlebnisberichte von 56 Gefangenen, überwiegend Beteiligten an der Verschwörung vom 20. Juli 1944 (IfZ, ED 106).

Lit.: V. v. GOSTOMSKI. W. LOCH: Der Tod von Plötzensee. 1969. - EHRENBUCH der Opfer. 1974.

Bernau, Strafanstalt MSt

Häftlingspersonalakten (1 148 Bde, überwiegend ab 1942, dabei Tschechen und Österreicher, zahlreiche Verurteilungen wegen Rundfunkverbrechen, einzelne wegen Rassenschande), Einzel- und Sammelakten über 356 italienische Gefangene und Kopien mit 9853 Namen 1937-1946 beim ISD.

Bielefeld, Haftanstalt

DT, Best. D 22

Häflingspersonalakten (ca. 4000 Bde, 1934-1942, davon 641 Verurteilungen wegen Hochverrat).

Bonn, Haftanstalt $\mathrm{D}-\mathrm{K}$ Häftlingspersonalakten (betr. 109 Schutzhäftlinge 1933, u. a. Angehörige der Universität Bonn), weitere 2526 Häftlingspersonalakten 1933-1946 und Kartei mit 3668 Namen beim ISD.

Braunschweig, Haftanstalt

WF, Best. 43 B Neu Gefangenenbücher (17 Bde, 1933-1945) und Verwaltungsakten (34 Bde, u. a. betr. Schutzhaft 1933-1940, Jahresberichte 1933-1935, Behandlung von Sittiichkeitsverbrechern 1933-1935).

Bremen-Oslebshausen, Zuchthaus und Strafgefängnis

HB, Best. 4,80 Generalakten (durchgehend 1873-1960) nach Generalaktenplan, u. a. betr. Vollzug der Todesstrafe und der Entmannung, Schutzhaft, Verzeichnisse der Häftlinge.

Lit.: F. BÖTTCHER: Hunder Jahre Strafanstalt Bremen-Oslebshausen. 1984.

Bruchsal, Zuchthaus und Gefängnis

KA, Best. 311

Verwaltungsakten (31 Bde, meist vor 1937, u. a. betr. Arbeitseinsatz) und Häftlingspersonalakten (über 14 wegen Vorbereitung zum Hochverrat Verurteilte, 1933-1939).

Lit.: R. KAUFMANN: Seilersbahn. 1989 (über Einzelfälle vollstreckter Todesurteile).

Butzbach, Sicherungsanstalt

DA, Best. G 30

Häftlingspersonalakten (ca. 800 über ab 1933, meist ab 1938 entlassene - auch in Konzentrationslager überführte - oder verstorbene Gefangene). Kopien mit 7911 Namen 1934-1945 beim ISD. 
Darmstadt, Haftanstalt

DA, Best. G 30

Häftlingspersonalakten (ca. 2500 1933-1944, dabei ca. $15 \%$ Verurteilungen wegen Heimtücke, Umgang mit Kriegsgefangenen, Arbeitsvertragsbruch).

Detmold, Haftanstalt

DT, Best. D 22

Gefangenenbücher (11 Bde, 1933-1937, 1940-1945. Häftlingspersonalakten (38 Bde). Verwaltungsakten.

Duisburg-Hamborn, Haftanstalt

$\mathrm{D}-\mathrm{K}$

Häftlingspersonalakten (74 Bde, 1941-1943). Kopien mit ca. 1500 Namen 1936-1948 beim ISD.

Düsseldorf-Derendorf, Gefängnis

$\mathrm{D}-\mathrm{K}$ Häftlingspersonalakten (559 Bde, zahlreiche Schutzhaftälle, auch Bibelforscher, 19331939, einzelne bis 1942). Kopien mit 16492 Namen 1933-1947 beim ISD.

Ebrach, Zuchthaus

BAM, Best. K 100/6

Verwaltungsakten (37 Bde, 1936-1945, vorwiegend betr. Dienststellenverwaltung), Kopien mit 7677 Namen von Häftlingen 1939-1945 beim ISD.

Emden, Haftanstalt

AUR, Best. 110 Häftlingspersonalakten (1 690 Bde, 1933-1944, Zugänge bis 1941, z. T. betr. in die Emslandlager weitergeleitete Häftlinge aus anderen Anstalten, dabei 142 Schutzhafffälle). Von den Häftlingen waren 10 Juden, 38 Polen, 37 Niederländer, je 4 Dänen und Tschechen, je 3 Norweger und Italiener, je 2 Ungarn und Rumänen, 1 Belgier. Vollstreckungsbehörden waren in 42 Fällen Staatsanwaltschaften im späteren Gebiet der DDR, in 26 in Berlin und in 21 in Schlesien, Pommern und Ostpreußen, 11 Gefangene waren von Wehrmachtsgerichten verurteilt worden. Als Grund der Verurteilung sind angegeben: Heimtücke in 76 Fällen, Arbeitsvertragsbruch und -verweigerung in 34, Vorbereitung zum Hochverrat und Devisenvergehen in je 24, Fahnenflucht und Entfernung von der Truppe in 21, Betätigung als Bibelforscher in 8, Aufruhr in 2 und Befehlsverweigerung, Rassenschande und Wehrkraftzersetzung in je einem Fall.

Essen, Untersuchungshaftanstalt

$\mathrm{D}-\mathrm{K}$ Häftlingspersonalakten (2 629 Bde, 1933-1939, dabei auch Schutzhaftfälle und einzelne Fälle von Strafhaft). Kopien mit 5542 Namen 1932-1949 beim ISD.

Flensburg, Gerichtsgefängnis und Untersuchungshaftanstalt

SL, Abt. 357 Häftlingspersonalakten bzw. -blätter (ca. $6000 \mathrm{Bde}, 1933-1945$ ) und Gefangenenbücher (4 Bde, 1941-1945).

Frankenthal, Haftanstalt

Häftlingspersonalakten (ca. 1000 Bde, unverzeichnet).

SP, Best. J 86

Frankfurt-Hammelsgasse, Untersuchungshaftanstalt

WI, Abt. $409 / 3$

Häftlingspersonalblätter und -akten (für ca. 5000 Gefangene, 1933-1945, dabei zeitweise mehr als $20 \%$ politische Gefangene), außerdem Belegungs- und Gefangenenbücher, Verwaltungsakten (25 Bde, 1880-1936, darin Liste der politischen Gefangenen 1934). Unterlagen über ein Verfahren vor einem englischen Militärgericht wegen Mißhandlung von Häftlingen im BArch (Best. All. Proz. 8). 
Frankfurt-Höchst, Frauengefängnis

WI, Abt. 409/6

Häftlingspersonalakten von 152 Frauen (1939-1945) und aus dem vorhergehenden Gerichtsgefängnis von 61 Männern (1933-1939), darunter von insgesamt 101 wegen politischer Delikte Verurteilter, davon 50 wegen Vorbereitung zum Hochverrat, und 7 ausländischen Arbeiterinnen.

Frankfurt-Preungesheim, Gefängnis

WI, Abt. 409/4 Häftlingspersonalakten (8 620 Bde, 1931-1945, nur Männer, ab 1943 auch von Kriegsgerichten in Frankreich Verurteilte) und -kartei (ca. 17 500 Karteikarten, 1931-1939).

Frankfurt-Preungesheim, Frauenjugendgefängnis

WI, Abt. $409 / 5$

Häftlingspersonalakten von jugendlichen Gefangenen (2 $120 \mathrm{Bde}, 1939$ ) und von Häftlingen der Frauenabteilung des Strafgefängnisses Frankfurt-Preungesheim (1931-1939), dabei 22 politische Fälle und 32 ausländische Arbeiterinnen (1940-1945).

Freiburg, Gefängnis

FR

Einzelne Verwaltungsakten und Manuskript „Geschichte der Freiburger Gefängnisse 1939-1949“.

\section{Hagen, Gefängnis}

MS

Häftlingspersonalakten (ca. 800 Bde, 1934-1945, ausschlieBlich betr. wegen politischer oder kriegsbedingter Straftaten Verurteilte).

Hamm, Haftanstalt

MS

Häftlingspersonalakten (65 Bde, 1933-1945: 52 Fälle von Vorbereitung zum Hochverrat, 8 Bibelforscher-, 5 Heimtückefälle). Kopien mit ca. 42000 Eintragungen über Häftlinge 1933-1944 beim ISD.

Hamburg-Fuhlsbüttel, Frauengefängnis

HH, Best. 242-2

Verwaltungsakten (1929-1956 durchgehend), überwiegend betr. Dienststellenverwaltung, Statistik und Gefangenenbücher (ab 1941). Für das KL Fuhlsbüttel vgl. oben Abschnit 2.2.2.2.

Herford, Strafanstalt und Jugendgefängnis

DT, Best. D 22

Gefangenenkartei (1932-1945), Namensverzeichnis (1941-1945), Häftlingspersonalakten (ca. 2500 Bde, 1931-1942, davon 1500 von Erwachsenen vor 1939, von diesen ca. 1000 wegen Vorbereitung zum Hochverrat, ca. 150 wegen Vergehen gegen die Reichstagsbrandverordnung Verurteilte mit hohem Anteil von Bergarbeitern) und kriminalbiologische Untersuchungsakten über Jugendliche der Geburtsjahrgänge 1920-1928 (539 Bde, 1939-1944, mit Sippentafeln) und einzelne erwachsene Gefangene (ab 1935).

Kaisheim, Zuchthaus

Häftlingspersonalakten (ca. 4000 Bde, 1933-1945), auch von wegen Vorbereitung zum Hochverrat, Landesverrats und Abhörens ausländischer Sender Verurteilten und von Ausländern. 6 Zigeuner, 213 Tschechen, 137 Franzosen, 86 Niederländer, 64 Belgier, 17 Polen, 18 
Luxemburger, 11 Jugoslawen, 8 Italiener, 5 Russen, je 1 Bulgare, Däne und Grieche. Unter den Vollstreckungsbehörden waren u. a. der Oberreichsanwalt beim Volksgerichtshof und Staatsanwaltschaften bei den Sondergerichten Halle und Bamberg, beim Kammergericht und dem Oberlandesgericht Breslau. Zahlreiche Urteile liegen von Wehrmachtund anderen Gerichten in besetzten Gebieten, einzelne von SS- und Polizeigerichten vor. Als Grund der Verurteilung sind angegeben: Vorbereitung zum Hochverrat, Störung des inneren Friedens, Landesverrat in 828 Fällen, Feindbegünstigung und Sabotage in 74 (Angehörige der Widerstandsbewegung), deutschfeindliche Propaganda in 47, Fahnenflucht und Wehrkraftzersetzung in 79 , Heimtücke in 37 , Wehrmittelbeschädigung in 25 . Rundfunkverbrechen in 56 und Umgang mit Kriegsgefangenen in 17 Fällen. 148 Häftlinge waren als Volksschädlinge, 102 wegen Kriegswirtschaftsverbrechen, 37 wegen Rassenschande und 10 wegen Arbeitsverweigerung verurteilt worden. Erlebnisberichte von Häftlingen besitzt das Dokumentationsarchiv des Widerstands in Frankfurt.

Lit.: W. FRENZ, J. KAMMLER: Volksgemeinschafi und Volksfeinde. 1987. S. 298-335.

Kiel, Gefängnis

SL, Abt. 357

Verwaltungsakten (125 Bde, 1933-1945, vor allem aus Aktengruppen 20, 44 und 45) und Häftlingspersonalakten (14 894 Bde, 1933-1945, davon 434 von Gefangenen, denen politische Delikte vorgeworfen wurden, ausschlieBlich aus Schleswig-Holstein).

Kislau (Baden), Arbeitshaus

KA, Best. 521

Häftlingspersonalakten (8 176 Bde, 1935-1945, vgl. auch Konzentrationslager Kislau, Abschnitt 2.2.2.2).

Kleve, Haftanstalt

$\mathrm{D}-\mathrm{K}$

Häftlingspersonalakten (64 Bde, 1941-1942 nur betr. Niederländer, u. a. wegen deutschfeindlicher Kundgebungen Verureilte).

Köln, Gefängnis

$\mathrm{D}-\mathrm{K}$

Häftlingspersonalakten (714 Bde, 1933-1944, auch über Schutzhaftgefangene und wegen kommunistischer Betätigung Verurteilte). Kopien mit 3155 Namen 1932-1944 beim ISD.

Landsberg (Lech), Gefängnis

MSt

Häftlingspersonalakten (287 Bde, 1933-1934, nur über Schutzhaftgefangene), Gefangenenbücher (14 Bde, 1933-1945). Kopien mit 3555 Namen 1939-1946 beim ISD, Erinnerungen eines Gefängnisbeamten 1920-1945 im IfZ (ED 153).

Lübeck, Gefängnis

SL, Abt. 357

Häftlingspersonalakten (4 227 Bde, 1933-1945, nur betr. männliche Straf- und Untersuchungsgefangene, dabei relativ zahlreiche Venurteilte aus dem Kammergerichtsbezirk, einzelne von Feldgerichten), Gefangenenbuicher (3 Bde, 1941-1943).

Lübeck-Lauerholz, Frauenzuchthaus und -sicherungsanstalt

SL, Abt. 357 Häftlingspersonalakten (5 322 Bde, 1933-1945, auch betr. Untersuchungsgefangene). Je ca. $30 \%$ der darin erhaltenen Ureile stammen aus den Oberlandesgerichtsbezirken Kiel und Hamburg, vor allem von Sondergerichten, der Rest überwiegend von anderen norddeutschen Gerichten; ab 1939 sind zahlreiche Urteile der Sondergerichte Königs- 
berg, Bromberg. Danzig, Elbing, Erfurt, Graudenz, Rostock und Schwerin sowie der Landgerichte Bartenstein, Insterburg und Lyck überliefert.

Ludwigsburg, Zuchthaus, mit Zweigstelle Hohenasperg B, Best. E 356 d Häftlingspersonalakten (2 819 und 163 Bde, 1933-1940 mit Vor- und Nachakten, etwa $20 \%$ wegen Vorbereitung zum Hochverrat, Heimtücke und anderer politischer Delikte Verurteilte, mit einzelnen Angaben über Verlegung in Konzentrationslager), Hauptbücher über Gefangene (5 Bde, 1928-1941) und Sicherungsverwahrte (1934-1940).

Lit.: H. BRANDSTÄTTER: Asperg. Ein deutsches Gefängnis. 1978.

Mannheim, Gefāngnis, mit Zweigstelle Heidelberg KA, Best. 310 und 503 Häftlingspersonalakten (ca. 5000, 1933-1945), auch von Ausländern.

Minden, Haftanstalt

DT, Best. D 22

Häftlingspersonalakten (1 221 Bde, 1934-1945).

München-Stadelheim, Gefāngnis

MSt

Häftlingspersonalakten (845 Bde, 1934-1945, nur über zum Tode verurteilte und hingerichtete wie begnadigte und durch Selbstmord verstorbene Gefangene, jedoch nicht über 536 wegen politischer Delikte verurteilte), Kopie des Verzeichnisses aller von 1934 bis 1945 vollstreckten Todesurteile, Gefangenenbücher und Listen (23 Bde, 1933-1938). Kopien mit 1305 Namen von Häftlingen 1938-1946 und mit 54177 Eintragungen auch aus anderen Münchener Haftanstalten 1920-1949 beim ISD.

Lit.: K. ALT: Todeskandidaren. Erlebnisse eines Seelsorgers. 1946.

Münster, Zuchthaus

MS

Häftlingspersonalakten (ca. 400 Bde, 1933-1945, überwiegend von wegen politischer Delikte oder als Volksschädlinge Verurteilten), Gefangenkartei. Kopien mit 6236 Namen 1925-1949 beim ISD.

Niederschönenfeld (Schwaben), Jugendgefängnis

A

Häftlingspersonalakten (ca. 850 Bde, 1933-1936, spätere noch bei der Anstalt, über zwischen 14 und 21 Jahre alte Gefangene, darunter Angehörige kommunistischer Jugendgruppen aus München, Nürnberg, Augsburg und Ludwigshafen 1933/34, mit Urteilen des Bayerischen Obersten Landesgerichts in Hochverratsverfahren).

Oldenburg, Haftanstalt

OL, Best. 145-1 Verwaltungsakten (61 Bde, 1933-1945, u. a. Jahresberichte und betr. Vollzug der Todesstrafe und Entmannung, Schutzhaft 1935/36), Häftlingspersonalakten (ungeordnet).

Rebdorf, Arbeitshaus

N, Rep. 238

Jahresberichte (1933-1938), Verwaltungsakten (Visitation 1944, Dienst- und Hausordnung. Verzeichnis verstorbener Gefangener).

Remscheid-Lüttringhausen, Zuchthaus

$\mathrm{D}-\mathrm{K}$

Häftlingspersonalakten (1 810 Bde, 1934-1945, überwiegend ab 1940, dabei ca. 200 von Niederländern, sonst auch Tschechen, Polen und Russen, von u. a. als Volksschädlingen, wegen Fahnenflucht und Rassenschande verurteilten Deutschen). Kopien mit ca. 3000 Namen 1932-1945 beim ISD. 
Rendsburg, Straf- und (1937-1942) Sicherungsanstalt $\quad$ SL, Abt. 357 Generalakten (150 Bde, 1933-1945, vor allem aus Gruppen 20, 24, 44 und 45), nahezu vollständige Gefangenenkartei und ein Teil der Häftlingspersonalakten, dazu zwei Gefangenenbücher und Häftlingskartei des Gerichtsgefängnisses (1933-1941), Namensverzeichnis von 88 norwegischen „Nacht-und-Nebel“-Gefangenen (1943).

Rheinbach, Zuchthaus

$D-K$

Häftlingspersonalakten (ca. 800 Bde, 1934-1945, überwiegend von Niederländern, Franzosen, Belgiern und Luxemburgern, sowohl Zwangsarbeitern als auch „Nacht- und Nebel"-Gefangenen). Kopien mit 6478 Namen 1932-1944 beim ISD.

\section{Rockenberg (Hessen), Zuchthaus, dann Jugendgefängnis Marienschloß}

DA, Best.G 30

Verwaltungsakten (ca. 200 Bde, 1933-1945, u. a. mit Vollzugsvorschriften, über Behandlung und disziplinarische Bestrafung Gefangener, Seelsorge, Arbeitseinsatz, Personalakten der Beamten); Häftingspersonalakten (914 Bde, 19. Jh. bis 1945, hauptsächlich 1933-1939, über Jugendliche ab 1939 auch in Best. H 18 Rockenberg).

Saarbrücken, Strafgefängnis SB Nur nach Namen erschlossene Häftlingspersonalakten (1935-1945) von deutschen männlichen (274 Pakete) und weiblichen (29 Pakete) sowie ausländischen (darunter viele Russen) Gefangenen mit nicht geringem Anteil aus politischen Gründen Verfolgter.

Siegburg, Zuchthaus und Gefängnis

$\mathrm{D}-\mathrm{K}$ Häftlingspersonalakten (576 Bde, 1933-1945, überwiegend von Deutschen, auch Untersuchungshäftlingen). Kopien von Listen und Karteien mit 12500 Eintragungen 19331945 beim ISD, Bericht eines Arztes über Fleckfieberepidemie im ersten Halbjahr 1945, bei der von den 2618 Gefangenen (davon 724 Deutsche, 732 Niederländer) 1255 erkrankten und 303 starben, im Dokumentationsarchiv des Widerstandes, Frankfurt.

Straubing, Sicherungsanstalt

LA, Rep. 176 Häftlingspersonalakten (1933-1938, ca. 34 Bde, davon 12 von wegen Vorbereitung zum Hochverrat Verurteilten, 4 von Kriminellen, die in Konzentrationslager überwiesen wurden, und 1938-1945, ca. 2500 Bde, vornehmlich über Personen, die von Sondergerichten wegen politischer Delikte verurteilt wurden, darunter vom Sondergericht Wien verurteilte Österreicher, Tschechen und Jugoslawen). Kopien mit ca. 7500 Namen 1939-1946 beim ISD.

Ulm, Gefängnis

LB, Best. E $356 \mathrm{~g}$

Häftlingspersonalakten (ca. 4000, 1933-1945, ca. $10 \%$ von Gefangenen mit Verurteilungen wegen Heimtücke, Rundfunkverbrechen u. dgl.).

Vaihingen (Enz), Arbeitshaus

LB, Best. E 188 b Gefangenenbücher u. a. Verzeichnisse (7 Bde, 1933-1945, auch betr. Zuchthausgefangene). Wegen Verbrechen an Häftlingen wurden zwei Verfahren vor den Landgerichten Stuttgart 1948 und Heilbronn 1953 durchgeführt (Urteile in: JUSTIZ UND NATIONALSOZIALISMUS, Nr. 100, 386). 
Vechta, Gefängnis

OL, Best. 145-2

Gefangenenbücher (6 Bde, 1933-1944, überwiegend ab 1942), Häftlingspersonalakten (21 Bde, 1941-1947, nur von weiblichen Jugendstrafgefangenen).

Werl, Sicherungsanstalt MS Gefangenenkartei (1933-1952, 7448 Namen, nur Anfangsbuchstaben F, H-Z), Häftlingspersonalakten noch bei der Anstalt.

Wittlich, Gefängnis

KO, Best. 605,2

Häftlingspersonalakten (ca. 10000 Bde, 1933-1945, über weibliche Gefangene ab Oktober 1942, 3000 Bde. über Jugendliche, bei Rückfalltätern mit Vorakten anderer Anstalten, einzelne Schutzhaftfälle der Stapostelle Trier, bei Akten über Gefangene aus Emslandlagern ab 1940 auch Urteile von Sondergerichten aus dem ganzen Reichsgebiet).

Wolfenbüttel, Gefängnis

WF, Best. 43 A Neu Gefangenenbücher (1933-1945), Häftlingspersonalakten (6 074 Bde, 1933-1945, davon 653 Bde bis 1938 überwiegend von Gefangenen mit Verurteilungen wegen politischer Vergehen, auch durch Volksgerichtshof, Oberlandesgerichte Hamm und Kassel, Kammergericht, 323 Bde über vollstreckte Todesurteile 1937-1945). Unter den Gefangenen aus der Zeit des Zweiten Weltkriegs (u. a. "Nacht-und-Nebel“-Gefangene aus den besetzten Westgebieten) waren ca. 850 Polen, je 200 Belgier, Niederländer und Tschechen, 180 Italiener und 120 Russen und Ukrainer. Erlebnisberichte im Dokumentationsarchiv des Widerstandes, Frankfurt.

Lit: K. JONCA, A. KONIECZNY: Nuit et brouillard. 1981. S. 72-88. - NATIONALSOZIALISTISCHE JUSTIZ und Todesstrafe. 1990.

Wuppertal, Gefängnis

$\mathrm{D}-\mathrm{K}$

Häftlingspersonalakten (1 923 Bde, 1934-1945, nur von Untersuchungsgefangenen, überwiegend Deutschen). Akten der britischen Militärgerichtsbarkeit (BArch, AllProz 8) dokumentieren die Mißhandlung von Häftlingen. Kopien mit 7343 Namen 1933-1945 beim ISD.

Zweibrücken, Strafanstalt

SP, Best. J 83

Häftlingspersonalakten (ca. 3000 Bde, 1933-1945, vielfach fortgeführte Akten anderer Anstalten).

\subsection{Gerichte}

Nach 1933 trat neben die bestehenden ordentlichen und Verwaltungsgerichte eine groBe Zahl besonderer Gerichte für spezielle Materien oder Personenkreise, die vor allem den Zweck hatten, Rechte zu mindern oder Strafmöglichkeiten zu erweitern. Für das Schriftgut der meisten Gerichte galt neben dem Generalaktenplan für die Verwaltungsakten für die Verfahrensakten die Aktenordnung vom 28. November 1934. Sie sah u. a. vor, daß bei den Landgerichten und Staatsanwaltschaften das Aktenzeichen von den Kennbuchstaben folgender Register eingeleitet wurde:

O Gewöhnliche Zivilprozesse

P Urkunden-, Wechsel- und Scheckprozesse 
$R$ Ehe-, Kindschafts- und Entmündigungssachen

Js Vorverfahren in Strafsachen (Ermittlungsverfahren)

Ks Strafsachen vor dem Schwurgericht

KLs Verfahren wegen Verbrechen vor der großen Strafkammer

KMs desgl. wegen Vergehen

Ls Verfahren wegen Verbrechen vor dem Schöffengericht

Ms desgl. wegen Vergehen.

Für alle Zweige der Rechtsprechung gilt, daB die wesentlichen Unterlagen beim erkennenden Gericht der ersten Instanz aufbewahrt werden und nach AbschluB von Berufungs- und Revisionsverfahren dorthin zurückgehen sollen. Bei Strafsachen ist zusätzlich zu berücksichtigen, daß die Akten grundsätzlich von den Geschäftsstellen der Anklagebehörde erster Instanz zu führen waren. Die Überlieferung über Einzelverfahren beschränkt sich daher in der Regel bei Berufungs- und Revisionsinstanzen und in Strafsachen bei allen Gerichten auf Urteile und Handakten.

Die Verfolgung von Straftaten nach nationalsozialistischem Sonderstrafrecht, z. B. nach der Verordnung zum Schutz von Volk und Staat vom 28. 2. 1933, dem Gesetz gegen heimtückische Angriffe auf Staat und Partei vom 20.12. 1934, der Kriegssonderstrafrechtsverordnung vom 17. 8. 1938, der Verordnung über außerordentliche Rundfunkmaßnahmen vom 1.9. 1939 und der Wehrkraftschutzverordnung vom 25. 11. 1939 ist in allen Instanzen dokumentiert, da zeitweise oder 2 . T. eine konkurrierende Rechtsprechung zwischen Volksgerichtshof, Strafsenaten der Oberlandesgerichte und Sondergerichten bestand. Die Unterlagen aus ca. 15000 derartigen Verfahren im ehem. ZPA der SED, die sowohl von Gerichten und Anklagebehörden selbst als auch aus Akten des Reichsjustizministeriums stammen, befinden sich jetzt im ZStA (vgl. zu Abschnitt 3.1.1 und unten 3.2.2.1), darunter auch aus zahlreichen Prozessen vor dem Kammergericht, dem Oberlandes- und dem Sondergericht Hamburg und anderen Gerichten im späteren Gebiet der Bundesrepublik Deutschland, von denen die entsprechenden Unterlagen nicht oder noch nicht in die zuständigen Archive gelangt sind.

Lit.: ANWEISUNG für die Verwaltung des Schriftguts bei den Geschäftstellen. o.J.

\subsubsection{Ordentliche Gerichtsbarkeit}

\subsubsection{Reichsgericht, Leipzig}

ZStA, Best. 30.02

BA, Best. R 23

Die erhalten gebliebenen Akten befinden sich fast ausschlieBlich im ZStA. Der Bestand enthält nur in geringem Umfang Generalakten (ca. 80 Bde, 1932-1944/45), darunter solche des Hauptbüros, der Bibliothek und des Richtervereins beim Reichsgericht. Der größere Teil besteht aus Prozeßakten (über 20000 Bde für den Zeitraum 1933-1945) der Strafsenate in Revisionsverfahren (nach einzelnen Senaten, innerhalb der Senate chronologisch geordnet) und des Besonderen Strafsenats über außerordentliche Einsprüche. Dazu kommen die Akten über die einzelnen „Nichtigkeitsbeschwerden in Strafsachen“* (Korrektur rechtskräftiger Urteile, ca. 38000 Bde, 1940-1945).

Von den Zivilsenaten sind nur für den Zeitraum 1939-1945 Akten aus Revisionsverfahren (ca. $9500 \mathrm{Bde}$ ) überliefert, die durch eine unvollständige Urteilssammlung (1900-1944, auch aus Strafsachen) ergänzt werden. Eine weitere Unteilssammlung befindet sich in der Bibliothek des ehemaligen Obersten Gerichts der DDR. Veröffentlicht sind Ureile in den „Entscheidungen des Reichsgerichts in Zivilsachen“ (Bd. 140-171) bzw. ,in Strafsachen“ (Bd. 66-77, jeweils 1933-1944). 
In den Koblenzer Bestand gelangten aus der NS-Zeit lediglich einzelne Revisionsurteile in Zivil- und Strafsachen, sowie Handakten des Rechtsanwalts Sack, des Verteidigers van der Lubbes, aus dem Reichstagsbrand-ProzeB (Kl. Erw. 396, 7 Bde, 1933). Nachgewiesen werden jedoch Ausfertigungen von ca. 2600 Urteilen in Zivilsachen (1933-1945 März), die in der Bibliothek des Bundesgerichtshofs in Karlsruhe und in anderen Archivbeständen überliefer sind; darunter sind 62 Urteile in Patentsachen, ca. $120 \mathrm{zu}$ Verfahren vor Gerichten in Österreich und 39 Entscheidungen über Urteile des Deutschen Oberlandesgerichts Prag (überwiegend 1943-1944).

Eine umfangreiche Ergänzungsüberlieferung für den Reichstagsbrandprozeß liegt als Kopien (ca. $6 \mathrm{lfm}$ ) aus dem Parteiarchiv der KPdSU in Moskau (Fonds 551) in dem vom ZStA übernommenen Teil der Bestände des ehem. ZPA der SED (Best. ST 65) vor.

Lit: F. K. KAUL: Geschichte des Reichsgerichts. 197I. - D. KOLBE: Reichsgerichtspräsident Dr. Erwin Bumke. 1975.

\subsubsection{Oberreichsanwalt beim Reichsgericht}

ZStA, Best.30.03

Einige Generalakten (1933-1945) enthalten vor allem Übersichten über Revisionssachen der Abteilungen 1 D und 4 D (1930-1943), Urteile in Landesverratssachen (1933-1934), Übersichten über die an die Reichsanwaltschaft beim Volksgerichtshof abgegebenen Landes- und Hochverratsverfahren (1935-1942) und über vollstreckte Strafen (1935) und betreffen Grundstücks- und Hausangelegenheiten (1941-1945). In Handakten des Beamten Dr.Lösche sind Haftbefehle und andere Unterlagen im Zusammenhang mit der strafrechtlichen Verfolgung von KPD-Angehörigen (1932-1934) überliefert.

Von den Einzelfallakten sind 5250 Bde bei der Erhebung von ,Nichtigkeitsbeschwerden“ (1940-1945) entstanden, durch die das Reichsjustizministerium, die erstinstanzlich zuständigen Generalstaatsanwälte und Verteidiger die Aufhebung von Urteilen durch das Reichsgericht, das in Verfahren vor Sondergerichten kein Revisionsrecht hatte, erwirken konnten, das selbst ein Endurteil fällte oder an die Vorinstanz zurückverwies; vielfach wurden dadurch nach Auffassung der NS-Juristen zu milde Urteile verschärft.

Nach Koblenz gelangten lediglich mit den Handakten des Rechtsanwalts Sack Durchschriften aus Akten des Oberreichsanwalts zum ReichstagsbrandprozeB 1933.

\subsubsection{Oberlandesgerichte}

Die schriftliche Überlieferung der 18 vor 1945 im späteren Gebiet der Bundesrepublik zuständigen Oberlandesgerichte befindet sich, soweit sie nicht im Krieg - wie anscheinend vollständig diejenige des Berliner Kammergerichts - vernichtet wurde, zum Teil, von Oldenburg und Stuttgart insgesamt noch bei deren Funktionsnachfolgern. Über ihre Tätigkeit von 1939 bis 1945, vereinzelt auch schon in der Vorkriegszeit, unterrichten die regelmäBigen Lageberichte der Präsidenten an den Reichsjustizminister (BA, Best. R 22). Zwischen 1960 und 1970 wurde in Stuttgart, Frankfurt und Limburg ein Ermittlungsverfahren gegen diejenigen damals noch lebenden OLG-Präsidenten und Generalstaatsanwälte geführt, die 1941 von Staatssekretär Schlegelberger über die Ermordung der Geisteskranken unterrichtet worden waren.

Lit.: K. H. ROTH: Nazi-Juristen als Meinungsforscher. - H. MICHELBERGER: Berichte aus der Justiz des Drituen Reiches. 1988. - H. KRAMER: Oberlandesgerichtspräsidenten und Generalstaatsanwälte als Gehilfen der NS-..Euthanasie“. 1984. 
In die Staatsarchive sind folgende Bestände gelangt, die in der Regel überwiegend älteres Schriftgut enthalten:

\section{OLG Bamberg}

BAM, Best. K 100

Generalakten (ca. 200 Bde, überwiegend ab 1936), u. a. betr. Dienststellenverwaltung (23 Bde, 1933-1945), Justizpressewesen, Verhältnis zur NSDAP (7 Bde), Lenkung der Strafrechtspflege (2 Bde, 1936-1942), Erbgesundheitspflege; Sammelberichte über Strafverfahren, Sammelakten zum Beschwerderegister in Strafsachen 1936-1944, Berufungsund Beschwerderegister für Zivilsachen 1933-1944, Sammelakten über die einzelnen Gerichte des Bezirks (meist bis 1936, z. T. bis 1944).

Lit: H. SCHÜTZ: Bamberger Berichte. 1983. - Ders.: Justiz im .Dritten Reich“. Dokumentation aus dem Bezirk des Oberlandesgerichtsbezirks Bamberg. 1984.

OLG Braunschweig

WF, Best. $36 \mathrm{Neu}$

Lediglich Akten über justizeigene Liegenschaften im Bezirk (1934-1944).

OLG Celle

H, Best. Hann. 173

Generalakten aus allen Gruppen des Aktenplans (ca. 1100 Bde bis1936, 182 Bde 19361945) und über den Geschäftsbetrieb der einzelnen Senate (20 Bde) und Sammlungen von Urteilen und Beschlüssen aus Revisionsverfahren in Strafsachen (23 Bde, 19331944), Privatklagesachen (3 Bde, 1933-1941) und Berufungs- und Beschwerdeverfahren folgender Gebiete der Zivilrechtspflege (ca. 110 Bde):

Schadenersatzansprüche gegen öffentliche Körperschaften (1936-1944). - Ansprüche von Beamten (1937-1943). - Dienst-, Lehr- und Architektenverträge (1937-1944). Privatversicherungsansprüche (1935-1944). - Ehesachen (1936-1945). - Ansprüche aus unerlaubter Handlung (1936-1945). - Enteignungsverfahren (1933-1945). - Kauf- und Tauschverträge (1935-1945). - Ansprüche aus Besitz, Eigentum, Hypotheken (19351945). - Dienst- und Werkverträge (1938-1945). - Ansprüche aus Pacht, Leihe und Verwahrung, Pachtschutz (1936-1945). - Zwangsvollstreckung in Grundstücke (19331939). - Wasser-, Fischerei- und Kirchenrecht (1934-1938).

Ferner sind Akten aus Einzelverfahren richterlicher Vertragshilfe (5 Bde, 1940-1944), über Abwesenheitspflegschaften (7 Bde, 1940-1944) und die Verwaltung feindlichen Vermögens ( 75 Bde, allgemeines und Einzelfälle, meist betr. Grundstücke, z. T. von Emigranten, 1940-1945) vorhanden.

Lit.: ZWEIHUNDERTFÜNFZIG JAHRE Oberlandesgericht Celle 1711-1961. 1961. - ZWEIHUNDERTFÜNFUNDSIEBZIG JAHRE Oberappellationsgericht - Oberlandesgericht Celle. 1986. - R. SCHRÖDER: ... aber im Zivilrecht sind die Richter standhaft geblieben. 1988. - G. BESIER: Der ProzeB ..Schramm gegen die Landeskirche". 1989. - V. KREGEL: Die Personalpolitik der Justiz im 3. Reich. 1986.

\section{OLG Darmstadt}

DA, Best. G 23

Protokolle der Präsidialabteilung (bis 1936), Generalakten und Sammelakten der Gruppen $10-14,20-25,30-38,40-47,50-56,60-63,70,72,73-76,80,82,83,85$ und 90-93 des Aktenplans (ca. 200 Bde, 1935-1945), darunter betr. Verhältnis zur NSDAP, Berichte über Straf- und Dienststrafsachen, Schulung der Beamten (u. a. Lehrgänge der Reichsburg Cochem), Zwangsversteigerungs- und Kriminalstatistik, Schutzhaft, Jugendstrafrecht, Reichstreuhänder der Arbeit, Volkssturm; Verfahrensakten vermutlich noch beim Gericht. 
OLG Düsseldorf

$\mathrm{D}-\mathrm{K}$

Urschriften der Urteile der 11 Zivilsenate (106 Bde, 1935/38-1943), General- und Sammelakten (ca. 300 Bde, 1933-1945), darunter Erlasse des Reichsjustizministers (1937-1945), Berichte über Sondergerichtsverfahren (1944-1945), Tätigkeitsberichte von Industrie- und Handelskammern (1938-1942) und Vorgänge über Abordnung von Beamten in die Ostgebiete, Verfahren vor Erbgesundheitsgerichten (10 Bde, 1934-1942), Peter-Klöckner-Familienstiftung, Verwaltung von Feindvermögen, Dienstaufsichts- und andere Beschwerden, gerichtliche Vertretung von Juden (1936-1944).

Lit: K. H. DINSLAGE: Das Oberiandesgericht in der Zeit des Nationalsozialismus. 1981.

OLG Frankfurt

WI, Abt. 458

General- und Sammelakten (ca. 400 Bde, 1933-1944) vor allem aus der Dienststellenund Personalverwaltung, u. a. über die Besetzung der einzelnen Gerichte, Verleihung von Auszeichnungen (5 Bde, 1939-1944), jüdische Rechtskonsulenten (mit 27 Personalakten 1938/39), aber auch betr. Staatsbürgerrecht (8 Bde, 1936-1943), Unterrichtung der Öffentlichkeit über einzelne Verfahren (5 Bde, 1936-1944) und Geschäftsübersichten.

Lit: E. ZIMMER: Die Geschichte des Oberlandesgerichts in Frankfun am Main. 1976. S. 76-87.

(Hanseatisches) OLG Hamburg

HH, Best. 213-1 (OLG)

Sammlung der Entscheidungen der 7 Zivilsenate (bis 1936, mit Register), General-. Sammel- und Einzelakten aus der Verwaltungstätigkeit, insbes. der Personalverwaltung (ab 1936), u. a. über Referendarlager, Unterlagen über die Befreiung von der Beibringung ausländischer Ehefähigkeitszeugnisse.

Lit.: W. JOHE: Die gleichgeschaltete Justiz. 1967.

OLG Hamm

MS

Generalakten (in der Regel ab 1920 bis 1936) im Anschluß an die älteren Akten seit 1879 (ca. 2200 Bde), soweit nicht in eine Sammlung zur Geschichte des Gerichts bei diesem selbst aufgenommen; hervorzuheben sind die Akten über die „Wiederherstellung des Berufsbeamtentums" und die Verdrängung der Juden aus Justizdienst und Rechtsanwaltschaft in den einzeinen 9 Landgerichts- und 114 Amtsgerichtsbezirken.

Lit.: RECHTSPFLEGE zwischen Rhein und Weser. 1970.

OLG Karlsruhe

KA, Best. 240

Einzelne Generalakten in älterer Überlieferung (ca. 30 Bde bis 1936, vereinzelt bis 1944), darunter betr. NSDAP und Verbände (4 Bde), Statistik (3 Bde), Erbgesundheitsgesetz (4 Bde), Regelung der landwirtschaftlichen Schuldverhältnisse, Behandlung feindlichen Vermögens (4 Bde, allg. und Einzelfälle, 1940-1944), vollständig aus der Verwaltungsabteilung (ca. 600 Bde, auch Sammelakten, ab 1936), ferner einzelne Verfahrensakten in politischen Strafsachen und Fideikommissangelegenheiten bis in die Vorkriegszeit.

OLG Kassel

MR, Best. 263

Nur Haushaltsakten (2 Bde, 1939-1944) und Unterlagen über Liegenschaften der Justiz (49 Bde, 1935-1945); nach 1945 zusammengestellte Unterlagen über 327 Verfahren wegen Vorbereitung zum Hochverrat beim OLG Frankfurt; Kopien von ca. 50 Anklageschriften und Urteilen aus Verfahren wegen Vorbereitung zum Hochverrat im 
Dokumentationsarchiv des Widerstands Frankfurt, weitere aus Häftlingsakten der JVA Kassel-Wehlheiden bei der Forschungsgruppe Nationalsozialismus in Hessen an der Gesamthochschule Kassel; 41 Urteile oder Anklageschriften (vereinzelt beide) aus Hochverratsverfahren 1933-1944 im Stadtarchiv Frankfurt/Main (Nachlaß Häbrich).

LiL: J. KAMMLER. D. KRAUSE-VILMAR: Volksgemeinschaft und Volksfeinde. 1984. - E. NOAM. W.-A. KROPAT: Juden vor Gericht. 1975. S. 38-40.

OLG Kiel

SL, Abt. 350

Sammlung von Revisionsurteilen und Entscheidungen über Beschwerden in Straf- und Privatklagesachen (17 Bde, 1933-1945), Akten über Berufungsverfahren gegen Urteile der Landgerichte in Zivilsachen (167 Bde, davon 68 gegen LG Kiel und 52 gegen LG Altona, 1933-1947), über richterliche Vertragshilfe in Energiewirtschaftssachen (13 Bde. 1940-1945) und über Verwaltung des Grundbesitzes von Emigranten als Feindvermögen (29 Bde, 1940-1947). Generalakten bis 1936 vollständig (ca. 620 Bde), ab 1937 nur aus den Gruppen 20, 21, 23, 25, 31, 32, 51 und 53 des Generalaktenplans (ca. 80 Bde, Rest beim Gericht).

\section{OLG Köln}

$\mathrm{D}-\mathrm{K}$

General- und Sammelakten (ca. 300 Bde, 1933-1945), darunter betr. „Staat und Rasse“ (Anwendung des Blutschutzgesetzes 1936-1939. Erstattung erbbiologischer Gutachten 1936), Stiftungen von Juden, politische Strafsachen (1936-1943 mit Kritik an Urteilen in Heimtückeverfahren 1940-1942), Strafverfahren gegen Polen und Juden, Rückgliederung der Amtsgerichtsbezirke Eupen, Malmedy und St. Vith (1940-1941). Besetzung der Arbeitsgerichte (1936-1940), Geschäftsberichte der Anerbengerichte (1936-1944), Jahresberichte von Wirtschafts- und Industrie- und Handelskammern (1936-1939).

Lit.: A. KLEIN: Die rheinische Justiz und der rechisstaatliche Gedanke in Deutschland. 1969.

OLG Köln, Nebenstelle Saarlouis (Saarlautern)

Register über Berufungen und Beschwerden gegen Urteile von Gerichten im Saarland in Zivilsachen (7 Bde, 1935-1938), für die vorher der Oberste Gerichtshof für das Saargebiet, ab 1938 das OLG Zweibrücken zuständig war, Allgemeines Register (19351942) und einzelne Unterlagen zur Organisation (1935/36).

OLG (zugleich Bayerisches Oberstes Landesgericht) München

MSt Generalakten (414 Bde, 1934-1944) insbes. über Dienststellenverwaltung und Personalangelegenheiten auch der nachgeordneten Gerichte, außerdem betr. Staatsschutz (dabei: Maßnahmen zum Schutz Hitlers in Berchtesgaden 1937-1942), Staatsbesuche und -begräbnisse (1942/43), Korrespondenz mit der Reichsleitung der NSDAP (1940-1943, Korrespondenz des OLG-Präsidenten Stepp s. unten, Abschnitt 9.4.5.2).

OLG Nürnberg

N, Rep. $280 / 2$

Generalakten betr. Amtsanwaltschaften und Staatsanwaltschaften (3 Bde, bis 1935), Gnadenrecht (4 Bde, allg. und Einzelfälle, 1935-1945), 3 einzelne Strafverfahrensakten (1938-1943).

OLG Zweibrücken

SP, Best. J 1

Generalakten aus allen Gebieten (156 Bde, 1935-1943), Akten über Befreiung von Ehefähigkeitszeugnissen von Ausländern (14 Bde, 1934-1944).

Lit.: K. OLDENHAGE: Die Pfalz und das Saarland während des Krieges (1940-1945). 1979. 1980. 


\subsubsection{Staatsanwaltschaften bei den Oberlandesgerichten}

Die Generalstaatsanwälte beim Kammergericht und den Oberlandesgerichten waren nicht nur für die Dienstaufsicht über die Staatsanwaltschaften ihres Bezirks und die Vertretung der Anklage in Revisionsverfahren gegen Urteile von Amts- und Landgerichten zuständig, sondern auch Anklagebehörde in erstinstanzlichen Verfahren wegen Hoch- und Landesverrats vor den „Volksschutzsenaten“ bestimmter Oberlandesgerichte, soweit sie nicht 1933/34 vor dem Reichsgericht, ab 1934 vor dem Volksgerichtshof durchgeführt wurden, und nach Aufhebung der Strafvollzugsämter unterstanden ihnen die Justizvollzugsanstalten ab September 1933. Für ihre Überlieferung gilt dasselbe wie für diejenige der Oberlandesgerichte. Auch hier geben regelmäBige Lageberichte an das Reichsjustizministerium (BA, Best. R 22) AufschluB über ihre Tätigkeit im Zweiten Weltkrieg (zum Ermittlungsverfahren wegen Teilnahme an der Ermordung der Geisteskranken vgl. zu 3.2.1.3). Anklageschriften und von ihnen erwirkte erstinstanzliche Urteile sind vielfach in Akten des Oberreichsanwalts beim Volksgerichtshof (BDC), wenn dieser das Verfahren an sie abgegeben hatte, und des Reichsjustizministeriums (ehem. ZPA der SED, jetzt ZStA) überliefert; auch Häftlingspersonalakten von Justizvollzugsanstalten belegen ihre Tätigkeit.

Aktenbestände sind von folgenden Staatsanwaltschaften bei Oberlandesgerichten archiviert:

Staatsanwaltschaft beim OLG Bamberg

BAM, Best. K $100 / \mathrm{V}$

Generalakten, insbes. betr. Strafvollzug (ca. 200 Bde, meist vor 1936), u. a. Aufsicht über einzelne Anstalten und deren Personal, Unterbringung, Behandlung und Arbeitseinsatz der Gefangenen, Jugendstrafvollzug, mit Jahresberichten und Belegungsstatistik (1933/34); Akten aus einzelnen Straf- und Ermittlungsverfahren (230 Verfahren, 1934-1945), vorwiegend wegen politischer Delikte, darunter gegen Geistliche (auch wegen Sittlichkeitsverbrechen), Juden (Rassenschandefälle), Ausländer, wegen verbotenen Umgangs mit Kriegsgefangenen, Verbreitung politischer Witze und defaitistischer Äußerungen nach dem 20. Juli 1944, außerdem wegen Landesverrat (1934-1935), Plünderung und über Ermittlungen wegen Mißhandlung von Schutzhaftgefangenen in Coburg (1933) und die Todesursache von Kultusminister und Gauleiter Schemm (19351936).

Staatsanwaltschaft beim OLG Braunschweig

WF, Best. 42 A Neu Generalakten betr. Strafvollzug im allgemeinen (61 Bde, 1933-1945), u. a. Nachweisungen und Listen von politischen Gefangenen (1935-1939), Schutzhäftlingen der Gestapo (1938), Ausländern (1936-1945), Todesurteilen (1942), Überführungen in Emslandlager (1935-1945), Akten über die Justizvollzugsanstalten Braunschweig (16 Bde) und Wolfenbüttel (21 Bde) sowie die einzelnen Gerichtsgefängnisse (32 Bde); weitere Generalakten als Vorakten in Best. 61 Nds (ca. 30 Bde, ab 1935), u. a. betr. Staat und Rasse (1935-1942), Statistik, Unterrichtung der Öffentlichkeit.

Lit: H. KRAMER: Die NS-Justiz in Braunschweig. 1981.

Staatsanwaltschaft beim OLG Celle

H, Best. Hann. 173a Generalakten (überwiegend bis 1936) u. a. betr. Verfassung und Verwaltung, Beamtenrecht (60 Bde, dabei Maßnahmen aus AnlaB der NS-Machtergreifung, gegen „Nichtarier", Justizreform), betr. Dienststellenverwaltung ( $8 \mathrm{Bde}$ ), betr. Gesetzgebung und Verfahren (51 Bde), u. a. über Sondergerichte (1933-1940), Verfahren zum Nachteil der 
NSDAP (1935/36), Erbgesundheitsgesetz (1934-1936), Überwachung der Presse (19331936), betr. Strafvollstreckung und -vollzug ( 7 Bde), betr. Gerichtsorganisation ( 9 Bde, 1941-1945).

Staatsanwaltschaft beim OLG Darmstadt

DA, Best. G 24 Generalakten als Nachakten zu älterer Überlieferung (bis 1936) und nach dem Generalaktenplan (691 Bde, 1935-1945), dabei Rundverfügungen (11 Bde), Mitteilungen der Justizpressestelle über Verfahren, Statistiken und Listen über Strafvollzug (9 Bde, 19351943), Arbeitseinsatz von Gefangenen (1938-1945), politische Gefangene, russische (1933-1936) und französische (1936-1940) Häftlinge, Sterilisierungen und Entmannungen, Berichte über geisteskranke und erbgeschädigte Gefangene, über Verfahren wegen Volksschädlingsverbrechen, Kriegswirtschaftsverbrechen, Fahnenflucht, Verstöße gegen Lohnstop, Gnadengesuche, Akten über Vollzug von Schutzhaft, Verhältnis zur NSDAP, Tätigkeit der Staatsanwaltschaften bei den 3 Landgerichten, den Sondergerichten und der Zentralstaatsanwaltschafi Berlin, Weisungen des Reichsverteidigungskommissars.

Staatsanwaltschaft beim OLG Düsseldorf

$\mathrm{D}-\mathrm{K}$

Neben Generalakten (meist vor 1936), u. a. über politische Beurteilungen von Beamten, Sicherungsverwahrung, Unterbringung in Heil- und Pflegeanstalten (1933-1941), Verkehr mit der NSDAP (1936-1944), vor allem Berichte der Staatsanwaltschaften über einzelne Ermittlungs- und Strafverfahren (ca. 2500 Fälle, 1933-1945), insbesondere wegen Heimtücke und Wehrkraftzersetzung, aber auch Korruptionsfällen in der NSDAP, Ausschreitungen im Konzentrationslager Wuppertal-Kemna (3 Bde, 1934-1935) und Duisburg (1935), Homosexualität, Delikten von Geistlichen mit Allgemeinem (AR-) Register über politische Strafsachen (8 Bde, 1935-1945), Akten über einzelne Verfahren wegen Devisenvergehen (100 Bde aus 56 Verfahren, 1935-1945, und Handakten aus 13 Verfahren, 1939-1942), Auslieferung von Ausländern (14 Bde, 1933-1940, Vollstreckung von Todesurteilen (1933-1936), Vertretung der Staatsinteressen bei Zivilprozessen gegen den Fiskus (5 Verfahren, 1933-1945), Ehrengerichtsverfahren gegen Rechtsanwälte (16 Verfahren, 1934-1942).

\section{Staatsanwaltschaft beim (Hanseatischen) OLG Hamburg}

HH, Best. 213-8 (GStA)

General- und Sammelakten betr. Strafvollzug (1934-1947), unverzeichnet.

Staatsanwaltschaft beim OLG Hamm

Neben Generalakten insbes. betr. Strafvollzug (ca. 900 Bde, 1933-1945, davon ca. 200 nach dem Generalaktenplan), u. a. über Beleidigung von Politikern (19331936), Ausübung des Gnadenrechts, Einziehung von Rundfunkgeräten wegen Abhörens ausländischer Sender (auch Einzelfälle) und "Wiederherstellung des Berufsbeamtentums", Akten über ca. 150 Revisionsverfahren und 20 Ehrengerichtsverfahren gegen Rechtsanwälte, vor allem Akten über 3757 von insgesamt 8533 belegten Verfahren wegen Hoch- und Landesverrats (1933-1945) sowie Wehrkraftzersetzung (ab 1940), für die das OLG Hamm außer im eigenen Sprengel auch in den Bezirken der Oberlandesgerichte Köln und Düsseldorf und der Landgerichte Aurich, Osnabrück, Detmold, Bückeburg, Hannover, zeitweise Hildesheim des OLG-Bezirks Celle zuständig war; vollständig im Original überliefert sind die Akten aus 2712 Verfahren der Jahre 1933-1936, aus den übrigen 1045 Verfahren liegen nur Ersatzakten aus der Zeit nach 1945 mit zahlreichen 
Originalunterlagen (besonders Urteilen) vor, umfangreiche Urteilssammlung außerdem im ehem. ZPA der SED.

Staatsanwaltschaft beim OLG Frankfurt

WI, Abt. 458a

Generalakten betr. Strafvollstreckung und Vollzug im allgemeinen und einzelnen Anstalten (138 Bde, 1933-1945), u. a. mit Angaben über Verlegung von Gefangenen in Straf- und Konzentrationslager, Vollzug der Todesstrafe (4 Bde), Gefangene aus besetzten Gebieten, Arbeitseinsatz.

Staatsanwaltschaft beim OLG Karlsruhe

KA, Best. 309

Generalakten (ca. 800 Bde, 1936-1945) mit Lageberichten des Generalstaatsanwalts (1935-1944), der Oberstaatsanwälte bei den Landgerichten Freiburg, Heidelberg, Karlsruhe, Konstanz, Mannheim, Mosbach, Offenburg und Waldshut (1935-1940, Mannheim auch 1945) und der Vollzugsanstalten (1936-1939) und eigener Überlieferung aus der Zuständigkeit für die Justiz im Elsaß (1940-1944).

Lit: J. SCHADT: Verfolgung und Widerstand in Baden. 1976. S. 221-299.

Staatsanwaltschaft beim OLG Kiel

SL, Abt. 351

Generalakten aus der gesamten Zuständigkeit (ca. 350 Bde, 1933-1945).

Staatsanwaltschaft beim OLG Köln

$\mathrm{D}-\mathrm{K}$

Neben Generalakten (bis 1936) u. a. betr. Strafrecht im allgemeinen, Jugendstrafrecht, Bekämpfung unlauteren Wettbewerbs, Statistik, Wiederherstellung des Berufsbeamtentums vor allem Berichte und Einzelfallakten in Gnadensachen (6 Bde, 1933-1937), auch bei Todesurteilen, und über Verfahren gegen Geistliche und Lehrer (14 Bde, 1934 1936), wegen Beleidigung der Reichs- und Staatsregierung oder eines Ministers (5 Bde, 1933-1936), politischer Straftaten (73 Bde, 1933-1936), dabei auch Korruptionsfälle, Untersuchung von MiBhandlungen im SA-Lager Hochkreuz in Porz-Eil und von Ausschreitungen gegen Juden, wegen Angriffen auf die „Volkskraft“ (87 Bde, 1933-1945), u. a. Devisenvergehen, Untreue, Rassenschande, Sittlichkeitsdelikte, Kriegswirtschaftsverbrechen, wegen Ausschreitungen gegen Juden beim Novemberpogrom 1938 (3 Bde, 1938-1941), gegen Volksschädlinge (56 Bde, 1939-1945) und wegen Verfahren zum „Schutz der Volksgenossen“, u. a. Mord, Betrug, Beleidigung, Körperverletzung, auch gegen NS-Funktionäre (35 Bde, 1933-1945).

Vertreter des Generalstaatsanwalts Köln in Saarlouis

SB

Generalakten und Register über Strafvollstreckung und -vollzug, Personalangelegenheiten von Beamten der Staats- und Amtsanwaltschaften und der Vollzugsanstalten, einzelne Berichte über - auch politische - Strafverfahren (70 Bde, 1935-1938 im AnschluB an Überlieferung des Generalstaatsanwalts beim Obersten Gerichtshof für das Saargebiet).

Staatsanwaltschaft beim OLG München

MSt Einzelne Vorgänge aus Generalakten betr. Zuständigkeit, Kriegssonderstrafrecht, Strafvollstreckung und Gnadenverfahren (16 Bde, 1935-1945, meist 1944/45), Notizen über Tagungen der Generalstaatsanwälte (1935-1944), Akten über einzelne Gerichtsgefängnisse und die Justizvollzugsanstalten Aichach (4 Bde, 1930-1945), Kaisheim, Landsberg, Laufen-Lebenau, München-Stadelheim, Niederschönenfeld, Rothenfeld; umfangreicher Bestand von Einzelfallakten (ca. 2800 Bde, 1933-1945) vorwiegend zu Verfahren wegen 
Hoch-und Landesverrat, Heimtückedelikten, Wehrkraftzersetzung und Feindbegünstigung, Fahnenflucht noch bei der Behörde.

Lit: WIDERSTAND UND VERFOLGUNG Bd. 7. 1977.

Staatsanwaltschaft beim OLG Nürnberg

Generalakten betr. Dienststellenverwaltung, Personalangelegenheiten, Aufsicht über Vollzugsanstalten, Arbeitseinsatz, Vollstreckung von Todesstrafen und Sicherungsverwahrung, Strafsachen gegen Geistliche (1937-1941), Verfahren wegen Rassenschande, Körperverletzung (130 Bde mit wenigen Einzelfallakten, 1935-1945).

Staatsanwaltschaft beim OLG Oldenburg OL, Best. 140-4 Akten aus dem Allgemeinen (AR-) Register über einzelne Verfahren, u. a. wegen VerstoB gegen Devisenbewirtschaftung, Heimtücke, Plünderung, Kriegswirtschaftsdelikten (124 Bde, meist 1943-1944).

Lit: J. WOLFF: Justizverwaltung im Bezirk des OLG Oldenburg 1933-1945. 1989.

Staatsanwaltschaft beim OLG Zweibrücken SP, Best. J 71 Akten über Untersuchungen nach dem Novemberpogrom 1938 im allgemeinen und von Einzelfällen von Synagogenbrandstiftung und Plünderung, die zu 8 Verfahren wegen Diebstahls führten (48 Bde, 1938-1940).

Lit: INVENTAR DER QUELLEN. 1982. Nr. 1798-1826 (S. 856-869). - K. H. DEBUS: Die Reichskrisıailnacht in der Pfaiz. 1981.

\subsubsection{Landgerichte}

Das Schriftgut der 90 Landgerichte, die es bei Kriegsbeginn im späteren Gebiet der Bundesrepublik gab, ist nur zu einem sehr kleinen Teil in die staatlichen Archive gelangt, soweit es ihnen überhaupt angeboten wurde; viel ist durch Kriegsereignisse und wahrscheinlich auch von den Geschäftsstellen selbst vernichtet worden. Bestände aus der NS-Zeit fehlen von folgenden Landgerichten: Berlin, Coburg, Darmstadt, Duisburg, Gießen, Hanau, Heilbronn, Kassel, Kleve, Lüneburg, Mainz, Memmingen, Mosbach, Münster, Nürnberg-Fürth, Siegen, Waldshut, Würzburg, Zweibrücken.

Die Archive hielten die Verfahrensakten, die nach der Aktenordnung ohnehin nur in Zivilsachen bei den Gerichten geführt wurden, in der Regel nicht für archivwürdig und beschränkten sich auf eine Auswahl, mitunter auch auf Urteilssammlungen, wobei gelegentlich eine vom Richter vorgenommene Kennzeichnung als „historisch wertvoll“ berücksichtigt wurde. Auswahlkriterien waren u. a. die ProzeBparteien, so daß z. B. Verfahren mit Beteiligung von Körperschaften bevorzugt wurden. Besonderes Interesse galt den Akten in Ehe- und Familiensachen.

Folgende Bestände sind vorhanden:

Landgericht Aachen

$\mathrm{D}-\mathrm{K}$ Akten aus 11 „gewöhnlichen“ Zivilprozessen (1933-1938) mit Firmen und Gemeinden als ProzeBparteien. burg 1937) betr. Aufsicht über Amtsgerichte, Akten aus 22 ,gewöhnlichen“ Zivilprozes- 
sen (1933-1937), darunter einer wegen Schadenersatzforderung eines jüdischen Kaufmanns nach einem Überfall durch SA (1935).

Landgericht Amberg

Akten aus einzelnen, fast ausschlieBlich „gewöhnlichen“ Zivilprozessen (ca. 900, 19341944), nur aus wenigen Urkunden-, Wechsel- und Scheckprozessen, Ehescheidungsakten (ca. 800 Verfahren, 1933-1945) und aus Strafverfahren (286 Verfahren, 1933-1935), überwiegend wegen Sittlichkeitsverbrechen, dabei ein Verfahren gegen einen Geistlichen, zwei Urteile auf Entmannung.

Landgericht Ansbach

N, Rep. 279/1 II

Akten aus 56 Zivilprozessen (1933-1942), überwiegend wegen Anerkennung der Vaterschaft und der Abstammung, dabei ein „Lebensborn“-Fall, und wegen schuldrechtlicher Ansprüche, dabei einige mit jüdischen ProzeBparteien, Register der Verfahren in Handelssachen (1933/34).

\section{Landgericht Arnsberg}

Generalakten über Personalangelegenheiten mit Richterlisten mit Beurteilungen (19331934) und Vorgängen über Teilnahme von Beamten an der Auseinandersetzung über Konfessionsschulen (1939) und über künftige Gerichtsorganisation (1944), Anträge auf Zulassung zur Rechtsanwaltschaft (auch von Juden), ca. 2000 Urteile in Zivilprozessen (1933-1940), Sammelakten über Beschwerden gegen Entscheidungen der Amtsgerichte (5 Bde, bis 1936).

Landgericht Aschaffenburg

WÜ, Best. II 1.1.2.-1

Akten aus 72 „gewöhnlichen“ Zivilprozessen (18 aus 1933-1936, 54 aus 1942-1944), dabei einmal Kirchen- gegen Zivilgemeinde.

\section{Landgericht Augsburg}

Akten aus 21 Verfahren wegen Vaterschaftsfeststellung (1937-1945) und 174 „gewöhnlichen“ Zivilprozessen (1938-1945).

Landgericht Aurich

AUR, Best. 107

Akten aus 5 Verfahren mit Beteiligung von Kommunen und Kirchengemeinden (19331937).

Landgericht Bamberg

BAM, Best. K 105

Akten aus 35 Zivilprozessen (1933-1941) wegen schuldrechtlicher Ansprüche und in Familienrechtssachen.

Landgericht Bayreuth

BAM, Best. K 106 Akten aus 10 Zivilprozessen (1933-1944), davon 7 unter Beteiligung einer Gemeinde.

Landgericht Bielefeld

DT, Best. D 20

Akten aus 30 Zivilprozessen (1933-1945), vor allem wegen Forderungen auf Schadenersatz, und ca. 5000 Urteile (1931-1935).

Akten aus 33 Zivilverfahren (1933-1945), an denen insbesondere Bergbauunternehmen, Kirchen- und Zivilgemeinden beteiligt waren, auch einigen Verfahren unter Mitwirkung 
jüdischer Rechtskonsulenten (nach 1938) und einem Verleumdungsprozeß gegen einen jüdischen Arzt (1929-1943).

\section{Landgericht Bonn}

$\mathrm{D}-\mathrm{K}$

Vollständige Sammlung aller Urteile in Zivilsachen (1933-1945).

Landgericht Braunschweig

WF, Best. 37 A neu

Generalakten (15 Bde, 1933-1944, weitere ca. 25 Bde als Vorakten Best. 58 Nds), u. a betr. zivile Reichsverteidigung, Verfolgung der kommunistischen Bewegung, Luftkrieg, Kriegsgerichtsbarkeit, Akten aus 264 überwiegend „gewöhnlichen“ Zivilprozessen (1933-1943) und 46 ,erbbiologisch bedeutenden“ Verfahren (Feststellung der Vaterschaft und Ehelichkeit, 1934-1938), Ehescheidungsurteile (55 Pakete, 1934-1945), Register über Berufungen (bis 1943) und Beschwerden (bis 1943).

Lit: A. LENN: Braunschweiger Justiz im Nationalsozialismus. 1981

Landgericht Bremen

HB, Best. $4,44 / 2$

Akten aus 180 ngewöhnlichen“ Zivilprozessen (1933-1945), vornehmlich mit Firmen, der NSDAP und Behörden als ProzeBparteien.

\section{Landgericht Bückeburg}

SHG, Rep. L 23

Generalakten (83 Bde, 1933-1939), überwiegend betr. Dienststellenverwaltung mit Geschäftsübersichten auch der Disziplinarkammer und des Erbgesundheitsgerichts, ferner über Amnestien (3 Bde), Akten aus 7 Zivilprozessen (1933-1944) unter Beteiligung des Fürsten zu Schaumburg-Lippe und wegen Unterbringung in einer Heilanstalt und Sterilisation, 80 Ehescheidungs- und anderen Familienrechtsverfahren (1936-1942), 8 Kindschafts- und Entmündigungsverfahren (1937-1943).

\section{Landgericht Deggendorf}

LA, Rep. $167 / 1$

Akten betr. Vollzug des Erbgesundheitsgesetzes im allg. (1933-1934), Befreiung vom Ehehindernis des Ehebruchs in Einzelfällen (32 Bde, 1940, 1944), aus einem Verfahren wegen Jagdrechten (1936-1937) und aus 30 Voruntersuchungen in unpolitischen Strafsachen (1933-1935), überwiegend wegen Brandstiftung.

\section{Landgericht Detmold}

DT, Best. D 20

Generalakten (172 Bde, durchgehend 1879-1936), gleichzeitig über die Landesjustizverwaltung und -gesetzgebung, Sammlung von Entscheidungen über Berufungen und Beschwerden in Zivil- (14 Bde, 1933-1937) und Strafsachen (8 Bde, 1933-1937), Akten aus 105 „gewöhnlichen“ Zivilprozessen (1933-1945), vor allem mit Beteiligung des Landes und der NSDAP.

\section{Landgericht Dortmund}

Akten aus 88 „gewöhnlichen“ Zivilprozessen (1933-1937), überwiegend mit Bergbauunternehmen, Gemeinden und Fiskus als Beklagten, dabei Forderungen von Juden auf Ersatz fuir Schäden.

Landgericht Düsseldorf

$\mathrm{D}-\mathrm{K}$ Akten aus 60 Zivilverfahren (1933-1945), u. a. um Patentrechte, Kunstwerke und zur Feststellung der Abstammung.

LiL: DÜSSELDORF und sein Landgericht 1820-1970. 1970. 
Landgericht Eichstätt

N, Rep. 279/2 I

Generalakten ( 80 Bde, 1933-1937), dabei betr. Ortspolizei (8 Bde, 1933-1934), sonst überwiegend Dienststellenverwaltung und Personalangelegenheiten; Sammelakten betr. Befreiung vom Ehehindernis des Ehebruchs (1930-1935); Akten aus 16 Strafverfahren (1933-1942), u. a. gegen Kreisleiter wegen Sachbeschädigung (1933), HJ-Führer wegen Körperverletzung.

Landgericht Ellwangen

Akten aus ca. 700 ,gewöhnlichen“ (1934-1937), ca. 90 Berufungsverfahren (1936-1937) und ca. 120 Ehescheidungs- und anderen Eherechtssachen (1934-1935), fermer aus 24 Beleidigungsprozessen (1937) und ca. 350 Strafverfahren.

\section{Landgericht Essen}

$\mathrm{D}-\mathrm{K}$

Akten aus 35 „gewöhnlichen“ Zivilprozessen und 3 Verfahren vor der Kammer in Handelssachen (1933-1945), darunter mit Beteiligung des RWE und der Fa. Fried. Krupp, u. a. wegen Bergschäden, und von Juden, ferner im Zusammenhang mit dem Bau der Reichsautobahn und der Auseinandersetzungen in der evangelischen Kirche.

Landgericht Flensburg

SL, Abt. 354

Generalakten (85 Bde, 1933-1936), u. a. betr. Aufsicht über Amtsgerichte, Erbgesundheits- und Sondergerichte, ProzeBagenten, Akten aus 10 „gewöhnlichen“ Zivilprozessen (1933-1945) und 3 Familienrechtssachen (1933-1939).

Landgericht Frankenthal

SP, Best. J 6 Register zu allen Verfahren, Sammlungen der Unteile in Zivilsachen (1933-1939), in Berufungsfällen (9 Bde, 1933-1939) und der Entscheidungen über Beschwerden (19331939), Akten aus ca. 250 „gewöhnlichen“ Zivilverfahren (1933-1939), vor allem unter Beteiligung juristischer Personen und der NSDAP, und 248 Ehescheidungs- und anderen Familienrechtsverfahren (1937-1941).

Lit: H. WEILER: Die Geschichte des Landgerichts Frankenthal. 1977.

Landgericht Frankfurt/Main

WI, Abt. 460

Generalakten (ca. 300 Bde, 1933-1943, mit Lageberichten 1940-1945), vor allem betr. Personalangelegenheiten und Besetzung der Gerichte, auch betr. Gerichtsorganisation, Arbeitsgerichtsbarkeit, Verhältnis zur NSDAP, Beschwerden (1938-1941), Urteile in "gewöhnlichen“ Zivilprozessen (1933-1945) und einzelne Akten auch aus Urkunden-, Wechsel- und Scheckprozessen (1933-1945) sowie Familienrechtssachen (bis 1934). Gesondert (Abt. 474) sind Handakten beim Landgericht oder OLG Frankfurt zugelassener jüdischer Rechtskonsulenten überliefert, vor allem aus den Kanzleien Dr. Gutenstein/Dr. Popper (2 419 Bde) und Dr. Julius Grünebaum (561 Bde), einzelne aus vier weiteren Frankfurter und vier Kanzleien in Darmstadt, Kassel und Wiesbaden; insgesamt stammen sie aus 3598 Verfahren für jüdische Mandanten, insbesondere in Verbindung mit der Regelung finanzieller Angelegenheiten bei der Emigration und zur Durchsetzung von Forderungen.

Lit.: E. NOAM, W. A. KROPAT: Juden vor Gericht 1975. S. 51, 64-75. 
Landgericht Freiburg

FR

Akten betr. Zulassung zur Rechtsanwaltschaft (Einzelfälle, 95 Bde), aus Zivilprozessen (13 Bde) wegen Forderungen von Versicherungen, Stiftungen und Verbänden, Vollstreckung in unbewegliches Vermögen und Strafverfahren (8 Bde) wegen Meineids gegen Reichskanzler Josef Wirth (1933) und wegen Sittlichkeitsdelikten.

Lit:: R. LIESSEM-BREINLINGER: .Der Feind steht rechts!". 1978.

\section{Landgericht Göttingen}

H, Best. Hann 171

Generalakten (ca. 500 Bde bis 1936), u. a. betr. Justizpressewesen, (2 Bde, 1928-1937), Erbgesundheitsgerichte (2 Bde, 1933-1936), MaBnahmen ,aus AnlaB der nationalen Erhebung" (5 Bde, 1933-1938), Uneile (3 Bde, 1933-1936) und Akten aus 23 ,gewöhnlichen“ Zivilprozessen (1933-1945), vor allem mit Beteiligung von Körperschaften, dabei 1 Verfahren wegen Amtspflichtverletzung bei Sterilisierung (1941-1944) und 3 Ehescheidungsverfahren.

\section{Landgericht Hagen}

MS

Generalakten (nur 1 Bd betr. „Umwälzung der Staatsform“, 1918-1934), Akten aus 27 „gewöhnlichen“" Zivilprozessen (1933-1937) unter Beteiligung von Gemeinden, Fiskus und Firmen, dabei wegen Ansprüchen entlassener Beamter.

\section{Landgericht Hamburg}

HH, Best. 213-3

Generalakten in undifferenzierten Teilbeständen 1879-1936 und 1936-1971, dabei Akten über 6 jüdische Rechtskonsulenten, Verhältnis zur NSDAP, Sondergerichte, Staatsangehörigkeitsrecht.

Lit.: Hans ROBINSOHN: Justiz als politische Verfolgung. 1977.

\section{Landgericht Hannover}

H, Best. Hann 171 Akten aus ca. 35 „gewöhnlichen“"Zivilprozessen (1933-1945) unter Beteiligung von Körperschaften, davon 6 wegen Auseinandersetzungen in der Evangelischen Kirche (11 Bde, 1933-1940), aus 20 Verfahren in Abstammungssachen (1937-1944) sowie Urteilssammlungen (17 Bde, 1937-1944).

Lit: G. BESIER: Der ProzeB .Schramm gegen die Landeskirche“. 1989.

\section{Landgericht Hechingen}

SIG, Best. Ho 399

Urteile und Akten aus 236 Ehescheidungsverfahren (1935-1942) und über Befreiung von Eheverboten (27 Bde, 1937-1945).

Landgericht Heidelberg

KA, Best. 242

Akten aus ca. 120 ,gewöhnlichen“ Zivilprozessen (1933-1944) mit juristischen Personen, ca. 6000 Ehescheidungsverfahren (ab 1937) und aus 11 Strafverfahren (1933-1935), darunter wegen kommunistischer Betätigung.

Landgericht Hildesheim

H, Best. Hann 171

Akten und Urteile aus 21 ,gewöhnlichen“ Zivilprozessen (1933-1945), fast alle mit Körperschaften und Firmen als Beteiligten, darunter Reichswerke „Hermann Göring“.

\section{Landgericht Hof}

BAM, Best. K 107

Akten aus 34 „gewöhnlichen“ Zivilverfahren (1936-1939, 1944) und aus 23 Ehe-, Ehelichkeitsanfechtungs- und Entmündigungssachen (1933-1934). 
Landgericht Itzehoe

SL, Abt. 352

Generalakten (4 Bde, 1937 ab Errichtung des Gerichts und 1938), u. a. betr. Vollstreckung der Todesstrafe und NS-Rechtsbetreuungsstellen.

Landgericht Kaiserslautern

SP, Best. J 7

Allgemeines Register (1940-1945), Akten aus 14 ,gewöhnlichen“ Zivilprozessen (19401944).

Landgericht Karlsruhe

KA, Best. 243

Generalakten (1936-1945) und Akten aus 10 „gewöhnlichen“ Zivil- (1936-1941) und einzelnen Strafprozessen wegen Totschlags und Landfriedensbruchs aus politischen Motiven (1933), Ehescheidungsurteile (1 Bd, 1917-1941).

\section{Landgericht Kempten}

Akten aus 434 Zivilprozessen (1935-1942), überwiegend "gewöhnliche“, sonst Ehescheidungssachen.

Landgericht Kiel

SL, Abt. 352

Generalakten (200 Bde, 1933-1936), u. a. betr. Erbgesundheitsgerichte, Parteigerichtsbarkeit der NSDAP, Arbeitsgerichtsbarkeit, Rechtsanwaltschaft, Akten aus 27 ,gewöhnlichen“ Zivilprozessen (1934-1946).

Lit: C. H. ULE: Als Richter im Dritten Reich. 1988.

Landgericht Koblenz

Akten aus 4 „gewöhnlichen“ Zivilprozessen (1937-1940).

KO, Best. 583,1

Lit: E. J. THUL: Das Landgericht Koblenz im nationalsozialistischen Unrechtsstaat. 1970.

Landgericht Köln

$\mathrm{D}-\mathbf{K}$

Generalakten (ca. 200 Bde, 1936-1945), u. a. Berichte über Entscheidungen von grundsätzlicher Bedeutung (13 Bde), erbbiologische Untersuchungen (1940-1941), über Anerbenrecht (5 Bde, ab 1934), Sammelakten in Justizverwaltungssachen, dabei Vorgänge über Tragen von Parteiabzeichen und -uniformen bei Gericht (19331940), Besetzungsakten der Amtsgerichte (150 Bde), Akten aus 32 Zivilprozessen, dabei „Görreshaus"-ProzeB (5 Bde, 1933-1934), Streit um einen AusschluB aus dem Jesuitenorden, sonst vor allem unter Beteiligung von GroBbetrieben.

Lit: A. KLEIN, G. RENNEN: Justitia Coloniensis. 1981.

Landgericht Konstanz

FR

Einzelne Generalakten, Sammelakten über Strafsachen (1935-1944), Urteile der GroBen Strafkammer (1933-1934) und in Ehesachen (297 Bde, 1933-1936), Akten aus ca. 100 Zivilprozessen (1933-1945) wegen Entmündigung, Vaterschaftsfeststellung, Forderungen aus erbrechtlichen und schuldrechtlichen Ansprüchen und auf Schadenersatz, Grunddienstbarkeiten und aus 26 Strafverfahren (1933-1934) wegen Tötungs- und Sittlichkeitsdelikten, Brandstiftung, Körperverletzung, Meineid, Devisenvergehen, Nötigung, Freiheitsberaubung, Münzverbrechen, VerstoB gegen das Gesetz gegen Neubildung von Parteien, Haftlisten (3 Bde, 1942). 
Landgericht Krefeld

$\mathrm{D}-\mathrm{K}$

Generalakten (ca. 110 Bde, 1933-1945), u. a. betr. Erbhofrecht, Organisation der Erbgesundheitsgerichte, NSDAP-Mitgliedschaft und Ariernachweis der Beamten (3 Bde, 1936-1941), MaBnahmmen aus AnlaB der „Machtergreifung“ (2 Bde, 1933-1936), Zusammenarbeit mit der HJ (1936-1945), Akten aus 17 ,gewöhnlichen“ Zivilprozessen (1933-1942), einige mit Politikern aus der Zeit der Weimarer Republik als Partei.

Landgericht Landau

SP, Best. J 8

Akten aus ca. 461 meist „gewöhnlichen“ Zivilverfahren (1934-1936), Urteile (19331945) und Akten (ab 1940) aus ca 1000 Ehescheidungsprozessen.

\section{Landgericht Landshut}

LA, Rep. $167 / 3$

Generalakten (ca. 120 Bde, 1933-1945) mit Monatsberichten (1935-1945) und u. a. betr. Gerichtsverfassung, allgemeine Personalangelegenheiten, Verhälmis zu NSDAP und SA (6 Bde), Wiederherstellung des Berufsbeamtentums (3 Bde), Aufsicht über Rechtsanwälte und Notare, Beschwerden über die Justiz, Besetzung der Arbeitsgerichte, Schutzhaft (1919-1937), Ausübung des Gnadenrechts (2 Bde, 1922-1938), Akten über Einzelfälle von Ehelichkeitserklärungen (30 Bde, 1933-1945) und Befreiung vom Ehehindernis der Schwägerschaft (5 Bde, 1938-1940), aus 10 Verfahren wegen Anfechtung der Ehelichkeit (1933-1934), 8 Verfahren vor der Kammer für Handelssachen (1935) und aus ca. 50 ,gewöhnlichen“ Zivilprozessen, ferner über Klage von Otto Braun und Karl Severing auf Unterlassung einer ehrenrührigen Behauptung (1933).

Landgericht Limburg

WI, Abt. 462

Generalakten (ca. 50 Bde), Register für Erbgesundheitssachen (1937-1944), Urteile in Zivilprozessen (1933-1943), in Ehesachen (bis 1938) und Akten aus ca. 100 Verfahren (1939-1941).

Landgericht Lübeck

SL, Abt. 352

Generalakten (ca. 210 Bde bis 1936, ca. 40 Bde 1937-1945, davon 10 aus Gruppe 91), Akten aus 9 ,gewöhnlichen“ Zivilprozessen (1934-1939) und 79 Ehe- und anderen Familienrechtsverfahren (1937-1944) mit psychiatrischen und erbbiologischen Gutachten in Vaterschaftsermittlungssachen.

Landgericht Mannheim

KA, Best. 245

Akten aus 140 ,gewöhnlichen“ Zivilprozessen (1933-1944), vor allem unter Beteiligung von Firmen, und Urteile (1933-1941) sowie Akten (1943-1945) aus 50 Ehescheidungsverfahren.

Landgericht Marburg

MR, Best. 270

Akten aus 2 „gewöhnlichen“ Zivilprozessen (1936-1940).

Landgericht Mönchengladbach

$\mathrm{D}-\mathrm{K}$

Akten aus 26 ,gewöhnlichen“ Zivilprozessen (1933-1945), vor allem mit Beteiligung von Industrieunternehmen.

Landgericht München I

Akten aus ca. 2 300, meist „gewöhnlichen“ Zivilprozessen (1936-1938, überwiegend 1940-1944), einzelnen Verfahren vor den Kammern für Handelssachen und in Vater- 
schaftssachen, nur aus 55 Ehescheidungsverfahren (1933-1934), 40 Verfahren wegen Anfechtung der Ehelichkeit (1933) und 7 Verfahren wegen Entmündigung (1933-1934).

Landgericht München II

MSt

Pressemitteilungen über einzelne Verfahren (1935-1936), ca. 900 Urteile in „gewöhnlichen" Zivilprozessen (1937-1944).

Landgericht Offenburg

FR, Zg. 1977/67

Geschäftsakten (1936-1945) und Akten aus 34 Zivilprozessen, bei denen juristische Personen beteiligt waren (1933-1945), Sammlung von Urteilen in Strafsachen (10 Bde, 1934-1943).

Landgericht Oldenburg

OL, Best. 143

Einzelne Generalakten, Akten und Urteile aus ca. 150 Zivilprozessen (1934-1943), meist wegen Ansprüchen aus Schuldrecht, Abstammungs- und Erbrechtssachen, Urteilsliste (1942-1945) und Terminkalender (1937-1938, 1943-1944) des Sondergerichts.

Landgericht Osnabrück

OS, Rep. 940

Akten aus 28 Prozessen vor den Zivilkammern (1933-1944), meist um Grundeigentum und Ersatz von Unfallschäden, dabei aber auch Klage eines entlassenen Bürgermeisters auf Pensionszahlung (1936-1937), des Reichsschatzmeisters der NSDAP gegen einen SA-Truppführer (1938-1939) und drei Klagen von Strafgefangenen gegen das Deutsche Reich auf Ersatz für Schädigungen in den Strafgefangenenlagern Emsland (1941-1944) und 12 Verfahren vor der Kammer für Handelssachen (1934-1943), dabei ein Verfahren wegen Ausschlusses eines OHG-Gesellschafters wegen Rassenschande (1939-1940).

Landgericht Paderborn

DT, Best. D 20C

Generalakten (12 Bde, 1935-1940), u. a. betr. Verfahren zur Sicherung der Landbewirtschaftung (1937-1940) und mit Verzeichnissen geschichtlich wertvoller Akten seit 1887 für das Gausippenamt und das Gesundheitsamt (1944), Polizeiverordnungen einzelner Ämter (bis 1937), Akten aus 174 Zivilprozessen (1933-1945), vor allem mit Beteiligung katholischer Kirchengemeinden und von Reichsbehörden.

Landgericht Passau

Akten aus 77 ,gewöhnlichen“ Zivilprozessen (1933-1944).

Landgericht Ravensburg

SIG, Best. Wü 28/1 Akten aus 36 meist „gewöhnlichen“ Zivilprozessen (1935-1938), Strafverfahren vor dem Schwurgericht (50 Bde, 1933-1935) und in Berufungsfällen (31 Bde, 1933-1935), 3 sonstigen Strafverfahren, darunter ein Verfahren wegen Zusammenrottung aus politischen Motiven (1935).

Landgericht Regensburg

$\mathrm{AMB}$

Beschwerderegister (1936) und Akten aus 380 Strafverfahren (1933-1935) wegen Sittlichkeitsverbrechen, Tötungsdelikten und Körperverletzung, Meineid, Urkundenfälschung, Brandstiftung, Amtsunterschlagung, Raub.

Landgericht Rottweil

SIG. Best. WÜ $28 / 2$

Akten aus 300 Ehescheidungsverfahren (1933-1937), 40 Verfahren wegen Grunddienstbarkeiten und Ansprüchen auf Unterhalt (1933-1938), 38 Fällen der Befreiung vom Ehe- 
hindernis des Ehebruchs (1933-1941), 15 Anfechtungen der Ehelichkeit (1933-1936), 2 Entmündigungsfällen und 20 Berufungen gegen Urteile von Amtsgerichten (1933-1938), ferner Beschwerden und Armenrechtsgesuche (1933-1939).

Landgericht Saarbrücken

SB

Generalakten betr. Dienststellenverwaltung, Aufsicht über Amtsgerichte, Personalangelegenheiten, auch Maßnahmen aus Anlaß der Rückgliederung des Saarlandes (ca. 70 Bde, 1935-1944), Akten aus 26 Ehescheidungsverfahren (1937-1945).

Lit: EINHUNDERTFÜNFZIG JAHRE Landgericht Saarbrücken. 1985.

Landgericht Schweinfurt

WÜ, Best. II 1.1.2.-1

Akten und Urteile aus 36 Verfahren vor der Kammer für Handelssachen (1933-1940).

Landgericht Stade

STD, Rep. 171

Einzelne Akten aus vor 1933 begonnenen Zivilprozessen (bis 1944) wegen schuldrechtlicher Ansprüche, Ehescheidung, Vaterschaftsfeststellung und Entmündigung.

Landgericht Stuttgart

LB, Best. E 315

Listen über durchgeführte Voruntersuchungen durch den Untersuchungsrichter (19331937), Namensverzeichnis aller Angeklagten (1933-1934).

Landgericht Traunstein

MSt

Akten aus 13 „gewöhnlichen“ Zivilprozessen (1935-1936) und 4 Grundstückssachen (1933-1934).

Landgericht Trier

KO, Best. 583.2

Generalakten (ca. 100 Bde, 1933-1936, ca. 50 Bde 1936-1945), Akten aus 3 Zivilprozessen (1936-1943).

Landgericht Tübingen

SIG, Best. WÜ 28/3

Akten aus ca. 320 Ehescheidungs- und anderen Familienrechtsverfahren (1933-1934), 38 „gewöhnlichen“ Zivilprozessen (1933-1943), 24 Berufungsverfahren in Zivilsachen (1936-1943) und 55 Strafverfahren (5 von 1933-1935, sonst 1944-1945) u. a. wegen Arbeitsvertragsbruchs und Verunglimpfung des Andenkens Gefallener.

Landgericht Ulm

LB, Best. E 346

Akten aus Ehescheidungsverfahren und anderen Familienrechtssachen (1933-1945) und einigen 100 Strafsachen ohne politischen Hintergrund (1933-1935).

Landgericht Verden

STD, Rep. 171

Akten aus 12 Zivilprozessen (1933-1942), u. a. wegen Bohr- und Schürfrechten der Wintershall A.G. (1934-1940), Auseinandersetzungen mit Kirchengemeinden (1932-1936), Forderungen aus Amtspflichtverletzungen (1936-1938).

\section{Landgericht Weiden}

AMB, Best.O I 11

Urteilsbücher (1933-1935), Akten aus ca. 600 „gewöhnlichen“ Zivilprozessen und Ehescheidungsverfahren mit einzelnen Anfechtungen der Ehelichkeit und Abstammungsfeststellungen (1933-1942), Akten aus 59 Strafverfahren ohne politische Bedeutung vor dem Schwurgericht (1933-1935). 
Landgericht Wiesbaden

WI, Abt. 467

Sammlung der Urteile in Zivilsachen (1933), Akten aus ca. 100 „gewöhnlichen“ Zivilprozessen (1933-1945), drei Berufungsverfahren und über 7 Anträge außerhalb eines Prozesses und aus 248 Ehescheidungsverfahren (1942).

Landgericht Wuppertal

$\mathrm{D}-\mathrm{K}$

Akten aus 44 „gewöhnlichen“ Zivilprozessen (1933-1944), u. a. im Zusammenhang mit den Auseinandersetzungen zwischen Bekennender Kirche und Deutschen Christen.

\subsubsection{Staatsanwaltschaften bei den Landgerichten}

Die Oberstaatsanwälte bei den Landgerichten vertraten die Anklage in Strafsachen nicht nur vor diesen, sondern auch vor den Schöffengerichten bei den Amtsgerichten und vor dem Einzelrichter, soweit sie nicht Amtsanwaltschaften überlassen war, und hatten Mitwirkungsrechte in Ehe-, Kindschafts- und Entmündigungssachen.

Von den Archiven wurde Schriftgut vor allem aus Verfahren übernommen, die mit Hauptverhandlung und Urteil abgeschlossen wurden, seltener aus eingestellten Ermittlungsverfahren. Die ErschlieBung der Akten beschränkt sich allerdings häufig auf die Angabe des Namens des oder der Angeklagten und allenfalls das StrafmaB und gibt keinen AufschluB über das Delikt, noch weniger über den Tatbestand. Als archivwürdig wurden insbesondere angesehen Unterlagen aus Verfahren

- vor der Großen Strafkammer (KLs-, KMs- Sachen) und vor dem Schwurgericht (Js-, Ks-Sachen), wobei außer den Fällen der schweren Kriminalität die Verfolgung von Sittlichkeitsdelikten, z. B. Homosexualität nach $175 \mathrm{StGB}$ und Blutschande zwischen Verschwägerten, dokumentiert ist, oder

- wegen Straftaten nach nationalsozialistischem Sonderstrafrecht für politische und kriegsbedingte (Verordnung gegen Volksschädlinge vom 5. 9. 1939, der Kriegswirtschaftsverordnung vom 4. 9. 1939) Delikte, soweit sie nicht vor dem Sondergericht verfolgt wurden, oder

- wegen anderer Tatbestände mit politischem Hintergrund, z. B. wegen Landfriedensbruch und Körperverletzung durch Angehörige von NS-Organisationen, gegen korrupte Parteifunktionäre, wegen Verstößen von Geistlichen gegen den Kanzelparagraph, das Flaggen- und das Sammlungsgesetz.

Wenn Staatsanwaltschaften gleichzeitig Anklagebehörde vor Landgericht und Sondergericht waren, wurde die Überlieferung in einigen Archiven nicht getrennt, jedoch werden hier die Akten der Sondergerichte im Abschnitt 3.2.2.2 zusammen behandelt. Andererseits ist zu beachten, daB politisch relevante Strafsachen minderer Bedeutung, die vom Schöffengericht abgeurteilt wurden, bei Amtsgerichten dokumentiert sein können; z. B. führt ein „Verzeichnis politisch relevanter Akten “ von Amtsgerichten in den Landgerichtsbezirken Landshut und Passau (LA) Heimtückefälle bei 5, Verfahren gegen Bibelforscher und wegen Kanzelmißbrauchs bei je 2, wegen verbotenen Umgangs mit Kriegsgefangenen bei 3 Amtsgerichten auf, und weist allein für das Amtsgericht Passau 44 Verfahren wegen groben Unfugs aus politischen Motiven vor 1939 nach.

Von den Staatsanwaltschaften bei folgenden Landgerichten ist Schriftgut aus der NS-Zeit nicht oder noch nicht in das zuständige Archiv gelangt: Bamberg, Bayreuth, Braunschweig, Coburg, Ellwangen, Gießen, Hamburg, Heilbronn, Mainz, Mosbach, Ravensburg, Saarbrücken, Schweinfurt, Siegen. Folgende Bestände sind vorhanden: 
Staatsanwaltschaft beim Landgericht Aachen

$\mathrm{D}-\mathrm{K}$

Urteile und Akten aus Verfahren wegen Heimtücke (6 Bde, 1936-1942), Devisenvergehen, u. a. von Juden (12 Bde, 1934-1942), PaBvergehen und Schmuggel (11 Bde), Betrug. Untreue und Urkundenfälschung (37 Bde), Rassenschande (6 Bde, 1936-1943). Sittlichkeitsverbrechen von Geistlichen (3 Bde, 1935-1942), Raub und Diebstahl zum Nachteil von Juden (5 Bde, 1933, 1938), Mord und Totschlag (6 Bde). Umgang mit Kriegsgefangenen (1 Bd, 1943).

Staatsanwaltschaft beim Landgericht Altona

SL, Abt. 352

Akten aus Ermittlungs- und Hauptverfahren vor den Strafkammern (4 500 Bde, 1933 1937), mit relativ hohem Anteil von Anklagen wegen Widerstands gegen die Staatsgewalt, Waffenbesitz, Körperverletzung.

Staatsanwaltschaft beim Landgericht Amberg

AMB Generalakten (ca. 100 Bde, 1933-1942), u. a. betr. allgemeine Anweisungen für Strafrechtspflege und Strafvollzug (30 Bde), Verwaltung der Gefängnisse (17 Bde), Behandlung der Gefangenen (15 Bde, dabei 5 Bde mit Verzeichnissen), Akten aus ca. 1000 Ermittlungs- und Hauptverfahren u. a. gegen Mitglieder verbotener Parteien (5 Bde), wegen Heimtücke und politischer Beleidigung ( 80 Bde), gegen Geistliche wegen KanzelmiBbrauch, Versto $B$ gegen Sammlungsgesetz, Abhaltung verbotener Fronleichramsprozessionen u. dgl. (70 Bde), gegen Juden (4 Bde), wegen Umgangs mit Kriegsgefangenen (10 Bde), Brandstiftung, Volkschädlings- und Kriegswirtschaftsverbrechen (40 Bde), Einzelfälle von Strafvollstreckung und -vollzug bei Wehrmachtangehörigen und NSDAP-Funktionären (10 Bde, u. a. Straftilgung bei einem wegen Beleidigung von Juden verurteilten stellvertretenden Kreisleiter 1936 und der Strafe wegen Diebstahls bei einem SS-Oberscharführer des $\mathrm{KL}$ Dachau), französischen, belgischen und jugoslawischen Kriegsgefangenen und polnischen Fremdarbeitern (40 Bde, 1943-1944).

Staatsanwaltschaft beim Landgericht Ansbach

Akten aus Strafverfahren (ca. 150 Bde, 1936-1945).

Staatsanwaltschaft beim Landgericht Arnsberg

MS

Generalakten (38 Bde, 1933-1945), Akten aus 85 Strafverfahren aller Art und 144 Akten, Urteile und Handakten aus Verfahren vor dem Sondergericht Dortmund (überwiegend 1933-1934).

Staatsanwaltschaft beim Landgericht Aschaffenburg

WÜ, Best.II 1.1.3.-1 Generalakten betr. Maßnahmen bei Kriegsausbruch (4 Bde), Akten aus 91 Verfahren (1933-1939) u. a. wegen Abtreibung (24 Fälle), Sittlichkeitsdelikten (14 Fälle), fahrlässiger Tötung (16 Fälle), Brandstiftung und Amtsunterschlagung (je 2 Fälle), Devisenvergehen, Landfriedensbruch, Körperverletzung (je 1 Fall).

Staatsanwaltschaft beim Landgericht Augsburg

Akten aus 583 Haupt- und Ermittlungsverfahren (1933-1945, 458 davon 1944/45), darunter zahlreiche Fälle von Kriegswirtschaftsdelikten, unerlaubtem Verlassen des Arbeitsplatzes durch Fremdarbeiter, Arbeitsvertragsbruch, einzelne von Landesverrat, Fahnenflucht und Beihilfe dazu. Umgang mit Kriegsgefangenen, Betätigung für die Ernsten Bibelforscher. 
Staatsanwaltschaft beim Landgericht Aurich

AUR, Rep. 109

48 Register und Akten aus 2575 Ermittlungs- und Hauptverfahren vor den Strafkammern (1933-1945) mit hohem Anteil von Prozessen wegen Sittlichkeitsverbrechen, relativ zahlreichen Fällen von Devisenvergehen, Schmuggel und Verstößen gegen Vierjahresplanvorschriften und Kriegswirtschaftsverordnung, insbes. Schwarzschlachtung, und Einzelfällen von Rassenschande (3 Verfahren, 1937, 1942), Vorbereitung zum Hochverrat, Heimtücke, Beamtenbeleidigung, Steuerhinterziehung, Beihilfe zu illegalem Grenzübertritt.

Staatsanwaltschaft beim Landgericht Berlin

B, Rep. 58

Die Mehrzahl der Akten der gröBten deutschen Staatsanwaltschaft vor 1945, die von einem Generalstaatsanwalt geleitet wurde, befindet sich noch bei der Nachfolgebehörde. Der Bestand enthält auBer Akten aus ca. 2500 Verfahren vor 1933, die u. a. wegen ihrer Bedeutung für die Geschichte der NSDAP in der NS-Zeit als "geschichtlich wertvoll" gekennzeichnet wurden, nur Akten über ein Verfahren wegen versuchten Totschlags an einem SA-Mann (11 Bde, 1934-1943), ein Landesverratsverfahren (1937), ein Ermittlungsverfahren wegen Ermordung eines SA-Manns 1933 (3 Bde), aus den Prozessen gegen die Einbrecher Brüder SaB (18 Bde ab 1934), die Verantwortlichen für ein Einsturzunglück beim U-Bahnbau 1935 (59 Bde) und gegen einen Scheckbetrüger (19331934), über Ermittlungen wegen Devisenvergehen in Verbindung mit der Verleihung des Nobelpreises an Carl v. Ossietzky (13 Bde) und wegen der Vorwürfe gegen den Leiter der Siedlungsgemeinschaft „Bauernland“ Heinrich Lübke (40 Bde, 1934-1941).

LiL: B. SCHIMMLER: .Stimmung der Bevöikerung und politische Lage“. 1986.

Staatsanwaltschaft beim Landgericht Bielefeld

DT, Best. D $21 \mathrm{~A}$ Sammlung von Urteilen (1936), Akten aus ca. 200 Verfahren (1933-1945) vor allem wegen Homosexualität, Verstößen gegen Bewirtschaftungsvorschriften, dabei ein Verfahren mit 37 Angeklagten (1937), Arbeitsverweigerung (1943-1945), Betätigung für die Ernsten Bibelforscher, Devisenvergehen, verbotenen Umgangs mit Kriegsgefangenen.

Staatsanwaltschaft beim Landgericht Bochum MS

Akten und Urteile aus ca. 3500 Verfahren (1933-1945) vor den Strafkammern.

Staatsanwaltschaft beim Landgericht Bonn

$\mathrm{D}-\mathrm{K}$

Urteile und Akten u. a. aus Verfahren wegen Sittlichkeitsdelikten von Geistlichen und Ordensangehörigen (3 Bde, 1935-1937), Kanzelmißbrauch (3 Bde, 1939-1940), wegen Rassenschande (2 Bde), Hinterziehung von Reichsfluchtsteuer (1938), Mord und Körperverletzung aus politischen Motiven ( 9 Bde), Verleumdung und falscher Anschuldigung (4 Bde), Devisenvergehen (3 Bde).

Staatsanwaltschaft beim Landgericht Bremen

HB, Best. $4,89 / 1$ u. $/ 2$ Generalakten (ca. 110 Bde, überwiegend bis 1935), dabei Jahresberichte (bis 1942), Akten aus ca. 450 Strafverfahren in Fällen gewöhnlicher Kriminalität (1933-1945).

Staatsanwaltschaft beim Landgericht Bückeburg

SHG, Rep. L 23b Generalakten (52 Bde, 1933-1944, überwiegend aus der Dienststellenverwaltung) und Akten aus 22 Verfahren (1933-1939) wegen Devisenvergehen, Verteilung illegaler Flugblätter und wegen Veruntreuungen eines SA-Standartenfihrers (1934). 
Staatsanwaltschaft beim Landgericht Darmstadt

DA, Best. G 2

Akten aus 1284 Verfahren vor den Strafkammern (1933-1944), überwiegend wegen Sittlichkeitsdelikten mit einzelnen Fällen von Rassenschande.

Staatsanwaltschaft beim Landgericht Deggendorf LA, Rep. $167 \mathrm{St} / 1$ Akten aus Strafverfahren (ca. 100, 1933-1945) überwiegend wegen gewöhnlicher Kriminalität, nur in einzelnen Fällen wegen KanzelmiBbrauch, Heimtücke, Volksschädlingsverbrechen.

\section{Staatsanwaltschaft beim Landgericht Detmold}

DT, Best. D 21B

Akten aus ca. 270 Ermittlungs- und Hauptverfahren (1933-1945), darunter 20 wegen verbotenen Umgangs mit Kriegsgefangenen, 7 wegen Arbeitsvertragsbruch, 4 wegen Beihilfe zur Fahnenflucht, je 2 wegen Rundfunkverbrechen und Wehrkraftzersetzung, einzelne wegen Wahlfälschung (1934), Beleidigung Hitlers und anderer führender $\mathrm{Na}$ tionalsozialisten, Entfernung vom Volkssturm (1945), gegen Geistliche und Ernste Bibelforscher.

Staatsanwaltschaft beim Landgericht Dortmund MS Ureile und Akten aus ca. 200 einzelnen Verfahren (1934-1937), darunter wegen Heimtücke, Widerstand gegen die Staatsgewalt und gegen Ernste Bibelforscher.

Staatsanwaltschaft beim Landgericht Duisburg

$D-K$ Uneile und Akten aus ca. 7000 Verfahren (1933-1940, überwiegend 1933-1934), u. a. wegen Hoch- und Landesverrats, Ermordung eines SA-Manns vor 1933 (1936). Devisenvergehen, in Korruptionsfallen, wegen Nötigung im evangelischen Kirchenstreit, Landfriedensbruch bei einem Vortrag von Muckermann, Rassenschande (4 Fälle, 19371940), Plünderung beim Pogrom vom 9. 11. 1938, Wehrpflichtentziehung, Arbeitsverweigerung, Verbrechen nach der Volksschädlingsverordnung.

Staatsanwaltschaft beim Landgericht Düsseldorf

$\mathrm{D}-\mathrm{K}$ Urteile und Akten aus Verfahren wegen Heimtücke (81 Bde, 1934-1944), Beleidigung von führenden Persönlichkeiten (6 Bde, 1939), Betätigung für die konfessionelle und bündische Jugend (32 Verfahren, 1937-1942) und für die Ernsten Bibelforscher und andere verbotene Sekten (6 Bde, 1938-1940), Verstößen von Geistlichen gegen das Sammlungsgesetz (5 Bde, 1939) und des Ordens der Steyler Missionare gegen Devisenvorschriften (5 Bde, 1935-1937), wegen Sittlichkeitsdelikten von Geistlichen und Ordensangehörigen (3 Bde, 1935-1937), Kanzelmißbrauch (3 Bde, 1939-1940), in Korruptionsfällen (10 Bde, 1933-1944), wegen Rassenschande, Tarnung jüdischer Gewerbebetriebe (1939), Unterdrückung von Akten (1933-1934), Pressevergehen (4 Bde).

Staatsanwaltschaft beim Landgericht Eichstätt N, Rep. 279/2 S Akten aus ca. 6500 Haupt- und Ermittlungsverfahren (1934-1943), dabei zahlreiche Fälle fahrlässiger Tötung bei Verkehrsunfällen und von Heimtücke (z. B. 50 Verfahren aus 1935), einzelne Verfahren wegen Verstößen gegen das Flaggengesetz und wegen Umgangs mit Kriegsgefangenen.

Staatsanwaltschaft beim Landgericht Essen

$\mathrm{D}-\mathrm{K}$ Urteile und Akten aus Verfahren wegen Hoch- und Landesverrats (1933-1935). Landfriedensbruchs (5 Bde, 1933-1934), Verstößen gegen die Staatsschutzverordnung von 
1933 und Heimtücke (5 Bde), verbotenen Umgangs mit Kriegsgefangenen (2 Bde), Kriegswirtschafts-, Preis- und Devisendelikten (5 Bde).

Staatsanwaltschaft beim Landgericht Flensburg

SL, Abt. 354

Generalakten (74 Bde, 1933-1945, hauptsächlich aus den Aktengruppen 20, 21, 40-42, 44), Akten aus 2156 Ermittlungs- und Hauptverfahren (1933-1945), mit relativ hohem Anteil von Verfahren (besonders 1933-1934) wegen Waffenbesitz, Landfriedensbruch, Sabotage, Pressedelikten, einzelne Fälle von Rundfunkverbrechen und Umgang mit Kriegsgefangenen, ein Fall von Rassenschande (1938).

Staatsanwaltschaft beim Landgericht Frankenthal

SP, Best. J 72

Akten aus ca. 200 Verfahren (1933-1935) wegen Delikten nach der Staatsschutzverordnung von 1933, Heimtücke, Nichtablieferung von Waffen, insbes. gegen Kommunisten und Ernste Bibelforscher und aus 5 weiteren (1938, 1941-1944), davon eins wegen Umgang mit Kriegsgefangenen.

Staatsanwaltschaft beim Landgericht Frankfurt/Main

WI, Abt. 461

General- und Sammelakten (ca. 140 Bde, 1933-1943), u. a. betr. Gerichtsverfassung und -organisation, Strafvollstreckung, Akten aus ca. 3000 Verfahren vor den Strafkammern (1933-1943), u. a. gegen Juden (auch Rassenschandefälle) und Ausländer und wegen politischer Äußerungen.

Lit.: E. NOAM, W. A. KROPAT: Juden vor Gericht. 1975. S. 118-180, 206-233.

Staatsanwaltschaft beim Landgericht Freiburg

Generalakten (ca. 350 Bde, 1933-1936), inbes. betr. Strafrecht und -vollzug, Akten aus Verfahren (775 Bde, 1934-1945) vor allem wegen Heimtücke, Devisenvergehen (u. a. gegen den Reichstagsabgeordneten Dr. Hackelsberger, 10 Bde, ab 1938), ferner Wehrmittelbeschädigung, Wehrkraftzersetzung, Rundfunk-, Kriegswirtschafts- und Volksschädlingsverbrechen, Vermögens- und Eigentumsdelikten, Sittlichkeitsverbrechen, Rassenschande, Umgang mit Kriegsgefangenen, außerdem Sammlung von Unterlagen über Strafsachen vor Kriegsgerichten, Akten über die Ermittlung von Todes- (167 Bände, 1936-1937) und Brandursachen (9 Bde, 1934-1938), Mitwirkung bei Entmündigungen (4 Bde, 1937), Beschuldigtenkartei (1927-1968), Terminkalender für Sondergerichtssachen (1940-1945).

Staatsanwaltschaft beim Landgericht Göttingen

H, Best. NDS 721

Akten aus 9 Strafverfahren (1934-1944), dabei wegen Korruption gegen Funktionäre der NSDAP-Kreisleitung Göttingen (8 Bde, 1934-1937), 2 Urteile gegen Häftlinge des Jugendschutzlagers Moringen, außerdem 2 Todesursachenermittlungsverfahren bei Luftkriegsopfern (1945).

Staatsanwaltschaft beim Landgericht Hagen

MS

Akten und Urteile aus 294 Verfahren (1934-1939), u. a. wegen Homosexualität, Untreue, auch Rassenschandefällen.

Staatsanwaltschaft beim Landgericht Hanau

MR, Best. 274

Generalakten (ca. 100 Bde, 1933-1938), Urteile und Akten aus 1541 Ermittlungs- und Hauptverfahren, überwiegend in Fällen unpolitischer Kriminalität, dabei einzelne Fälle 
von Devisenvergehen. Kanzelmißbrauch ( 3 Verfahren), VerstoB gegen die VO zur Anmeldung jüdischen Vermögens (2 Fälle), verbotenem Umgang mit Kriegsgefangenen (11 Fälle), Rassenschande ( 3 Verfahren), Störung jüdischen Gottesdienstes, Beschimpfung der Reichsflagge, Arbeitsverweigerung, Kriegswirschaftsdelikten.

Staatsanwaltschaft beim Landgericht Hannover H, Best. Hann. 171 a Hannover Akten aus 540 Hauptverfahren wegen Kriegswirtschaftsverbrechen vorwiegend vor dem Sondergericht (1941-1945) und aus dem Allgemeinen (AR-) Register (3 Bde, 1944/45).

Staatsanwaltschaft beim Landgericht Hechingen

SIG. Best. Ho 400 Akten aus 25 Verfahren (1933-1945, davon 17 aus 1933-1934), u. a. gegen einen Pfarrer, wegen Abhaltung einer verbotenen Versammlung und wegen Wehrkraftzersetzung.

Staatsanwaltschaft beim Landgericht Heidelberg

KA, Best. 309

Akten aus 50 Verfahren (1933-1945) wegen Körperverletzung aus politischen Motiven, Plünderungen beim Pogrom vom 9. 11. 1938, Rassenschande, Kriegswirtschafts- und Volksschädlingsverbrechen.

Staatsanwaltschaft beim Landgericht Hildesheim H, Best. Harn 17 la Hildesheim Akten aus 31 Verfahren (1933-1945), davon 16 mit politischem Hintergrund, u. a. gegen 18 Reichsbanner-Mitglieder (5 Bde, 1932-1936), wegen Beleidigung von NSFunktionären, unbefugter Verwendung von NS-Symbolen, Rassenschande (2 Fälle).

Staatsanwaltschaft beim Landgericht Hof BAM. Best. K 107 Generalakten betr. Blutschutzgesetz (1936), Akten aus 50 und Urteile in 153 Strafverfahren (1933-1934, 1936-1939, 1942-1945), überwiegend KLs-Sachen mit hohem Anteil an Sittlichkeitsdelikten.

Staatsanwaltschaft beim Landgericht Itzehoe

SL, Abt. 352

Generalakten (18 Bde, 1936-1945), Akten aus 170 Ermittlungs- und Hauptverfahren (1937-1945) mit hohem Anteil an Verfahren wegen Sittlichkeitsdelikten und Abtreibung.

Staatsanwaltschaft beim Landgericht Kaiserslautern

SP, Best. J 73

Akten aus 36 Verfahren wegen Heimtücke, je einem wegen VerstoB gegen das Sammlungsgesetz und nach der Staatsschutzverordnung von 1933 (1938-1939).

Staatsanwaltschaft beim Landgericht Karlsruhe

KA, Best. 309 Akten (ca. 500 Bde, 1933-1945) aus Verfahren vor allem wegen Eigentumsdelikten (Betrug, Diebstahl), Sittlichkeitsverbrechen, Devisen- und Steuervergehen, Kriegswirtschafts- und Volksschädlingsverbrechen, einzelnen Fällen von Körperverletzung und Landfriedensbruch aus politischen Motiven, dabei auch Ausschreitungen am 9. 11. 1938, Rassenschande, Nichtanmeldung jüdischen Vermögens, ferner Beihilfe zur Fahnenflucht und verbotenen Umgangs mit Kriegsgefangenen, Sammelakten (13 Bde, 1942-1945) über Ermittlung der Todesursache bei Opfern von Luftangriffen, Vorgänge über die Vollstreckung von 11 Todesurteilen des Sondergerichts Stuttgart und von Kriegsgerichten (1943-1944). 
und Polizisten, Heimtücke, Rassenschande, Plünderung u. a. Volksschädlingsverbrechen, Kriegswirtschaftsverbrechen, ca. 400 „geschichtlich wertvolle Akten“ (1933-1945) noch bei der Staatsanwaltschaft Kassel.

\section{Staatsanwaltschaft beim Landgericht Kempten}

General- und Sammelakten (126 Bde, 1936-1945), u. a. betr. Schutzhaft, Strafvollstreckung; Akten aus ca. 6000 Haupt- und Ermittlungsverfahren (1933-1944) mit nur geringem Anteil politisch relevanter Fälle.

Staatsanwaltschaft beim Landgericht Kiel

SL, Abt. 352

Generalakten (168 Bde, 1933-1936), Akten aus Ermittlungs- und Hauptverfahren (672 Bde, 1933-1945), hauptsächlich wegen Körperverletzung und Beleidigung und relativ zahlreichen Fällen von Widerstand gegen die Staatsgewalt, Waffenbesitz, Vorbereitung zum Hochverrat, VerstoB gegen Uniformverbot.

\section{Staatsanwaltschaft beim Landgericht Kleve}

$\mathrm{D}-\mathrm{K}$

Urteile und Akten aus Ermittlungsverfahren (1933-1945) wegen Verbreitung verbotener Druckschriften (3 Bde, 1933-1934), Pressevergehen (12 Bde), Hochverrat (1938), Heimtücke (2 Bde, 1933, 1937-1938), VerstöBen gegen das Flaggengesetz, Weiterführung verbotener Jugendorganisationen ( 5 Bde), in sonstigen politischen Strafsachen (21 Bde, 1933-1941), u. a. wegen Tod eines Kommunisten (1934-1935), wegen Devisenvergehen und Kapitalflucht (23 Bde), Kriegswirtschaftsverbrechen ( 9 Fälle, 24 Bde), Betrug und Amtsvergehen (70 Bde), Sittlichkeitsdelikten (15 Bde), Rassenschande (5 Fälle, 6 Bde, 1938-1945), Ausschreitungen gegen Juden (4 Bde, 1935-1940), AmtsanmaBung.

Staatsanwaltschaft beim Landgericht Koblenz

KO, Best. 584,1 Akten aus ca. 800 Ermittlungs- und Hauptverfahren (1933-1944) fast sämtlich wegen unpolitischer Delikte mit einzelnen Fällen von Heimtücke und Kanzelmißbrauch.

Lit.: E. J. THUL: Das Landgericht Koblenz im nationalsozialistischen Unrechtsstaal. 1970.

Staatsanwaltschaft beim Landgericht Köln

$\mathrm{D}-\mathrm{K}$

Urteile und Akten aus Verfahren wegen MiBhandlung von Häftlingen im SA-Lager Hochkreuz bei Porz-Eil (4 Bde, 1933-1934), wegen Diebstahls (5 Bde), Sittlichkeitsdelikten, u. a. von HJ-Führern (8 Bde), Devisenvergehen (10 Bde, 1935-1940), Mord (4 Bde), gegen „Edelweißpiraten“ (2 Bde, 1944).

Staatsanwaltschaft beim Landgericht Konstanz FR

Akten aus 792 Verfahren (1933-1945) u. a. gegen zahlreiche Geistliche wegen Bekanntgabe von Kirchenaustritten, verbotener Sammlungen und Verstößen gegen das Flaggengesetz, wegen Heimtücke und Beleidigung Hitlers, kommunistischer Betätigung, Umgangs mit Kriegsgefangenen, ferner Ermittlung der Ursachen von Todes- und Brandfälen (32 Bde, 1933-1944).

Generalakten (ca. 120 Bde, 1933-1945) mit Niederschriften über Besprechungen beim Generalstaatsanwalt in Düsseldorf (1933-1935), Berichten an den Oberreichsanwalt beim Volksgerichtshof über Ermittlungen (1936-1944) und u. a. betr. Sondergerichte (1932-1934). Vertretung von Juden (1936-1945), Zusammenarbeit mit der Gestapo 
(1937-1942), Bekämpfung der Jugendverwahrlosung (2 Bde, 1936-1944), Bekämpfung der Abtreibungen (1936-1943), Arbeitsvertragsbruch (1936-1944), Urteile (36 Bde) und Akten aus einzelnen Verfahren wegen Pressevergehen, Hochverrat und Heimtücke (10 Bde), Devisenvergehen (3 Verfahren, 25 Bde, u. a. gegen 13 Herz-Jesu-Priester, 1935 1940), Rassenschande (2 Bde, 1939), Sittlichkeitsverbrechen (u. a. gegen einen HJFührer, 1937), Korruption (5 Bde, 1933-1944), schweren Diebstahls (5 Bde).

Staatsanwaltschaft beim Landgericht Landau

SP, Best. J 74

Akten aus ca. 1600 Ermittlungs- und Hauptverfahren (1933-1940) überwiegend ohne politische Bedeutung und über Ermittlungen in 33 Selbstmordfällen (1934).

Staatsanwaltschaft beim Landgericht Landshut

LA, Rep. 167/2

Akten aus 604 Verfahren (1933-1945) u. a. wegen Heimtücke (38 Fälle, 1935-1945), KanzelmiBbrauch (12 Fälle, 1935-1943), Beleidigung Hitlers u. a. Politiker (9 Fälle, 1935), nach der StaatsschutzVO von 1933 (6 Fälle, 1935-1938), wegen Sabotage (5 Fälle, 1935-1936, 1944-1945), Verstößen gegen Flaggen- (2 Fälle, 1935-1936) und Sammlungsgesetz (2 Fälle, 1938), Fahnenflucht und Wehrdienstentziehung (3 Fälle, 1942-1944), Umgang mit Kriegsgefangenen (10 Fälle, 1942-1945), Rundfunkverbrechen und Wehrkraftzersetzung (je ein Fall, 1944), gegen Bibelforscher (1935) und nach der VolksschädlingsVO (8 Fälle, 1940-1944).

Staatsanwaltschaft beim Landgericht Limburg

WI, Abt. 463 Generalakten (ca. 100 Bde, meist bis 1939), Urteile und Akten aus ca. 700 Strafverfahren (1933-1945), vorwiegend wegen Vermögens- und Sittlichkeitsdelikten, unter den Angeklagten 8 Juden, 90 Polen, 34 Franzosen, 28 Russen, 19 Italiener, 8 Tschechen.

Staatsanwaltschaft beim Landgericht Lübeck

SL, Abt. 352 Akten aus Ermittlungs- und Hauptverfahren (43 Bde, 1933-1945), überwiegend wegen Sittlichkeitsdelikten, je einem Fall von Heimtücke (1936) und Rassenschande (1938).

Staatsanwaltschaft beim Landgericht Lüneburg

H, Best. Hann 171a Akten und Urteile aus 20 Hauptverfahren wegen Verbrechen (1939-1943), dabei gegen zwei Beamte des Zuchthauses Celle wegen Tod eines Gefangenen (1942), 9 wegen Vergehen (1939-1944) vor der Strafkammer und 14 vor dem Schöffengericht (1939).

Staatsanwaltschaft beim Landgericht Marburg

MR, Best. 274

Akten aus 350 Verfahren (1933-1944) ohne politischen Hintergrund, überwiegend wegen Sittlichkeits- und Eigentumsdelikten.

Staatsanwaltschaft beim Landgericht Mannheim

KA, Best. 309

General- und Sammelakten (31 Bde), Akten aus 72 Verfahren insbes. mit anschlieBender Überführung in Konzentrationslager und Euthanasie-Anstalten und wegen Sittlichkeitsdelikten von Geistlichen.

Staatsanwaltschaft beim Landgericht Memmingen

A Generalakten (meist ab 1936) mit Berichten über Strafverfahren (8 Bde, 1933-1944), Protokollen der Dienstbesprechungen (1940-1944), Register (1933-1945) und Akten (1933-1939) aus ca. 10000 Ermittlungsverfahren u. a. wegen Heimtücke, KanzelmiBbrauch, Rassenschande, Verstößen gegen Bewirtschaftungsvorschriften. 
Staatsanwaltschaft beim Landgericht Mönchengladbach

$\mathrm{D}-\mathrm{K}$

Urteile und Akten aus Verfahren wegen öffentlicher Beleidigung (2 Bde, 19351939), Verbreitung verbotener Druckschriften (10 Bde), Heimtücke (3 Bde), verbotenen Waffenbesitzes (3 Bde, 1933-1934), Landfriedensbruch (SA-Schlägerei, 1935-1936), Fortführung der verbotenen Gottlosenbewegung, VerstoB gegen die Pflicht zur Anmeldung jüdischen Vermögens, Devisenvergehen (4 Fälle, 15 Bde, 1935-1944), Vergehen gegen das Genossenschaftsgesetz (23 Bde betr. Westdeutsche Kreditgenossenschaft und Gladbacher Gewerbebank), Sittlichkeitsverbrechen u. a. von Geistlichem und einem HJ-Führer (14 Bde), Rassenschande (4 Bde, 1936-1938), Betrug und Untreue (85 Bde), Kriegswirtschaftsverbrechen (2 Bde).

Staatsanwaltschaft beim Landgericht München I

MSt Verwaltungsakten betr. LuftschutzmaBnahmen (1933-1943) und Vergütungen für die vom Scharfrichter Johann Reichart vollzogenen Hinrichtungen (36 Bde, 1937-1945); Akten aus 51 Verfahren wegen Rassenschande (1939-1941) und je 1 wegen Vorbereitung zum Hochverrat und Landesverrat (1940), weiteren 919 Ks-, KLs- und KMs-Verfahren (1936-1945).

Staatsanwaltschaft beim Landgericht München II

MSt

Akten aus ca. 650 Verfahren (vorwiegend 1940-1942), dabei zahlreiche Fälle von Sittlichkeitsdelikten (Homosexualität, Unzucht mit Kindern, Blutschande) und verbotenem Umgang mit Kriegsgefangenen, einzelne Fälle von Heimtücke und Wehrkraftzersetzung, Ermittlungsakten über drei Todesfälle im Konzentrationslager Dachau (1933).

Lit.: H. G. RICHARDI: Schule der Gewalt. 1983.

Staatsanwaltschaft beim Landgericht Münster MS Akten aus 25 Verfahren (1933-1945).

Staatsanwaltschaft beim Landgericht Nürnberg-Fürth $\mathrm{N}$ Akten aus ca. 120 Verfahren (1933-1945) u. a. wegen öffentlicher Beleidigung (12 Fälle, vor allem durch den ,Stürmer", 1927-1939), im Zusammenhang mit dem Kirchenkampf (24 Fälle, u. a. wegen Kanzelmißbrauch, Beleidigung und Sachbeschädigung, 1934 1942), wegen Heimtücke, Unterlassung der Führung des Vornamens Israel (1939), über eine Beschwerde wegen Schutzhaft im KL Dachau (1933-1937), Überstellung aus der Sicherungsverwahrung in das KL Mauthausen (1942-1943), Ermittlung der Todesursache bei Luftkriegsopfern (1942-1943).

Staatsanwaltschaft beim Landgericht Offenburg

FR

Akten aus 1047 Verfahren (1595 Bde, 1935-1945) vor allem wegen Kriegswirtschaftsverbrechen, Meineid, Urkundenfälschung, Umgang mit Kriegsgefangenen, Volksschädlingsverbrechen, außerdem wegen Sittlichkeits-, Vermögens- und Eigentumsdelikten, Abtreibung, Beleidigung, Fahnenflucht, Handakten über 24 Sicherungsverwahrte (1933-1937), Unterlagen über Untersuchung von Bränden (210 Bde, 1935-1945) und des Absturzes eines tschechischen Flugzeugs (1938).

Staatsanwaltschaft beim Landgericht Oldenburg

OL, Best. 140-5

Akten aus 80 einzelnen Strafverfahren (1935-1945, überwiegend ab 1941), u. a. wegen Heimtücke, Rundfunkverbrechen, Beihilfe zur Fahnenflucht, Kriegswirtschaftsverbre- 
chen, und 8 Verfahren zur Feststellung der Todesursache bei Opfern von Luftangriffen (1943-1945).

Staatsanwaltschaft beim Landgericht Osnabrück

OS, Rep. 945

Akten aus einem Verfahren wegen Beleidigung des oldenburgischen Ministerpräsidenten Röver (1932-1937), aus 3 Ermittlungsverfahren wegen Devisenvergehen (8 Bde, 19391942), Plünderung (1943-1944) und fahrlässiger Tötung (1944-1946) und aus 62 Hauptverfahren vor den Strafkammern (1934-1945), dabei je 1 wegen Umgangs mit Kriegsgefangenen und wegen Gefangenenmeuterei im Strafgefangenenlager Brual-Rhede (1945), und 5 vor dem Schöffengericht.

Staatsanwaltschaft beim Landgericht Paderborn $\quad$ DT, Best. D 21C Akten aus 19 Verfahren (1936-1940), davon 3 wegen Vorbereitung zum Hochverrat, 7 wegen (fahrlässigen) Landesverrats, 2 wegen Sabotage.

Staatsanwaltschaft beim Landgericht Passau

Akten aus Verfahren vor dem Schwurgericht (59 Bde, 1933-1938), u. a. wegen gewerbsmäBiger Abtreibung, 6 Verfahren gegen Sittliçhkeitsverbrecher mit Anordnung der Entmannung (1934-1940) und 7 Verfahren wegen Heimtücke (1936-1940), 58 wegen Arbeitsvertragsbruch (1940-1943), 5 wegen Dienstpflichtverletzung (1941), 5 wegen Kanzelmißbrauchs (1936-1941), 8 wegen Umgangs mit Kriegsgefangenen (1941 -1944), 4 wegen Devisenvergehen (1936-1937), 6 wegen Kriegswirtschaftsdelikten (1940-1944), 2 wegen Wehrkraftzersetzung (1941-1943), je 1 wegen Rassenschande (1938), Vernichtung von Feldpostbriefen (1943) und Betätigung für die Ernsten Bibelforscher (1936).

Zweigstelle Pforzheim der Staatsanwaltschaft beim Landgericht Karlsruhe

KA, Best. 309

Akten aus ca. 200 einzelnen Strafverfahren vor dem Landgericht Karlsruhe (1935-1944), u. a. wegen Devisenvergehen, Verbrechen nach der Volksschädlingsverordnung, verbotenen Umgangs mit Kriegsgefangenen.

Staatsanwaltschaft beim Landgericht Regensburg

$A M B$

Register in Js-Sachen (10 Bde, 1938-1945, mit Namenskartei 1934-1945) und andere Register, Akten aus 1720 Ermittlungs- und Strafverfahren (1935-1945).

Staatsanwaltschaft beim Landgericht Rottweil

SIG, Best. WÜ 29/2 Akten aus 138 Hauptverfahren (1936-1938) wegen Sittlichkeitsverbrechen, Diebstahl, Amtsunterschlagung, Devisenvergehen, Heimtücke (1 Fall).

Staatsanwaltschaft beim Landgericht Stade

STD, Rep. 171 a Generalakten (durchlaufender Bestand, ca. 1900-1970), Register (1933-1945, dabei auch über Vorermittlungen für Verfahren vor dem Sondergericht Hannover), Akten aus ca. 425 Ermittlungsverfahren (1933-1945), dabei Heimtückefälle, Vorbereitung zum Hochverrat, Sittlichkeitsdelikte (mit Anordnung der Entmannung), Kriegswirtschaftsverbrechen, Fahnenflucht, Feindbegünstigung.

Staatsanwaltschaft beim Landgericht Stuttgart

LB, Best. E 323 II

Restakten aus ca. 500 Ermittlungsverfahren (1933-1945, davon 158 aus 1944) mit kleinem Anteil politischer Strafsachen, auch Einzelfällen von Rassenschande, außerdem 
(Best. EL 317) Akten aus Verfahren gegen Ausländer (1942-1945), u. a. wegen Meuterei und Feindbegünstigung.

Staatsanwaltschaft beim Landgericht Traunstein

MSt

Sammlung von ca. 1800 Urteilen und Einstellungsverfügungen (33 Bde, 1933-1941), Akten aus ca 400 Verfahren (1933-1945) vor allem wegen Sittlichkeitsdelikten, z. T. mit Anordnung der Entmannung, sonst u. a. Heimtücke, verbotenen Umgangs mit Kriegsgefangenen, Kriegswirtschafts- und Volksschädlingsverbrechen, auch einzelnen Fällen von Rassenschande (1939) und von Untersuchungen wegen Ausschreitungen beim Pogrom vom 9. 11. 1938.

Staatsanwaltschaft beim Landgericht Trier

KO, Best. 584,2 Als "geschichtlich wertvoll“ gekennzeichnete Akten aus ca. 500 Ermittlungs- und Hauptverfahren (1933-1945) mit zahlreichen Fällen von politischer Beleidigung (19331934), Spionage und Landesverrat, insbes. gegen Luxemburger (ab 1941), Landfriedensbruch, wegen Versto $B$ gegen das Sammlungsgesetz, Sittlichkeitsverbrechen und anderer Straftaten von Geistlichen, Heimtücke, Wehrmittelbeschädigung, Rundfunkverbrechen, kommunistischer Propaganda, verbotenen Umgangs mit Kriegsgefangenen, Kriegswirtschafts- und Volksschädlingsverbrechen.

Staatsanwaltschaft beim Landgericht Tübingen

SIG, Best. WÜ 29/3 Akten aus 1458 Ermittlungs- und Hauptverfahren (1936-1945), davon ca. 30 \% wegen Sittlichkeitsdelikten, sonst u. a. wegen Umgangs mit Kriegsgefangenen (24 Fälle), Selbstverstïmmelung, Beihilfe zur Fahnenflucht, Vergehen gegen Bewirtschaftungs- und Preisvorschriften, fahrlässige Gefangenenbefreiung.

Staatsanwaltschaft beim Landgericht Ulm

LB, Best. E 352 Akten aus ca. 1000 Haupt- und Ermittlungsverfahren (1940-1945), davon etwa die Hälfte gegen Fremdarbeiter, sonst nur einzelne Fälle von Wehrkraftzersetzung und verbotenen Umgangs mit Kriegsgefangenen, 9 Vollstreckungsakten in Fällen besonderer Bedeutung, Akten aus 12 Verfahren wegen Löschung einer Strafe.

Staatsanwaltschaft beim Landgericht Verden

STD, Rep. $171 \mathrm{a}$ Wenige Generalakten und Register (18 Bde, 1933-1945), Akten aus 180 Hauptverfahren (1933-1945), u. a. wegen Beleidigung von NS-Funktionären (1932-1935), nach der Staatsschutzverordnung vom 4. 2. 1933, wegen Gefangenenmeuterei (1933-1935), Devisenvergehen (1938), Verstößen gegen Preisvorschriften (1936-1945), Schwarzhandel, Schwarzschlachtungen und anderen Kriegswirtschaftsdelikten, Sittlichkeitsverbrechen (1933-1945, mit Anordnung der Entmannung), Wehrdienstentziehung (1936-1944), Wehrmittelbeschädigung durch Kriegsgefangene (1943-1944).

Staatsanwaltschaft beim Landgericht Waldshut FR Unteile und Akten aus 20 Verfahren (36 Bde, 1938-1945) ohne politischen Hintergrund, dabei wegen Brandstiftung und Eisenbahntransportgefährdung. 
Staatsanwaltschaft beim Landgericht Wiesbaden

WI, Abt. 468

Sammlung der Urteile des Landgerichts in Strafsachen (1933-1940), Akten aus einem Ermittlungsverfahren wegen Betrug (1942).

\section{Staatsanwaltschaft beim Landgericht Wuppertal}

$\mathrm{D}-\mathrm{K}$

Urteile und Akten aus Verfahren wegen Landesverrat und Sabotage (9 Fälle, 17 Bde, 1933-1944), auch gegen Niederländer und Franzosen, Beleidigung von Politikern und Funktionären (29 Bde, 1933-1942), Besitz und Verbreitung politischer und kirchlicher Flugschriften (23 Bde), Heimtücke (140 Bde, 1938-1945), Hochverrat (30 Bde), Betätigung für verbotene Parteien und Sekten (4 Bde), gegen die Ernsten Bibelforscher (7 Bde), konfessionelle (3 Bde, 1938-1941) und bündische (11 Bde, 1938-1945) Jugendorganisationen, wegen KanzelmiBbrauch und anderer Delikte von Geistlichen (45 Bde), Körperverletzung und Gewalttaten unter Beteiligung von Nationalsozialisten (28 Bde, 1933-1936, dabei 5 Bde Ermittlungen gegen Unbekannt wegen Mißhandlung von Gefangenen im Konzentrationslager Wuppertal-Kemna, 1934-1936), Rassenschande (19 Bde, 1936-1943), Sittlichkeitsverbrechen (u. a. 28 Bde gegen Mitglieder der „Auferstehungsgemeinde" auch wegen Untreue und Heimtücke, 1924-1940), Amtsvergehen (5 Bde), Verbrechen nach der Volksschädlingsverordnung (55 Bde, auch Korruptionsfälle), Kriegswirtschaftsverbrechen (35 Bde), Wehrpflichtentziehung und Fahnenflucht (12 Bde, 1940-1945), Mord (4 Bde), Akten über die Vollstreckung von Feldurteilen verschiedener Divisionsgerichte (30 Fälle 1944, je 1 von 1943 und 1945).

Staatsanwaltschaft beim Landgericht Würzburg

WÜ, Best. II 1.1.3.-3

Akten aus 61 Ermittlungs- und Hauptverfahren (1933-1945, z. T. Rekonstruktion bei Wiederaufnahme nach 1945) mit relativ hohem Anteil von Einweisungen in Heilund Pflegeanstalten und einzelnen Urteilen von Kriegsgerichten, u. a. wegen Behinderung von Geistlichen durch HJ-Führer, öffentlicher und nichtöffentlicher Beleidigung (6 Fälle), Sittlichkeitsdelikten (9 Fälle), Diebstahl (8 Fälle), PaB- und Devisenvergehen (2 Fälle), Tarnung eines jüdischen Gewerbebetriebs.

Staatsanwaltschaft beim Landgericht Zweibrücken

SP, Best. J 75 Akten aus ca. 1150 Verfahren (1936-1945, meist ab 1940) mit relativ zahlreichen Fällen von Arbeitsverweigerung, sonst wegen Sittlichkeits-, Eigentums- und Kriegswirtschaftsdelikten, Körperverletzung (bei Verkehrsunfällen), Umgang mit Kriegsgefangenen, einzelne Fälle von Rassenschande.

\subsubsection{Sondergerichtsbarkeit in Strafsachen}

\subsubsection{Volksgerichtshof und Oberreichsanwalt beim Volksgerichtshof}

BA, Best. R 60 I und II

ZStA, Best. 30.16 und 30.17

Ein erheblicher Teil der Akten des Volksgerichtshofs aus den ca. 7000 Verfahren, die wegen Hoch- und Landesverrats nach dem Strafrechtsänderungsgesetz vom 24. 4. 1934 und wegen Wehrkraftzersetzung und anderer politischer Delikte nach den Strafrechtsänderungsverordnungen vom 21. 2. 1940 / 29.1. 1943 geführt wurden, ist durch einen Luftangriff und bei Kriegsende systematisch vernichtet worden. Erhalten blieben in Potsdam (Bestand 30.16) Generalakten (ca. 270 Bde, 1934-1944/45) und Einzelfallakten aus dem ehem. ZPA der SED (Best. NJ und NJ-U, vgl. zu 3.1.1) und aus 1990 aufgelösten Ministerien der DDR, deren Umfang erst nach Trennung der Provenienzen angegeben werden 
kann, mit einer Gesamtkartei der Verurteilten (ca. 9200 Karteikarten, 1933-1945), die auch Akten des Reichsjustizministeriums und des Oberreichsanwalts berücksichtigt und nicht überlieferte Urteile nachweist.

Die Generalakten betreffen Verfassung und Verwaltung (32 Bde, 1934-1945); Rechtsund Dienstverhälmisse der Staatsbediensteten (48 Bde, 1934-1945, mit „Mitteilungen des Amtes für Gemeinschaftspflege ${ }^{*}$ 1942-1945); Zivilrecht und Zivilrechtsgang einschlieBlich Gerichtsverfassung (16 Bde, 1934-1945); Strafrecht und Strafrechtsgang einschlieBlich Strafvollzug und Polizei (37 Bde, 1934-1945, u. a. Vollzug der Todesstrafe 1935-1937, 1942-1945, Reichskriminalstatistik 1938); Finanzwesen (103 Bde, 1934 1944); Kultur und Wohlfahrtspflege (10 Bde, 1934-1945, dabei Vorgänge zur Verurteilung und KZ-Einweisung Martin Niemöllers); Wehrmacht und auswärtige Angelegenheiten (5 Bde, 1937-1945). Handakten einzelner Richter und Staatsanwälte (4 Bde, 1936-1942) enthalten u. a. Auszïge aus Urteilen wegen Landesverrats (1936-1942), eine Kartei weist zu Freiheitsstrafen verurteilte Tschechen nach (1940-1941).

Der Bestand des Bundesarchivs enthält Ausfertigungen von 626 Urteilen. Sie ergingen - mit Ausnahme von einigen des Besonderen Senats in Wiederaufnahmeverfahren - vom 1. Senat unter dem Vorsitz des Präsidenten Roland Freisler (fast sämtlich 1943 und 1944), dessen Mitglied Kammergerichtsrat Rehse sie zusammengestellt hatte, davon etwa $60 \%$ gegen Tschechen, $10 \%$ gegen Österreicher, $8 \%$ gegen Elsässer und Lothringer; aus seiner Sammlung stammen ferner 4 Anklageschriften und Fragmente von Handakten.

Wesentlich umfangreicher ist das überlieferte Schriftgut des Oberreichsanwalts. Das Koblenzer Bundesarchiv (Best. R 60 II) besitzt allerdings lediglich einige Geschäftsübersichten (4 Bde, 1934-1944), Akten aus mehreren hundert Ermittlungsverfahren gegen unbekannte Täter (1933-1944) und einzelne Anklageschriften, Urteile, Einstellungsverfügungen und Vollstreckungsakten (ca. $100 \mathrm{Bde}, 1934-1944$ ), bei denen es sich überwiegend um Kopien aus Akten anderer Behörden handelt; zu etwa zwei Dritteln wurden die Verfahren wegen Hochverrats geführt, wobei unter den Angeklagten deutsche Kommunisten und Tschechen überwiegen, knapp 50 verfolgten Landesverrat und Feindbegünstigung auch von Einwohnern besetzter Gebiete, in etwa 70 Fällen wurde wegen Wehrkraftzersetzung angeklagt.

Im Bestand 30.17 des ZStA befinden sich Reste von Generalakten (ca. 30 Bde, 1932-1945 u. a. über Vollzug der Todesstrafe 1942-1945 mit Listen der in den Justizvollzugsanstalten Berlin-Plötzensee, Brandenburg-Görden, Leipzig II. Waldheim einsitzenden zum Tode Verurteilten) und ProzeBakten (ca. 18920 Bde), deren Anzahl steigen wird, wenn die aus dem ehem. ZPA der SED und aufgelösten DDR-Ministerien übernommenen Justizakten nach der Provenienz geordnet sind. Vorhanden sind auch Namensverzeichnisse von Häftlingen verschiedener Anstalten (3 Bde, 1933-1945), ein Bericht über die Strafanstalten in Dresden nach den Luftangriffen im März 1945 und in Handakten eines Staatsanwalts Erläuterungen zur Auslegung und Verwendung der Strafbestimmungen in Hoch- und Landesverratssachen (1935-1937).

Von gleicher Bedeutung ist die Überlieferung im Berliner Document Center mit Unterlagen aus ca. 15000 Verfahren (1934-1945). Von ihnen wurden ca. 2000 durch ein Urteil abgeschlossen, in den übrigen Fällen wurden die Ermittlungen - auch nach Einweisung von Beschuldigten in ein Konzentrationslager - eingestellt oder die Verfolgung an einen Generalstaatsanwalt abgegeben, so daB die Akten neben Vernehmungsniederschriften und AbschluBberichten der Gestapo vielfach Anklageschriften und Urteile 
aus Verfahren vor Oberlandesgerichten enthalten. Anklageschriften des Oberreichsanwalts liegen z. T. in Form von Matrizen zur Herstellung von Vervielfältigungen vor, die überlieferten Urteile können auch aus Geschäftsstellen der Senate stammen. Dem Nationalarchiv in Paris wurden die Akten aus ca. 700 Verfahren gegen französische Staatsangehörige überlassen (48 Rollen Mikrofilm im BA).

Die Verfahren gegen die Beteiligten am Umsturzversuch des 20. Juli 1944 sind in allen bisher erschlossenen Akten des Volksgerichtshofs wie des Oberreichsanwalts bis auf wenige Fragmente nicht dokumentiert. Eine schriftliche Ergänzungsüberlieferung liegt jedoch in den Berichten vor, die der Parteikanzlei der NSDAP über die Verhandlungen erstattet wurden (Best. NS 6), und ein stenographisches Protokoll der Hauptverhandlung gegen Generalfeldmarschall v. Witzleben und 7 Mitangeklagte am 7./8. August 1944 ist in Abschriften überliefert (FB $1316 \mathrm{~N}$ ). Umfangreicher sind die Bild-, Film- und Tondokumente aus diesen Prozessen. Die Bildsammlung zum Zweiten Weltkrieg enthält ca. 1500 Fotografien (BA, Best. Bild 151) aus Hauptverhandlungen, und im BA-Tonarchiv befinden sich 12 Tonbänder mit unvollständigen Aufnahmen, die für die Reichspropagandaleitung der NSDAP angefertigt wurden; sie stammen vor allem aus den Hauptverhandlungen gegen Witzleben und vom 7./8. September gegen Goerdeler und vermitteln einen Eindruck von der Verhandlungsführung Freislers und den geringen Möglichkeiten der Pflichtverteidiger, während die Angeklagten, darunter Graf Helldorf, Kaplan Wehrle, Gerstenmaier und Haubach, kaum zu Wort kommen. Aus den während der Prozesse gedrehten Filmaufnahmen wurde für das Reichsministerium für Volksaufklärung und Propaganda der Film „Verräter vor dem Volksgericht“ (407 m) zusammengestellt.

Die unheilvolle Wirksamkeit des Volksgerichtshofes, der als Instrument politischen Terrors 5234 Angeklagte zum Tode verurteilte, ergibt sich ebenfalls aus Akten des Reichsjustizministeriums im Bundesarchiv und aus Akten und Aufzeichnungen von Anwälten, die als Verteidiger aufgetreten sind (BA, NL Behling und Kl. Erw. 460 und 653). Weiteres Material enthalten die Protokolle und Dokumentenbücher des sogenannten Juristenprozesses vor dem amerikanischen Militärgerichtshof in Nürnberg, in dem Oberreichsanwalt Ernst Lautz, die Reichsanwälte Paul Barnickel und Oswald Rothaug, der Senatspräsident Günther Nebelung und der als Laienrichter dort tätige SA-Führer Hans Petersen zu den Angeklagten gehörten. Von 1966 bis 1969 wurde vor dem Landgericht Berlin ein Strafverfahren gegen den Richter Rehse gefuihrt; die darin ergangenen Urteile wurden wegen seines Todes nicht rechtskräftig. Ab 1979 führte der Generalstaatsanwalt beim Landgericht Berlin ein Ermittlungsverfahren gegen 17 Richter, 25 ehrenamtliche Beisitzer und 68 Staatsanwälte der Oberreichsanwaltschaft; es wurde 1986 eingestellt, nachdem 57 Beschuldigte verstorben oder für verhandlungsunfähig befunden worden waren. Zu den Akten aus diesem Verfahren (ca. 150 Bde) gehören Kopien von 2648 Urteilen und mit ihnen in Verbindung stehenden Dokumenten (113 Bde) aus verschiedenen Archiven; soweit sie aus der DDR und der CSSR zur Verfugung gestellt wurden, hat das Bundesarchiv Koblenz davon weitere Kopien erhalten.

Lit.: TRIALS of WAR CRIMINALS. vol. 3. - Die DEUTSCHE JUSTIZ UND DER NATIONALSOZIALISMUS. Bd. 3. 1974. - G. BUCHHEIT: Richter in roter Robe. 1968. - H. HILLERMEIER: Im Namen des Deutschen Volkes. 1980. - H.-A. JACOBSEN: Spiegelbild einer Verschwörung. 1984. - VOLKSGERICHTSHOFPROZESSE zUm 20. Juli 1944. 1961. - B. JAHNTZ, V. KÄHNE: Der Volksgerichtshof. 1986. - INVENTAIRE des archives du Volksgerichtshof. 1953. - H. KOCH: Volksgerichtshof. 1987. - G. WIELAND: Das war der Volksgerichtshof. 1989. - H. v. GODIN: Strafjustiz in rechuloser Zeit. 1990. 


\subsubsection{Sondergerichte}

Durch die Verordnung über die Bildung von Sondergerichten vom 21. 3. 1933 wurde für die Aburteilung von Straftaten nach der Staatsschutzverordnung vom 28. 2. 1933 und der Heimtückeverordnung, soweit nicht Reichsgericht oder Oberlandesgericht zuständig waren, in jedem OLG-Bezirk ein Sondergericht errichtet. Bis zum Kriegsbeginn entstanden im späteren Gebiet der Bundesrepublik Sondergerichte an den Sitzen aller Oberlandesgerichte mit Ausnahme von Celle, Hamm, Karlsruhe und Zweibrücken und in Hannover, Bremen, Dortmund, Essen, Mannheim und Saarbrücken, 1940 kamen die Sondergerichte Bielefeld, Freiburg und Koblenz, 194I Aachen, 1942 Bayreuth, Würzburg, Hagen. Duisburg und Wuppertal hinzu. Gleichzeitig wurde die Zuständigkeit mehrfach erweitert, insbesondere konnten alle Delikte nach dem politischen und unpolitischen (Volksschädlingsverordnung, Kriegswirtschaftsverordnung) Kriegssonderstrafrecht dort angeklagt werden. Einige Sondergerichte hatten zusätzlich die Aufgabe, Angehörige der Widerstandsbewegungen in den besetzten Gebieten abzuurteilen (,Nacht-und-Nebel"“Gefangene). Das Verfahren war summarisch, Rechtsmittel waren nicht zugelassen, jedoch Wiederaufnahme des Verfahrens möglich. In den letzten Kriegsjahren wurden bis zu $73 \%$ (Hamburg) aller ursprünglich in die Zuständigkeit der Landgerichte fallenden Strafsachen von den z. T. aus mehreren Kammern bestehenden Sondergerichten entschieden.

Aus dieser Zuständigkeit ergibt sich, daß schwierig sein kann, in der Überlieferung der Staatsanwaltschaften zwischen Akten aus Verfahren vor den Strafkammern und dem Sondergericht zu unterscheiden. Es ist daher nicht auszuschließen, daB sich, abgesehen von den noch bei bestehenden Justizbehörden lagernden Akten, Unterlagen aus Sondergerichtsverfahren auch in anderen als den nachfolgend aufgeführten Beständen befinden. Urteilsausfertigungen, insbesondere von Todesurteilen, von denen Kopien vielfach in Verbindung mit Vorwürfen gegen beteiligte Richter verbreitet wurden, enthalten die Akten des Reichsjustizministeriums im ZStA; auch die Häftlingspersonalakten der Justizvollzugsanstalten sind heranzuziehen.

Lit.: H. RÜPING: Bibliographie zum Strafrecht. 1985. S. 200-215 (Verzeichnis der veröffentlichten Entscheidungen der Sondergerichte). - W. KOPPEL: Ungesühnte Nazijustiz. 1960. - Ders.: Justiz im Zwielicht. 1963. - K. JONCA, A. KONIECZNY: Nuit et brouillard. 1981. - L. GRUCHMANN: „Nacht- und Nebel”-Justiz. 1981. - A. BLUMBERG-EBEL: Sondergerichtsbarkeit und ..politischer Katholizismus”. 1990.

Sondergericht Aachen

$\mathrm{D}-\mathrm{K}$

Verfahrensakten aus allen Zuständigkeiten (616 Bde, 1941-1945), aus 8 Verfahren mit Todesurteilen (1941-1944) in Schriftgut des Justizministeriums von Nordrhein-Westfalen (D, Best. NW 174).

Sondergericht Altona

SL, Abt. 358

Akten aus 483 Hauptverfahren (1933 bis zur Aufhebung und Übertragung der Zuständigkeit auf das Sondergericht Hamburg und das neu errichtete Sondergericht Kiel am 1. 4. 1937), fast ausschlieBlich wegen Straftaten nach der Staatsschutzverordnung vom 28.2. 1933 und wegen Heimtücke, dabei auch über den Prozeß gegen Kommunisten wegen des sog. „Altonaer Blutsonntags“ im Juli 1932 (unvollständig).

\section{Sondergericht Bamberg}

Von den Akten aus den dort nach einer Mitteilung des Generalstaatsanwalts in Bamberg vom 10. 6. 86 durchgeführten 1727 Verfahren befindet sich eine unbekannte Anzahl noch bei der Justizverwaltung. 


\section{Sondergericht Bayreuth}

Akten aus den dor ab 1942 durchgeführten 222 Verfahren (Mitteilung des Generalstaatsanwalts in Bamberg vom 10.6.86) noch bei der Justizverwaltung.

\section{Sondergericht Berlin}

Im Archiv der Staatsanwaltschaft beim Landgericht Berlin Register, Sammlungen von Urteilen und ca. 30000 Verfahrensakten (1933-1945). Kopien von Urteilen gegen 876 Juden und Ausländer (8 Bde, 1935-1945) beim ISD Arolsen.

Lit: B. SCHIMMLER: Recht ohne Gerechtigkeit. 1984. - W. KOPPEL: Ungesühnte Nazijustiz. 1960. Nr. 4. $13,16,18-20,38,59,75,77,86$.

\section{Sondergericht Bielefeld}

DT, Best. D 21 A Akten aus 1883 Verfahren (1940-1945), davon etwa ein Drittel wegen Kriegswirtschaftsverbrechen, $20 \%$ gegen Volksschädlinge, $15 \%$ wegen Heimtücke- und Rundfunkverbrechen, $10 \%$ nach der Polenstrafrechtsverordnung, $5 \%$ wegen verbotenen Umgangs mit Kriegsgefangenen, sonst u. a. gegen Adventisten und Bibelforscher wegen Wehrdienstentziehung und wegen Arbeitsvertragsbruch, Akten aus 5 Verfahren mit Todesurteilen (1942-1945) im Bestand Justizministerium NRW (D, NW 174).

Lit.: A. KNOBELSDORF: Politische Strafjustiz in Ostwestfalen-Lippe von 1933 bis 1945.1990.

\section{Sondergericht Braunschweig}

WF. Best. 42 B Neu Hauptteil der Überlieferung aus 1611 von der Staatsanwaltschaft beim Landgericht durchgeführten Ermittlungs- und Hauptverfahren (1933-1945) u. a. wegen Heimtücke. Rundfunkverbrechen, nach der Volksschädlings- und Kriegswirtschaftsverordnung, davon ca. 215 aus der Kriegszeit auch gegen Fremdarbeiter und mit zahlreichen Todesurteilen.

Lit.: H. KRAMER: NS-Justiz in Braunschweig. 1981.

\section{Sondergericht Bremen}

HB, Best. $4.89 / 5$

Akten aus 562 Hauptverfahren (1940-1945, vor 1940 tagte eine Kammer des Sondergerichts Hamburg in Bremen) mit 49 Todesurteilen (davon 45 vollstreckt), darunter wegen Verbrechen nach der Volksschädlingsverordnung (301 Fälle, u. a. Plünderung nach Luftangriffen), dem Heimtückegesetz (102 Fälle), der Kriegswirtschaftsverordnung (92 Fälle mit Todesurteil wegen Schwarzschlachtung), der Rundfunkverordnung (18 Fälle) und gegen „gefährliche Gewohnheitsverbrecher" (19 Fälle).

Lit.: C. U. SCHMINCK-GUSTAVUS: Das Heimweh des Walerjan Wróbel. 1986. - I. MARBOLEK. R. OTT: Bremen im Dritten Reich. 1986. S. 161-183.

Sondergericht Darmstadt DA, Best. G 27 Akten aus 1468 Verfahren (1933-1945) aus der gesamten Zuständigkeit.

Sondergericht Duisburg $\mathrm{D}-\mathrm{K}$ Akten aus Verfahren der gesamten Zuständigkeit (523 Bde, 1942-1945), aus 26 Verfahren mit Todesurteilen im Bestand Justizministerium NRW (D, NW 174). 
Sondergericht Dortmund

MS

Akten aus ca. 2400 Ermittlungs- (ab 1936) und Hauptverfahren (1939-1945), davon jedoch ca. 1000 in Form nach 1945 angelegter Ersatzüberlieferung, aus 36 Verfahren mit Todesstrafe (1934-1945) im Bestand Justizministerium NRW (D. NW 174), Handakten aus 82 Verfahren mit 66 Urteilen (überwiegend 1933-1934) bei der Staatsanwaltschaft Arnsberg überliefert (Best. B 525).

Lit: L KEWER: Aus der Geschichte des OLG Hamm. 1970.

Sondergericht Essen

$\mathrm{D}-\mathrm{K}$

Akten aus Verfahren der gesamten Zuständigkeit (527 Bde, 1940-1945), aus 56 Verfahren mit Todesurteilen (1935-1944) im Bestand Justizministerium NRW (D, NW 174).

Sondergericht Frankfurt

WI, Abt. 461

Register über Ermittlungs- (1933-1945) und Hauptverfahren (1938-1945), Akten aus ca. 3000 Ermittlungs- und Hauptverfahren (davon 630 bis 1939, Rest 1940-1944) aus der gesamten Zuständigkeit.

Lit: E. NOAM, W.-A. KROPAT: Juden vor Gericht. 1975. S. 191. 199. 229-233.

Sondergericht Freiburg

FR

Terminkalender, Beschwerderegister, Aktenkontrollisten (12 Bde, 1940-1944), Akten aus 24 Verfahren (1942-1944) bei der Überlieferung von Landgericht und Staatsanwaltschaft Freiburg, weitere 390 Verfahren in Akten des Landgerichts über Anträge auf Aufhebung politisch motivierter Urteile (1947-1969) dokumentiert.

\section{Sondergericht Hagen}

Lediglich einzelne Urteile (das Gericht bestand nur 1943) im ZSLA.

\section{Sondergericht Hamburg}

Nahezu vollständiges Register, Akten in großem Umfang, jedoch nicht getrennt von den Akten aus Verfahren vor den Strafkammern bei der Staatsanwaltschaft (Auskunft des Leitenden Oberstaatsanwalts vom 9. 6. 1986).

Lit.: H. ROBINSOHN: Justiz als politische Verfolgung. 1977.

\section{Sondergericht Hannover}

H, Best. Hann 171a Hannover

Akten aus 1168 Verfahren (davon 1153 von 1943-1945), vorwiegend wegen Heimtückeund Rundfunkverbrechen, Diebstahl nach der Volksschädlingsverordnung (dabei Postdiebstahl), Umgang mit Kriegsgefangenen, einzelne Fälle von Wehrkraftzersetzung und nach der Polenstrafrechtsverordnung, aus Verfahren wegen Kriegswirtschaftsverbrechen vgl. Staatsanwaltschaft beim Landgericht Hannover (vgl. auch Staatsanwaltschaft beim Landgericht Stade).

\section{Sondergericht Kassel}

Akten (z. T. Rekonstnuktionen nach 1945) aus 130 Verfahren noch bei der Staatsanwaltschaft Kassel, Unterlagen über 54 politische Verfahren bei der Forschungsstelle Nationalsozialismus in Hessen an der Gesamthochschule Kassel. Die Verurteilung eines Juden wegen Rassenschande als gefährlicher Gewohnheitsverbrecher zum Tode war 1950-1951 Gegenstand eines Strafverfahrens gegen den Vorsitzenden Fritz Hassencamp und den Untersuchungsrichter Edmund Kessler vor dem Landgericht Kassel. 
Lit.: E. NOAM. W.-A. KROPAT: Juden vor Gericht. 1975. S. 260-272. - J. FRIEDRICH: Freispruch für die Nazijustiz. 1983. S. 302-317. - J. KAMMLER. D. KRAUSE-VILMAR: Volksgemeinschaft und Volksfeinde. 1984. S. 298-335.

Sondergericht Kiel

SL, Abt. 358

Akten aus ca. 6600 Ermittlungs- und Hauptverfahren (7 700 Bde, 1937-1945) aus der gesamten Zuständigkeit.

Lit.: K. BÄSTLEIN: Die Akten des ehemaligen Sondergerichts Kiel als zeitgeschichtliche Quelle. 1988.

Sondergericht Koblenz

KO, Best. 584,1

Akten aus 643 Verfahren (1940-1945, aus 1940 nur 19 von 82 nachgewiesenen) mit hohem Anteil eingestellter Ermittlungsverfahren, überwiegend wegen Heimtücke, Rundfunk-, Kriegswirtschafts- und Volksschädlingsverbrechen, aus 9 Verfahren mit Todesurteilen (1941-1943) in Akten des nordrhein-westfälischen Justizministeriums (D, Best. NW 174), auBerdem Akten aus 37 vor der Zweigstelle Trier geführten Verfahren (1944-1945), davon 17 wegen Plünderung, 2 wegen Wehrkraftzersetzung, 1 wegen Notdienstverweigerung, in Akten der Staatsanwaltschaft beim Landgericht Trier (KO, Best. 584,2), 2 Todesurteile (1939-1940) ebenfalls in Düsseldorf.

Sondergericht Köln

$\mathrm{D}-\mathrm{K}$

Akten aus Ermittlungs- (etwa $75 \%$ ) und Hauptverfahren (19 046 Bde, 1933-1945) aus allen Zuständigkeiten, aus 95 Verfahren mit Todesurteilen (1939-1944) im Bestand Justizministerium NRW (D, NW 174). Die exzessive Anwendung des NS-Strafrechts durch das Gericht, das auch für die Aburteilung von ,Nacht-und-Nebel“-Gefangenen aus besetzten Westgebieten zuständig war, war 1948-1953 Gegenstand eines Strafverfahrens gegen den Landgerichtspräsidenten Walter Müller vor dem Landgericht Bonn.

Lit.: J. FRIEDRICH: Freispruch für die Nazijustiz. 1983. S. 232-258 mit Auszügen aus Uneilen gegen Müller. - K. JONCA, A. KONIECZNY: Nuit et Brouillard. 1981. - A. KLEIN: Hundert Jahre Akten - hundert Jahre Fakten. 1981. S. 164-169. - B.-A. RUSINEK: Gesellschaft in der Katastrophe. 1989.

Sondergericht Mannheim

KA, Best. 507

Register, Akten aus ca. 12000 Ermittlungs- und Hauptverfahren (1933-1945) aus der gesamten Zuständigkeit, dabei 150 Todesurteile.

Sondergericht München

MSt Register, Akten aus Ermittlungs- und Hauptverfahren (9955 Bde mit Todesurteilen in 237 Fällen, 1933-1945) aus allen Zuständigkeiten, davon ca. 1200 wegen Diebstahls. 1000 wegen verbotenen Umgangs mit Kriegsgefangenen, 500 wegen Schwarzschlachtung, 400 wegen Betrug, 260 wegen Abhörens ausländischer Rundfunksender, unter den Angeklagten und Beschuldigten 277 katholische (davon 52 Ordens-) und 27 evangelische Geistliche, 250 Mitglieder von KPD und SPD, 100 Bibelforscher, 49 Juden (7 Fälle von Rassenschande), auch Arbeiter aus der Sowjetunion, Frankreich und Italien wegen sexueller Beziehungen zu deutschen Frauen und tätlichen Angriffen auf Arbeitgeber oder Vorgesetzte.

Lit.: WIDERSTAND UND VERFOLGUNG in Bayern 1933-1945. Bd.3. 1975-1977. - O. GRITSCHNEDER: Die Akten des Sondergerichts München über Pater Rupen Mayer SJ und über Stadtpfarrer Dr. Emil Muhler. 1975. - P. HÜTTENBERGER: Heimtückefälle vor dem Sondergericht München. 1981. 
Sondergericht Nürnberg

N, Rep. 279/4 SG

Akten aus 1829 eingestellten oder an andere Gerichte abgegebenen Ermittlungsverfahren (1933-1945, mit einzelnen bei Kriegsende noch laufenden Verfahren) und aus 2644 Hauptverfahren (1933-1945, davon 716 bis Kriegsbeginn) mit 142 Todesurteilen (1938-1945) und zahlreichen Hinweisen auf Überstellungen an die Gestapo und Einlieferungen in Konzentrationslager, darunter 80 Hauptverfahren gegen Geistliche oder in Verbindung mit dem Kirchenkampf, 23 Verfahren gegen Juden, 12 gegen Emste Bibelforscher, 95 wegen Diebstahls und Unterschlagung von Feldpostsendungen, 8 wegen Fluchthilfe und ca. 200 wegen verbotenen Umgangs mit Kriegsgefangenen und Fremdarbeitern, 36 wegen Schwarzhandels und ca. 180 wegen Schwarzschlachtung. Nachdem bereits im JuristenprozeB vor dem amerikanischen Militärgerichtshof in Nürnberg der Vorsitzende des Sondergerichts, Landgerichtsdirektor Oswald Rothaug, u. a. wegen des Todesurteils wegen Rassenschande nach der Volksschädlingsverordnung gegen einen Juden angeklagt worden war, muBten sich seine beiden Beisitzer Karl Ferber und Heinz Hugo Hoffmann deshalb 1968 bis 1976 vor dem Landgericht Nürnberg verantworten.

Lit: TRIALS of WAR CRIMINALS. vol. 3. - J. FRIEDRICH: Freispruch für die Nazijustiz. 1983. S. 269-301.

Sondergericht Oldenburg

OL, Best. 143

Terminkalender für die Verhandlungen (1937-1938, 1943-1944), Urteilsliste (19421945), ferner Berichte der Staatsanwaltschaft an den Generalstaatsanwalt in Oldenburg über 124 Verfahren (mit Anlagen, 1933-1944, überwiegend ab 1943) u. a. wegen Devisenvergehen, Heimtücke, Plünderung, Wirtschaftsstraftaten in Überliefenung der Staatsanwaltschaft beim Landgericht.

Sondergericht Saarbrücken

Register, Akten (z. T. unvollständig) aus ca. 1000 Hauptverfahren (1936-1945, überwiegend aus der Kriegszeit) vor allem gegen Kriegswirtschaftsverbrecher, Volksschädlinge (dabei Fälle von Plünderung und Diebstahl von Feldpostsendungen), wegen Heimtücke, Rundfunkverbrechen und Umgang mit Kriegsgefangenen (dabei ein Vorgang über die Bekanntgabe der Urteile an die Gauleitungen).

Lit.: E. MÜLLER: Das Sondergericht Saarbrücken. 1985.

Sondergericht Stuttgart

LB, Best. EL 317

In „Reststrafakten“, „Ersatzvollstreckungsakten“ und im Zusammenhang mit der Aufhebung von Urteilen oder Wiedergutmachungsansprüchen nach 1945 sind 856 Verfahren (1933-1945, davon 553 ab 1940) sowohl gegen politische Gegner als auch gegen Volksschädlinge dokumentiert, weitere in Protokollen und Dokumentenbüchern des Juristenprozesses vor dem amerikanischen Militärgerichtshof in Nürnberg, in dem der Vorsitzende Hermann Cuhorst angeklagt war, und 81 Verfahren im Bestand des ehem. ZPA der SED.

Lit:TRIALS of WAR CRIMINALS, vol. 3.

Sondergericht Würzburg

WÜ, Best. II 1.2.0.-1 Akten - z. T. nach dem Krieg bei Wiederaufnahme rekonstruiert - aus 30 Verfahren (1942-1945), davon 5 gegen Volksschädlinge, 4 wegen Heimtücke, je 3 wegen Umgangs mit Kriegsgefangenen, Abhören ausländischer Sender und Kriegswirtschaftsverbrechen, 1 wegen Beihilfe zur Fahnenflucht (mit Akten des Gerichts der Infanterie-Division 465, Ludwigsburg). 
Sondergericht Wuppertal

$D-K$

Akten aus Ermittlungsverfahren (51 Bde, z. T. schon vor 1942), aus 16 Verfahren mit Todesurteilen (1943) im Bestand Justizministerium NRW (D, NW 174).

\subsubsection{Wehrmachtgerichte}

$B A-Z N S$

Was vom Schriftgut der im Mai 1933 neu errichteten Wehrmachtgerichte, die nach der Kriegsstrafverfahrensordnung vom 17. August 1938 unter bestimmten Voraussetzungen auch für die Aburteilung von Zivilpersonen zuständig waren, erhalten blieb. befindet sich überwiegend bei der AuBenstelle ZNS des Bundesarchivs in Aachen, wird aber, soweit archivwürdig, später zum BA-Militärarchiv kommen. Es handelt sich dabei um Verfahrensakten und Listen, die auch über Urteile in solchen Verfahren AufschluB geben, deren Akten nicht überliefert sind, und die auBerdem in Angelegenheiten der freiwilligen Gerichtsbarkeit und über Todesermittlungen geführt wurden. Die weitaus meisten Verfahren wurden wegen krimineller Delikte, Wachvergehen und Verstößen gegen Verkehrsvorschriften gefuhr, aber auch aus den Prozessen wegen Wehrkraftzersetzung, Fahnenflucht, Befehlsverweigerung, Angriff auf Vorgesetzte, Feindbegünstigung, Selbstverstümmelung sind zahlreiche Akten erhalten; in ihnen ergingen viele der von August 1939 bis Ende Juni 1944 von Gerichten aller drei Wehrmachtteile verhängten Todesurteile. Für die Zeit danach bis Kriegsende sind aus den Akten 908 weitere Todesurteile nachweisbar, von denen 582 mit Sicherheit vollstreckt wurden.

Die überlieferten Akten stammen hauptsächlich von Gerichten der Kriegsmarine (72 390 Verfahrensakten, nicht nach Provenienzen getrennt, Listen u. a. über mehr als 100000 Strafverfahren) und des Heeres (ca. 44000 Verfahrensakten, 1800 Listen), kaum von Luftwaffenkriegsgerichten (3839 Verfahrensakten, Listen über ca. 8000 Strafverfahren); Akten aus Verfahren gegen nichtdeutsche Wehrmachtsangehörige liegen beim ISD Arclsen. Die meisten Wehrmachtgerichte waren im Krieg für mobile Einheiten mit wechselnden Einsatzgebieten und für stationäre Dienststellen in besetzten Gebieten zuständig, und ihre Überlieferung bleibt hier unberücksichtigt, und der Nachweis beschränkt sich auf die zentralen Gerichte und diejenigen, die vor Kriegsausbruch oder auch später einen festen Sitz im späteren Gebiet der Bundesrepublik Deutschland hatten, soweit von ihnen umfangreichere Bestände vorhanden sind.

Ein weiterer Sammelbestand mit Generalakten, Allgemeinen, Fahndungs-, Strafsachen-, Rechtshilfelisten, Sammelerlassen (insgesamt ca. $400 \mathrm{Bde}$ ) und alphabetisch geordneten Einzelfallakten (ca. 18000 Bde) gelangte in das ehem. DDR-Militärarchiv. Er stammt vom Feldgericht des Befehlshabers des Luftgaues VIII, Außenstelle Breslau, von Aktenaufbewahrungsstellen in Greisa/Rhön, Kassel und Potsdam sowie den Gerichten von ca. 25 Divisionen und 20 Kommandobehörden des Heeres sowie 20 Luftwaffengerichten.

Lit.: M. MESSERSCHMIDT, F. WÜLLNER: Die Wehrmachtjustiz im Dienst des Nationalsozialismus. 1987. - TRIALS of WAR CRIMINALS. vol. 11 und 12. - D. GÜSTROW: Tödlicher Alltag. 1981 (über Verfahren vor dem Reichskriegsgericht und dem Zentralgericht des Heeres). - N. HAASE: Deutsche Deserteure. 1987 (über Verfahren vor dem Gericht der Wehmachtkommandantur Berlin). - H. HÜRTEN: Die Tätigkeit Hans Filbingers als Marinerichter. 1980 (u. a bei den Gerichten der 2. Admirale der Nord- und Ostsee in Westerland). - J. FRIEDRICH: Freispruch für die Nazijustiz. 1983. S. 54-185. 


\subsection{Reichskriegsgericht}

Aus der Restüberlieferung im Umfang von 89 Kartons, die sich im Militärhistorischen Archiv der CSFR befindet, liegen einzelne Kopien aus Verfahren wegen Spionage und Feindbegünstigung vor, ferner Wehrstrafrechtsstatistiken 1937 bis 1939 (BA-MA, Best. RW 11) und Mikrofilme von 836 StrafprozeBlisten (1942-1944) und von Unteilen gegen Angehörige der Widerstands- und Spionageorganisation "Rote Kapelle“ (ehem. Militärarchiv der DDR). Aus Schriftgut anderer Provenienz und den Angaben über 15 vollstreckte Todesurteile wegen Landesverrats in den Heeresmitteilungen (1937-1939) konnten Verfahren mit insgesamt 58 Angeklagten z. T. mit Anklageschriften und Urteilen oder Unteilstenor dokumentiert werden (1938-1944, BA-ZNS); darunter sind 6 Verfahren gegen Norweger wegen Spionage und Feindbegünstigung, 2 Uneile gegen Bibelforscher, aber auch Revisionsurteile in Fällen von Gehorsamsverweigerung, je ein Fall von Dienstpflichtverletzung, MiBhandlung von Untergebenen und Kriegswirtschaftsverbrechen.

Die Rechtsprechung des Reichskriegsgerichts wurde im sog. OKW-ProzeB vor dem amerikanischen Militärgericht in Nürnberg, in dem der Generalstabsrichter Rudolf Lehmann angeklagt war, und in einem Ermittlungsverfahren der Staatsanwaltschaft Lüneburg gegen Generalrichter Manfred Roeder, Anklagevertreter in den Prozessen gegen Oberleutnant Schulze-Boysen und die Angehörigen der „Roten Kapelle“, kritisch behandelt.

\subsection{Andere zentrale Gerichte}

\section{Zentralgericht des Heeres}

Im ehem. DDR-Militärarchiv werden Akten über flüchtige Wehrmachtangehörige aufbewahrt, die der unerlaubten Entfernung (17800 Bde) bzw. der Fahnenflucht (14200 Bde) beschuldigt wurden; sie wurden von der im April 1944 nach Gera verlegten Fahndungsabteilung angelegt. Weiter sind dort Listen von Todesurteilen, in der BA-ZNS einzelne Verfahrensakten (14 Bde) und 4 Todesurteile (1944/45) überliefert.

Gericht des Oberkommandos der Kriegsmarine

$\mathrm{BA}-\mathrm{ZNS}$

10 Listen, unbekannte Anzahl von Verfahrensakten.

Oberkriegsgericht der Flotte

$\mathrm{BA}-\mathrm{ZNS}$

15 Listen (bis 1939), unbekannte Anzahl von Verfahrensakten.

Luftwaffen-Oberkriegsgericht München

$\mathrm{BA}-\mathrm{ZNS}$

Nur 1 Band Verfahrensakten.

\subsection{Untere Gerichte der Wehrmacht und der Wehrmachtteile}

BA - ZNS

Gericht der Wehrmachtkommandantur Berlin: Verfahrensakten (6211 Bde), 29 Todesurteile 1944/45.

Gericht der Wehrmachtkommandantur Düsseldorf: Verfahrensakten (661 Bde), 24 Listen.

Gericht der Wehrmachtkommandantur Hamburg: Verfahrensakten (84 Bde), 7 Listen, Angaben über 29 Todesurteile 1944/45.

Gericht der 6. Infanterie-Division, Bielefeld: 9 Listen (ab 1935). 
Gerichte der Kommandanturen der Befestigungen am Niederrhein mit Zweigstellen Düsseldorf, Aachen und Düren und der Befestigungen Eifel/Saarpfalz: Verfahrensakten (204 bzw. 552 Bde), 18 Listen.

Gericht des Kommandeurs der Kriegsgefangenen im Wehrkreis VI (Münster): Verfahrensakten (1 441 Bde), 10 Listen, Angaben über 4 Todesurteile 1944/45.

Gericht der Standort-Kommandantur Ingolstadt: Verfahrensakten (32 Bde)

Gericht der Kriegsmarine Berlin: 13 Listen, unbekannte Anzahl von Verfahrensakten, 9 Todesurteile 1944/45 nachgewiesen.

Gerichte der Marine-Bereichskommandanten Schleswig und Eckernförde: 5 bzw. 9 Listen, unbekannte Anzahl von Verfahrensakten.

Gericht des 2. Admirals der Ostseestation mit Zweigstelle Westerland: 46 Listen (ab 1934), unbekannte Anzahl von Verfahrensakten, 4 Todesurteile 1944/45 nachgewiesen. Gericht des 2. Admirals der Nordseestation mit Zweigstellen Wilhelmshaven, Buxtehude und Wesermünde (Bremerhaven): 78 Listen (ab 1934), unbekannte Anzahl von Verfahrensakten, 33 Todesurteile 1944/45 nachgewiesen.

Gerichte der Küstenbefehlshaber westliche Ostsee, Deutsche Bucht (Ostfriesland) mit Zweigstellen Emden, Wilhelmshaven, Norderney und Borkum, Deutsche Bucht (Nordfriesland) mit Zweigstellen Wesermünde (Bremerhaven) und Westerland: 43 (ab 1934) bzw. 64 bzw. 52 Listen, unbekannte Anzahl von Verfahrensakten.

Gericht des Admirals der Kampfverbände mit Zweigstelle Wilhelmshaven: 6 Listen, unbekannte Anzahl von Verfahrensakten.

Gericht des Admirals der Kriegsmarinedienststelle Hamburg: 40 Listen, unbekannte Anzahl von Verfahrensakten, 20 Todesurteile 1944/45 (auch gegen Besatzungsmitglieder von Handelsschiffen) nachgewiesen.

Gericht der Aufklärungsstreitkräfte mit Zweigstellen Cuxhaven, Wilhelmshaven, Wesermünde: 21 Listen (bis 1939), unbekannte Anzahl von Verfahrensakten.

Gericht des Befehlshabers der Panzerschiffe bzw. Schlachtschiffe mit Zweigstellen Kiel, Cuxhaven: 40 Listen ab 1932, unbekannte Anzahl von Verfahrensakten.

Gericht des Befehlshabers der Sicherung West mit Zweigstellen Wilhelmshaven, Cuxhaven, Wesermünde (Bremerhaven): 25 Listen, unbekannte Anzahl von Verfahrensakten. Gericht der 5. Sicherungsdivision, Cuxhaven: 4 Listen, unbekannte Anzahl von Verfahrensakten.

Gericht des Führers der U-Boote-Ausbildungsflottillen mit Zweigstellen Wilhelmshaven, Hamburg: 15 Listen, unbekannte Anzahl von Verfahrensakten.

Feldgericht des Kommandierenden Generals und Befehlshabers im Luftgau VI, AuBenstelle Düsseldorf: Verfahrensakten (106 Bde).

Gericht des Kommandierenden Generals und Befehlshabers im Luftgau VII, München: Verfahrensakten (280 Bde).

Gericht des Kommandierenden Generals und Befehlshabers im Luftgau XI, Hannover: Verfahrensakten (199 Bde).

Gericht des Kommandierenden Generals und Befehlshabers im Luftgau XII/XIII, Außenstelle Wiesbaden: Verfahrensakten (164 Bde), 8 Listen.

Gericht des Kommandierenden Generals und Befehlshabers im Luftgau XIV, Wiesbaden: Verfahrensakten (449 Bde), 3 Todesurteile 1944/45 nachgewiesen.

Gericht des Kommandeurs der 3. Flakdivision, Hamburg: Verfahrensakten (320 Bde). Feldgericht des Kommandeurs der 4. Flakdivision, Zweigstelle Ratingen: Verfahrensakten (748 Bde), 10 Listen. 
Gericht des Kommandeurs der 21. Flakdivision, Darmstadt: Verfahrensakten (638 Bde).

Gericht des Kommandeurs der 26. Flakdivision, München: Verfahrensakten (128 Bde).

Gericht des Kommandeurs des Luftverteidigungsgebiets Hannover: Verfahrensakten (20 Bde).

\subsection{Standgerichte}

BA - ZNS

Nur von wenigen der in den letzten Kriegsmonaten gebildeten Standgerichte, deren willkürliche Todesurteile gegen Soldaten und Zivilisten, die den sinnlosen Kampf nicht fortsetzen wollten, nach 1945 den Gegenstand zahlreicher Strafverfahren bildeten, sind Aktensplitter überliefert. Sie stammen u. a. von den Standgerichten der Wehrmachtkommandanturen Düsseldorf (mit allgemeinen Verfügungen und Angaben über ein Todesurteil) und Hamburg (mit Angaben über 4 Todesurteile), den Fliegenden Standgerichten (4 Todesurteile) West und im Wehrkreis III (Berlin) und dem Standgericht des Kommandierenden Generals im Luftgau XIV, Wiesbaden (2 Todesurteile).

\subsubsection{SS- und Polizeigerichtsbarkeit}

In Konkurrenz zur Wehrmachtsgerichtsbarkeit wurde die seit 1934 bestehende Disziplinargerichtsbarkeit der SS im Oktober 1939 zu einer Sondergerichtsbarkeit für Angehörige der Sicherheits- und Ordnungspolizei und der Waffen-SS erweitert, deren Zuständigkeit nach und nach auf Angehörige anderer Himmler unterstehender Organisationen und auf Straftaten gegen die Besatzungsmacht in besetzten Gebieten erweitert wurde. Thre Tätigkeit ergibt sich aus folgender Überlieferung und war außerdem Gegenstand des Strafverfahrens gegen den Inspektionsrichter Süd, SS-Sturmbannführer Otto Thorbeck, wegen Ermordung von Bonhoeffer, Canaris u. a. in Flossenbürg vor den Landgerichten München I und Augsburg 1952-1956.

Lit: W. SCHEFFLER: Zur Praxis der SS- und Polizeigerichtsbarkeit im Dritten Reich 1973. - H. RÜPING: Nationalsozialistische Rechtsprechung am Beispiel der SS- und Polizeigerichte. 1983. - B. WEGNER: Die Sondergerichtsbarkeit von SS und Polizei. 1986. - J. WEINGARTNER: Law and justice in the Nazi SS. 1983.

\subsection{Oberstes Gericht für die Sondergerichtsbarkeit der SS und Polizei}

Die Akten des Gerichts, das zugleich als Hauptamt SS-Gericht Verwaltungsspitze war, sind verloren, doch wird seine Wirksamkeit durch eine Sammlung unveröffentlichter $\mathrm{Er}$ lasse (6 Bde, überwiegend 1942-1944, BA, Best. NS 7) und folgende Veröffentlichungen dokumentiert (BA, NSD):

- Erlaßsammlung nach dem Stand vom 30. 10. 1942.

- Mitteilungen über die SS- und Polizeigerichtsbarkeit bzw. des Hauptamtes SSGericht (13 Hefte, 1940-1944).

- Hinweise für den SS-Richter (3 Hefte, 1944).

- Anordnungsblatt des Hauptamtes SS-Gericht (1943-1945).

- Die SS- und Polizeigerichtsbarkeit. Ein Leitfaden. 1. 7. 1944. 


\subsection{SS-Richter beim Reichsführer SS}

BA, Best. NS 7

Die Registratur des SS-Oberführers Bender (ca. 400 Bde, überwiegend aus den letzten Kriegsjahren), der Verbindungsfuihrer des Hauptamtes SS-Gericht zum Gerichtsherrn Himmler war, blieb zu einem erheblichen Teil erhalten. Neben den Akten über Dienststellenverwaltung gehören dazu vor allem die Unterlagen über die Organisation der Gerichte (128 Bde), u. a. über die Einrichtung von Standgerichten im Reichsgebiet (4 Bde, 1943, 1945) und des Gerichts z. B. V. zur Aburteilung von Komuptionsfallen in Konzentrationslagern (1943), über die Befugnisse Himmlers mit Angaben über ihm zur Bestätigung vorgelegte Urteile gegen SS-Führer und Polizeioffiziere (4 Bde, 1940-1945), über Rechtsprechung (123 Bde, davon 38 betr. Ahndung von Verbrechen gegen Staatsordnung und Manneszucht, 1942-1945), Strafvollstreckung und -vollzug (80 Bde, u. a. über Bewährungseinheiten). Von den 24 einzelnen Verfahren, aus denen Akten vorliegen, richteten sich je eins gegen einen SS-Gruppen- und einen SS-Standartenführer, eins gegen einen SS-Untersturmführer wegen ErschieBung von Juden ohne Befehl (1943). Der Rest einer „Vollstreckungs- und Gnadenkartei“ unbekannter Provenienz enthält ca. 2000 Karten (Juli-Oktober 1944) mit Angaben über den Namen und Dienstgrad des Verurteilten, das erkennende Gericht und die Entscheidung über Vollstreckung oder $\mathrm{Zu}$ billigung von Bewährung, nicht jedoch über Straftat und Strafmaß.

\subsection{SS- und Polizeigerichte}

BA, Best. NS 7

Nur von folgenden Gerichten erster Instanz mit Sitz im späteren Gebiet der Buridesrepublik Deutschland sind Verfahrensakten überliefert:

SS- und Polizeigericht I, München

Akten über 54 Verfahren, davon 52 gegen Angehörige des SS-Nachrichten-Ersatzregiments Nürnberg, meist wegen Verkehrsdelikten, in zwei Fällen wegen Verbrechen nach 175 StGB (1943-1945).

SS- und Polizeigericht III, Berlin

Akten über Verfahren gegen Angehörige der SS-Kriegsberichter-Abteilung „Kurt Eggers" (37 Bde, 1941-1944) mit einzelnen Fällen von Fahnenflucht.

SS- und Polizeigericht XIV, Wiesbaden (vorher Metz)

Reste von Unterlagen über die Dienststellenverwaltung und Akten über 17 Verfahren (1942-1944).

Von den SS- und Polizeigerichten II, Düsseldorf, XI, Stuttgart, XII, Hamburg, XXV, Nürnberg, und XXVI, Braunschweig, sind jeweils nur ein oder zwei, bei Hamburg acht Verfahren (z. T. durch Wiederaufnahmen nach dem Krieg) dokumentiert, aus dem Verfahren gegen den Lagerkommandanten von Buchenwald, SS-Standartenführer Koch, wegen Komuption vor dem SS- und Polizeigericht z. b. V. in Kassel sind Kopien der Ermittlungsakten und der Anklageschrift vorhanden.

\subsubsection{Sondergerichtsbarkeit in Zivilsachen}

\subsubsection{Erbhofgerichte}

Um „das Bauerntum als Blutquelle des deutschen Volkes" zu erhalten, beschränkte das Reichserbhofgesetz vom 29. September die freie Verfügungsgewalt über land- und forst- 
wirtschaftlichen Besitz im Erbfall. Zur Führung der Register der davon betroffenen Höfe und zur Entscheidung von Rechtsstreitigkeiten wurden Anerbengerichte bei den Amtsgerichten, z. T. auch für mehrere Amtsgerichte zusammen, gebildet; ihre Überlieferung ist hier nicht berücksichtigt ( $\mathrm{vgl}$. aber Hinweise auf Einzelfallakten bei Landes- und Kreisbauernschaften in Abschnitt 6.4.4). Von den Rechtsmittelinstanzen sind folgende Bestände vorhanden:

\subsection{Reichserbhofgericht, Celle}

BA, Best. R 46

Das Gericht entschied unter dem Präsidium des Reichsernährungsministers über ,sofortige weitere Beschwerden" gegen Urteile der Erbhofgerichte. Überliefert ist als Ergänzung zu den veröffentlichten "Entscheidungen des Reichserbhofgerichts“ (19341944) eine unvollständige Sammlung der Entscheidungen (142 Bde, 1934-1940, 1942 1944) mit Kartei zu den einzelnen angezogenen Bestimmungen und Stichwortkartei und Akten aus 297 Verfahren aus allen OLG-Bezirken, die bei Kriegsende noch nicht abgeschlossen waren (weitere Einzelfälle in Akten des Reichsjustizministeriums).

\subsection{Oberstes Fideikommißgericht}

ZSLA Merseburg, Best. 5.2.15

Die Akten über die Rechtsprechung dieser beim Reichsjustizministerium 1935 eingerichteten Rechtsmittelinstanz gegen Entscheidungen der FideikommiBsenate der Oberlandesgerichte zur Auflösung von Fideikommissen sind als Nachakten des Landesamtes für Familiengüter vollständig überliefert (ca. 2200 Bde, 1920-1945, davon ca. 270 nach 1933, nur teilweise erschlossen). Sie betreffen allgemeine Angelegenheiten (u. a. Sitzungen des Landesamtes 1930-1935, Entscheidungssammlung 19331945, Statistik 1933-1944) und Einzelfälle (ca. 260 Bde, jeweils mit mehreren Fällen, in alphabetischer Ordnung), darunter die Familiengüter der Herzöge von Arenberg (1940), Fürsten Metternich-Winneberg (1 Bd), Grafen Münster (1 Bd), Fürsten Öttingen, GroBherzöge von Oldenburg (2 Bde), Fürsten Ysenburg-Büdingen und die hohenzollernschen Hausgüter in Preußen (13 Bde). Das Verfahren zur Umwandlung ehemaliger Familienbesitzungen in Erbhöfe ist außerdem durch Einzelfallakten des Reichsjustizministeriums dokumentiert.

Lit.: C. v. BAR, P. STIEWE: Die Auflösung der Familienfideikommisse im Deutschen Reich und in PreuBen im 20. Jahrhunder 1981.

\subsection{Preußisches Landeserbhofgericht, Celle}

GStA, Rep. 217

Den Hauptteil des Bestandes bildet die Entscheidungssammlung (346 Bde, 1934-1944, dazu 80 Registerbde); außerdem sind Generalakten (50 Bde) mit einer Sammlung von Entscheidungen über das Bestehen örtlicher Anerbensitten in 6 OLG-Bezirken und Akten aus 6 Verfahren (1937-1945) vorhanden.

\subsection{Erbhofgerichte}

Schriftgut der bei den Oberlandesgerichten, z. T. für mehrere Bezirke, gebildeten Rechtsmittelinstanz gegen die Entscheidungen der Anerbengerichte befindet sich $z$. T. (so vom Erbhofgericht Darmstadt) noch bei den heutigen Oberlandesgerichten, z. T. nicht abgesondert in den für deren Überlieferung gebildeten Archivbeständen. Nachgewiesen sind folgende Provenienzen: 
Erbhofgericht Bamberg

BAM

Beschwerderegister (1934-1935).

Erbhofgericht Hamburg

$\mathrm{HH}$, Best. 222-10

Generalakten betr. Organisation und Verwaltung (16 Bde, 1933-1943) und Erbhofrecht (18 Bde, 1934-1942), Entscheidungssammlung (10 Bde, 1934-1943, mit Registern).

Erbhofgericht Karlsruhe

KA, Best. 540

Entscheidungssammlung (ca. 700 Fälle, 1934-1944).

Erbhofgericht München

MSt

Rest von Generalakten (2 Bde, 1933-1944), Entscheidungssammlung (34 Bde für ca. 5000 Verfahren, 1934-1944).

\subsubsection{Erbgesundheitsgerichte}

Nach dem Gesetz zur Verhütung erbkranken Nachwuchses vom 14. Juli 1933 hatten Erbgesundheitsgerichte über die von den Gesundheitsbehörden zu stellenden Anträge auf Unfruchtbarmachung der von den Vorschriften betroffenen Personen und ab 1935 auch über Eheverbote nach dem Ehegesundheitsgesetz zu entscheiden. Sie wurden grundsätzlich für einen Landgerichtsbezirk bei dem Amtsgericht gebildet, das seinen Sitz am Ort des Landgerichts hatte. Gegen ihre Entscheidungen konnten die Erbgesundheitsobergerichte bei den Oberlandesgerichten angerufen werden.

Die Rechtsprechung folgender Erbgesundheitsobergerichte ist dokumentiert:

Erbgesundheitsobergericht Hamburg

$\mathrm{HH}$, Best. 224-1

Generalakten betr. Organisation, Personalien, Statistik (12 Bde, 1933-1944), Sammlung der Beschlüsse (19 Bde, 1934-1944).

Erbgesundheitsobergericht Karlsruhe

KA, Best. 539

Sammlung der Beschlüsse (ca. 4000 Fälle, 1934-1944).

Erbgesundheitsobergericht Köln

$\mathrm{D}-\mathrm{K}$

Sammlung der Beschlüsse (7 Bde, 1934-1938, in den Akten des OLG).

Die Überlieferung der Gerichte der ersten Instanz ist sehr zersplittert. Zum Teil ist sie mit dem Schriftgut der entsprechenden Amtsgerichte vermischt, in Bayern bei den Oberlandesgerichten, so in München, konzentriert worden, und vielfach sind Gerichtsakten weisungsgemäß an Beratungsstellen für Erb- und Rassenpflege bei den Gesundheitsämtern abgeliefert und dort mit deren Parallelüberlieferung vereinigt worden. Von folgenden Gerichten sind Verfahrensakten fast ausschlieBlich über Unfruchtbarmachung und deren Ablehnung, nur ausnahmsweise über Eheverbote, im jeweils - soweit möglich - angegebenen Umfang in den genannten Archiven bzw. beim OLG München in Beständen verschiedener Provenienz, die im einzelnen nicht erwähnt wird, vorhanden:

Erbgesundheitsgericht Arnsberg (ca. 2000)

MS

Erbgesundheitsgericht Augsburg (2020) OLGM

Erbgesundheitsgericht Berlin (ca. 3000) B

Erbgesundheitsgericht Bielefeld (ca. 1200) DT

Erbgesundheitsgericht Braunschweig (Register und Verzeichnisse) WF Erbgesundheitsgericht Bremen (ca. 1700) 
Erbgesundheitsgericht Deggendorf (609)

OLGM

Erbgesundheitsgericht Dortmund (ca. 2000)

MS

Erbgesundheitsgericht Flensburg (ca. 1000)

SL

Erbgesundheitsgericht Freiburg (auch Register, Tabellen und Sammelakten) FR

Erbgesundheitsgericht Gießen (nur Kreise Büdingen und Friedberg) DA

Erbgesundheitsgericht Hagen (ca. 500) MS

Erbgesundheitsgericht Hanau (76) MR

Erbgesundheitsgericht Hannover (564 Einzelfallakten, 38 Bde mit Beschlüssen) H

Erbgesundheitsgericht Kempten (2023) OLGM

Erbgesundheitsgericht Kiel (176)

SL

Erbgesundheitsgericht Konstanz (ca. 1000)

FR

Erbgesundheitsgericht Landshut (716)

OLGM

Erbgesundheitsgericht Limburg (643)

KO

Erbgesundheitsgericht Lörrach (ca. 700)

FR

Erbgesundheitsgericht Lübeck (92)

SL

Erbgesundheitsgericht Marburg (ca. 2000)

MR

Erbgesundheitsgericht Memmingen (1 314)

OLGM

Erbgesundheitsgericht München (6884)

OLGM

Erbgesundheitsgericht Offenbach (Gesamtregister und Kreis Groß-Gerau)

DA

Erbgesundheitsgericht Osnabrück (210)

OS

Erbgesundheitsgericht Passau (771)

OLGM

Erbgesundheitsgericht Saarbrücken (Register, allgemeine Verfügungen, Besetzungs-

akten, 386 Einzelfälle, 6 nach Ehegesundheitsgesetz)

Erbgesundheitsgericht Schweinfurt (100)

Erbgesundheitsgericht Traunstein (2071)

SB

Erbgesundheitsgericht Trier (189)

WÜ

Erbgesundheitsgericht Waldshut (ca. 450)

OLGM

KO

Erbgesundheitsgericht Wiesbaden (801)

FR

Weitere Akten von Erbgesundheitsgerichten enthält die Überlieferung folgender Gesundheitsämter, wobei zu beriucksichtigen ist, $\mathrm{daB}$ relativ viele Verfahren auch durch Akten von Gerichten auBerhalb des Zuständigkeitsbereichs des Gesundheitsamtes dokumentiert sind; z. B. finden sich im Schriftgut des Gesundheitsamts Bremen außer den Unterlagen der Erbgesundheitsgerichte Bremen und Verden auch solche von Bielefeld (16) und von Gerichten in Süddeutschland, wobei es sich z. T. um Vorgänge über Anträge handeln dürfte, die vom Gesundheitsamt bei dem Gericht gestellt wurden, das für die Heil- und Pflegeanstalt zuständig war (z. B. Bielefeld für Bethel), in der der Betroffene sich befand:

Gesundheitsamt Ahrweiler (894)

KO

Gesundheitsamt Alzey (ca. 1000)

Gesundheitsamt Backnang

Gesundheitsamt Bad Ems (587)

KO

Gesundheitsamt Bad Kreuznach (964)

KO

Gesundheitsamt Bergzabern (592)

SP

Gesundheitsamt Birkenfeld (1071)

KO

Gesundheitsamt Germersheim (696)

SP

Gesundheitsamt Koblenz (2593)

KO

Gesundheitsamt Kusel (386) 
Gesundheitsamt Landau (ca. 1000) SP

Gesundheitsamt Ludwigshafen (6409) SP

Gesundheitsamt Melle (111) OS

Gesundheitsamt Neustadt/Weinstr. (123) SP

Gesundheitsamt Neuwied (1061) KO

Gesundheitsamt Nordhorn (26) OS

Gesundheitsamt Pirmasens (894) SP

Gesundheitsamt Recklinghausen (ca. 1000) MS

Gesundheitsamt Simmern (259) KO

Gesundheitsamt Speyer (1 329) SP

Gesundheitsamt St. Goar (294) KO

Gesundheitsamt St. Goarshausen (801) KO

Gesundheitsamt Trier (819) KO

Gesundheitsamt Villingen (818) FR

Gesundheitsamt Westerburg (283) KO

Gesundheitsamt Wittlich (266) KO

Gesundheitsamt Worms (1 547) P

Gesundheitsamt Zell/Mosel (230) KO

Darüber hinaus dürften sich weitere Akten noch in den Registraturen vieler anderer Gesundheitsämter befinden, die noch nicht vom zuständigen Archiv übernommen wurden, wie es z. B. für das Erbgesundheitsgericht Wuppertal, bei dem über Sterilisationen in der Heil- und Pflegeanstalt Aprath entschieden wurde, bekannt ist.

Lit.: C. WIESENBERG: Die Rechtsprechung der Erbgesundheitsgerichte Hanau und GieBen zu dem Gesetz zur Verhütung erbkranken Nachwuchses vom 14. Juli 1933. 1986. - G. BOCK: Zwangssterilisation imı Nationalsozialismus. 1986, insbes. S. 209-230. - N. SCHMACKE, H. G. NÜSE: Zwangssterilisiert, verleugnet und vergessen. 1984.

\subsubsection{Verwaltungsgerichtsbarkeit}

Das nationalsozialistische Regime hat die Verwaltungsgerichtsbarkeit nicht beseitigt, sondern ihr sogar durch die Errichtung des Reichsverwaltungsgerichts 1941 einen organisatorischen AbschluB gegeben. Die zunächst noch bestehenden Möglichkeiten, mit Hilfe der Verwaltungsgerichte gegen Behördenwillkür einzuschreiten, wurden freilich, insbesondere dadurch, daß Maßnahmen der politischen Polizei keiner Nachprüfung unterliegen sollten, immer mehr beschränkt, wenn auch vielfach Entscheidungen zugunsten der Kirchen oder von Gewerbetreibenden ergingen, denen aus politischen oder rassischen Gründen die Gewerbeerlaubnis entzogen oder versagt werden sollte.

Lit.: Die DEUTSCHE JUSTLZ UND DER NATIONALSOZIALISMUS. Bd. II. 1970. - M. STOLLEIS: Die Verwaltungsgerichtsbarkeit im Nationalsozial ismus. 1985.

\subsubsection{Reichsverwaltungsgericht}

BA, Best. R 122

Der Bestand enthält Generalakten über Kassensachen (45 Bde, 1941-1944, 3 Personalakten ZStA, Best. 15.10), die gesammelten Erkenntnisse der Verwaltungsgerichtshöfe Bayerns und Sachsens, der Wiener Senate und des 3. und 4. Senats (ca. 40 Bde, 1941-1944) und vor allem Schriftgut der nachstehenden, im Reichsverwaltungsgericht vereinigten Gerichte, während die Überlieferung des Dienststrafsenats bei derjenigen des Reichsdienststrafhofs (unten 3.2.6.1) verblieb und die Akten aus den bisherigen Zuständigkeiten des Reichswirtschafts- und des PreuBischen Oberverwaltungsgerichts 
mit den Vorakten dieser Provenienzen vereinigt wurden (vgl. unten und 3.2.4.4.1); von den veröffentlichten ,Entscheidungen des Reichsverwaltungsgerichts“ liegen noch 2 Bände (1942-1943) vor.

\section{Reichskriegsschädenamt}

Generalakten (382 Bde, 1941-1945) über Dienststellenverwaltung und Organisation mit Erlassen und Rundschreiben und betr. Härteausgleich, Volkstumsschäden, Nutzungsund Sachschäden, Kriegsschäden einzelner Wirtschaftszweige (u. a. der Filmwirtschaft), Personengruppen (u. a. Volksdeutsche im Ausland, Juden) und in einzelnen Gebieten, insbes. den besetzten Ostgebieten, Sammlung von Entscheidungen (ca. 800 Verfahren), Einzelfallakten über Entschädigungsansprüche für Kriegssachschäden im Reichsgebiet (ca. 5600), in Frankreich (ca. 5000), Belgien (1050) und den besetzten Ostgebieten (ca. 9200 ).

Oberste Spruchstelle für Umlegungen und für Wasser- und Bodenverbände (9.

Senat)

Generalakten (ca. 50 Bde, 1938-1945), Sammlung der Entscheidungen (9 Bde, 1938 1944) und von Materialien zum Umlegungsrecht in Österreich, Einzelfallakten über Beschwerden gegen Entscheidungen der Spruchkammern für Siedlung bei den preuBischen Oberpräsidenten und der Oberen Spruchstellen für Umlegungen (215 Bde) in Flurbereinigungsverfahren, u. a. wegen der Ablösung von Holz-, Weide- und kirchlichen Reichnisrechten und Landbeschaffung für den Bau der Reichsautobahnen, und gegen Entscheidungen der Spruchstellen für Wasser- und Bodenverbände (70 Bde) zur Festsetzung von Beiträgen und Kosten.

\section{Entschädigungsgericht (10. Senat)}

Einzelfallakten aus Verfahren wegen Enteignungen nach dem Gesetz über die Landbeschaffung für Zwecke der Wehrmacht von 1935 (280 Bde, 1941-1945) und wegen Entschädigungsansprüchen für die Beschlagnahme von Gebäuden (u. a. Schulen, Hotels, Krankenhäuser) nach dem Reichsleistungsgesetz oder Beschädigungen durch Wehrmachtangehörige (50 Bde, 1941-1945). Beklagter war in der Regel der Reichsfiskus (Heer, Kriegsmarine, Luftwaffe), vertreten durch die Reichsumsiedlungsgesellschaft, auch Wehrkreisverwaltungen, Marineintendanturen und die Reichswerke Hermann Göring, Kläger neben Privaten auch Firmen (u. a. Fried. Krupp), Zivil- und Kirchengemeinden. Dazu kommen Unterlagen aus einzelnen Verfahren in Wasser- und Fischerei- (15 Bde, 1941-1944) und in Landeskultursachen (12 Bde, 1941-1945).

Außerdem sind noch Urteile und Verfahrensakten des 6. Senats aus Prozessen wegen Ordnungsstrafen bei Versto $B$ gegen Bewirtschaftungsvorschriften (700 Bde, $1942-$ 1945) und des 8. Senats aus Auseinandersetzungen wegen Kommunalabgaben, vor allem Hauszinssteuer, Wertzuwachssteuer (dabei auch Arisierungsfälle) und Anliegerund ErschlieBungskosten (200 Bde, 1942-1944) vorhanden.

\subsubsection{Reichswirtschaftsgericht}

BA, Best. R 123

Der Hauptteil der Überlieferung aus der Zuständigkeit für die Regelung von Ansprüchen für Schäden in Verbindung mit BewirtschaftungsmaBnahmen im Ersten Weltkrieg und der Abtretung von Reichsgebiet und der Kolonien, aus Enteignungen für Besatzungstruppen und Reparationen und für sog. Tumultschäden bei Unruhen stammt aus der Zeit der Weimarer Republik, reicht aber nicht selten (4 507 Verfahren) bis 1942. 
Bei den Verfahren, die nach 1933 eingeleitet wurden, ging es um Ansprüche von Angehörigen deutscher Minderheiten vor allem in der Tschechoslowakei wegen Benachteiligungen vor dem AnschluB an das Reich (Volkstumsschäden), meistens jedoch um Ordnungsstrafen, die von den Reichsstellen für die gewerbliche und für die Ernährungs- und Landwirtschaft wegen Verstößen gegen die Verordnung über den Warenverkehr, z. B. Kontingentüberziehung, verhängt worden waren; dabei sind auch Fälle, in denen die Zuteilung von Rohstoffen wegen politischer Unzuverlässigkeit eingestellt werden sollte. Andere Verfahren wurden wegen VerstöBen gegen Preis- und Devisenvorschriften, der Anerkennung der Gemeinnützigkeit von Wohnungsunternehmen und der Versagung der Eintragung in die Handwerksrolle geführt.

Die Akten aus der Funktion als Kartellgericht dokumentieren die Vorbereitung des Gesetzes über die Errichtung von Zwangskartellen von 1933, Preisabsprachen in einzelnen Wirtschaftszweigen, die Durchfuhnung der Gemeinschaftshilfe der Wirtschaft im 2. Weltkrieg und der Verordnung über die Nachprüfung von „Entjudungsgeschäften“; sie enthalten Anordnungen der Reichsstellen der gewerblichen Wirtschafi, Materialsammlungen über einzelne Wirtschaftszweige und stammen aus ca. 21500 einzelnen Verfahren (1935-1945). Grundsatzurteile sind in den .Entscheidungen des Reichswirtschaftsgerichts" veröffentlicht.

\subsubsection{Reichsfeststellungsbehörde BA, Best. R 18 Anh.}

Die Behörde beim Reichsministerium des Innern entschied ab 1938 mit mehreren Karmmern über Beschwerden gegen Entscheidungen der Feststellungsbehörden bei den Bezirksregierungen oder obersten Landesbehörden bei Ansprüchen für Nachteile, die durch die Einziehung von kommunistischem, anderem „volks- und staatsfeindlichem" Vermögen, des Vermögens Ausgebürgerter oder des an die DAF übergegangenen Vermögens von Gewerkschaften und Arbeitgeberverbänden entstanden waren; bei Bedürftigkeit konnte auch entschädigt werden, wer „vorsätzlich staatsfeindliche Bestrebungen" mit Ausnahme von kommunistischen gefördert hatte.

Überliefert sind Akten aus ca. 2000 Verfahren (820 Bde). Sie betrafen hauptsächlich Ansprüche an das Vermögen von Gewerkschaften und einigen politischen Organisationen (462 Bde), darunter an erster Stelle der Mitglieder an den Unterstützungsverein der in der modernen Arbeiterbewegung tätigen Angestellten (76 Bde), ferner an ArbeiterGesangvereine, den Christlichen Metallarbeiterverband (5 Bde), den Deutschnationalen Handlungsgehilfenverband ( 9 Bde), des Deutschen Metallarbeiterverbandes (14 Bde), das Reichsbanner und an SPD-Ortsvereine (je 3 Bde). Weitere Verfahren wurden wegen des Vermögens von (Arbeiter-)Turn- und Sportvereinen (110 Bde), konfessionellen Organisationen (14 Bde, darunter Katholischer Jungmännerverein Paderborn, Volksverein für das katholische Deutschland), Freimaurerlogen (14 Bde), der Vereinigung der „Naturfreunde“ und anderer Träger von Erholungs- und Kinderheimen (26 Bde), von Druckereien und Verlagen (93 Bde, darunter „Vorwärts“ und „Weltbühne“) und an Volksund Genossenschaftshäusern (46 Bde) geführ. Zu den Ausgebürgerten, deren Vermögen Gegenstand von Verfahren war (35 Bde mit ca. 180 Einzelfällen), gehören Albert Grzesinski, Wieland Herzfelde, Heinrich Imbusch, Thomas, Katja und Erika Mann, Walter Mehring.

Lit: H. BOBERACH: Die Regelung von Ansprüchen von Gewerkschaftlern auf beschlagnahmtes Vermögen. 1989. 


\subsubsection{Oberverwaltungsgerichte der Länder}

Das Schriftgut der unter verschiedenen Bezeichnungen bestehenden Obergerichte für die Verwaltungsgerichtsbarkeit der Länder ist, soweit es nicht im Krieg oder - in Baden - nach seiner wissenschaftlichen Auswertung vernichtet wurde, von den Staatsarchiven offenbar noch nicht vollständig übernommen oder aus anderen Überlieferungen ausgesondert worden.

Lit.: C. KIRCHBERG: Der Badische Verwaltungsgerichtshof im Dritten Reich. 1982.

Folgende Bestände sind vorhanden:

\subsection{Preußisches Oberverwaltungsgericht}

GStA, Rep. 184

Die Generalakten betreffen u. a. Geschäftsgang und -verteilung, Verfahrensrecht (81 Bde, 1933-1941), Haushalts-, Kassen- und Rechnungswesen (ca. 100 Bde), Beamten-, Tarif- und Besoldungsrecht (ca. 60 Bde) und enthalten gutachtliche Äußerungen zu 15 Gesetzen (23 Bde, 1933-1940), darunter zum Berufsbeamtengesetz, zum Dienststrafgesetz und zum Gemeindeverfassungsrecht. Die Sammlung der Entscheidungen ist sachlich geordnet (ca. 70 Bde, 1933-1941). Verwaltungs- und Einzelfallakten liegen vor zum Steuer- und Gebührenrecht (2. Senat, 1729 Bde, 1933-1940), zum Polizeiverwaltungsund Konzessionsrecht (3. Senat, 1748 Bde, u. a. betr. Auflösung von Vereinen, Erteilung von Pässen, 1933-1944), zu Bau- und Wegesachen (4. Senat, 1147 Bde, auch betr. Entzug von Führerscheinen, 1933-1941), Wasserrecht und Fischereisachen (5. Senat, 359 Bde, 1933-1935). Zur Überlieferung der Dienststrafsenate vgl. unten 3.2.6.2.1.

Lit.: W. HEMPFER: Die nationalsozialistische Staatsauffassung in der Rechtsprechung des PreuBischen Oberverwaltungsgerichts. 1974. - C. H. ULE: Über das Wirken des Präsidenten des PreuBischen Oberverwallungsgerichts Prof. Dr. Dr. h. c. B. Drews in der Zeit nach 1933. 1984.

\subsection{Preußischer Gerichtshof zur Entscheidung der Kompetenzkon- flikte GStA, Rep. 204}

Akten aus 34 Verfahren (1933-1937) zur Klärung der Zuständigkeit von Gerichten und Behörden, unter den Prozeßbeteiligten verschiedene Krankenkassen, der Provinzialverband Hannover, die Siedlungsgesellschaft „Bauernland“ und die Harpener Bergbau A.G.

\subsection{Württembergischer Verwaltungsgerichtshof LB, Best. E 136}

Sitzungsprotokolle (1937-1943), Verwaltungs- und Verfahrensakten, ungetrennt von der Überlieferung des Dienststrafhofs und der Reichsdisziplinarkammer (vgl. unten 3.2.6.2.3), u. a. aus folgenden Gebieten (1933-1941, z. T. bis 1944): Staatsangehörigkeitsrecht (bis 1936), Beamtenrecht, Schulrecht, Unterbringung in Heilanstalten, Wegerecht, Baupolizei (bis 1935), Erteilung von Konzessionen, Kommunalabgaberecht, Fürsorgerecht.

\subsection{Lippisches Oberverwaltungsgericht}

DT, Best. L 80 I b C

Generalakten (8 Bde, 1898-1947) mit Geschäftsübersichten und Vorgängen über Ernennung der Beisitzer, Verfahrensakten (6 Bündel, unverzeichnet). 


\subsection{Landesverwaltungsgericht Hamburg}

HH, Best. $221-5$

Verfahrensakten (1922-1943 ohne Differenzierung) u. a. aus Prozessen wegen Diskriminierung von Juden, Kirchensteuerforderungen, Erteilung von Gewerbekonzessionen und ärztlichen Bestallungen, Entziehung von Führerscheinen wegen politischer Unzuverlässigkeit, Verbot von Vereinen und Druckschriften, in Bau- (dabei ein Vorgang betr. KL Neuengamme), Wasser-, Deich- und Wegesachen.

Lit.: I. v. VOSS: Die Verwaltungsgerichtsbarkeit in Hamburg von 1921 bis 1945. 1988.

\subsection{Verwaltungsgericht Bremen}

HB, Best. 4,139

General- (hauptsächlich über Haushalts- und Kassenangelegenheiten) und Verfahrensakten (ca. 1000 Bde, 1933-1943), vor allem betr. Konzessionen für Gastwirtschaften und andere Gewerbebetriebe, Erteilung von Führerscheinen.

\subsection{Verwaltungsgericht Lübeck}

HI

Generalakten mit Jahresberichten und Besetzungsunterlagen (1917-1937) und Verfahrensakten (135 Bde, 1933-1937, fortgesetzt bis 1941 durch 652 Bde des Stadtverwaltungsgerichts), hauptsächlich wegen Erhebung von Kosten für Fürsorgemaßnahmen, Erteilung von Gewerbescheinen, Enteignungen, auch aus Verfahren gegen Gestapo wegen Beschlagnahme von Druckschriften.

\subsubsection{Preußische Bezirksverwaltungsgerichte}

Die seit 1883 bei den Regierungspräsidenten bestehenden Bezirksausschüsse wurden Ende 1933 in Bezirksverwaltungsgerichte umgewandelt, deren Mitglieder im Benehmen mit den Gauleitern berufen wurden. Sie waren Berufungsinstanz für die Kreis- und Stadtverwaltungsgerichte und erste Instanz für Klagen gegen die Regierungspräsidenten. Ihr Schriftgut ist in einigen Archiven nicht von der Überlieferung der Regierung getrennt. Folgende Bestände sind vorhanden:

Bezirksverwaltungsgericht Aachen

Generalakten über Organisation und Besetzung (4 Bde, 1933-1943) sowie Verfahrensrecht (13 Bde), Sammelakten über Verfahren vor den Kreisverwaltungsgerichten (8 Bde, 1933-1942), Verfahrensakten (21 Fälle, 1933-1943), dabei je zwei über Verweigerung des Reisepasses und Unterbringung in einer Arbeitsanstalt, je einer über Verweigerung der Entlassung aus dem Staatsverband und Ausweisung aus dem Grenzgebiet.

Bezirksverwaltungsgericht Arnsberg MS Verfahrensakten (9 Bde, 1936-1943) aus Verfahren wegen Heranziehung zu Abgaben, Gewerbekonzessionen, Verweigerung eines Reisepasses, Betätigungsverbot für eine katholische Kongregation.

Bezirksverwaltungsgericht Aurich

AUR, Rep. 16/1

Generalakten mit Geschäftsanweisungen und -übersichten (6 Bde, 1900-1944), einzelne Verfahrensakten (1933-1939) betr. Konzessionen für Branntweinhandel und Schankerlaubnis. 
Bezirksverwaltungsgericht Berlin

B, Pr. Br. Rep. 31

General- und Grundsatzakten (55 Bde, 1933-1940), u. a. betr. Verbot von Büchern durch die Polizei (1933-1935) und mit Sammlungen von Entscheidungen des Oberverwaltungsgerichts (17 Bde, 1933-1943) und des Bundesamtes für das Heimatwesen in Fürsorgekosten-Erstattungsfällen (3 Bde, 1933-1939), Entscheidungen in Gewerbeaufsichtssachen vor allem bei Betrieben der chemischen Industrie (ca. 150, darunter mehrfach Kodak, Riedel - de Haen, Schering A. G., 1933-1941), Verfahrensakten (ca. 3000, 1933-1944, darunter Klagen von Juden gegen die Stadiverwaltung).

\section{Bezirksverwaltungsgericht Düsseldorf}

Verfahrensakten aus ca. 250 Verfahren (1934-1945), vor allem wegen Konzessionen fuir Gewerbebetriebe (dabei 12 für chemische Werke 1933-1934), Forderungen von Wertzuwachssteuer, Straßenbau-, Fürsorge und Pflegekosten, Erteilung, von Führer- und Wandergewerbescheinen, auch aus je 3 Verfahren wegen polizeilicher MaBnahmen gegen den "Stahlhelm“-Bund (1935) und Verweigerung eines Reisepasses, weiterer Teilbestand (273 Bde, 1933-1944), u. a. mit Klagen von Organisationen der NSDAP, als Depositum im Stadtarchiv Düsseldorf.

Bezirksverwaltungsgericht Hannover

H, Best. Hann 180a Verfahrensakten (5 Bde, 1939-1942), davon 5 wegen Erteilung der Erlaubnis zur Berufsausübung für Ärzte und Hebammen, 1 wegen Erschließungskosten.

Bezirksverwaltungsgericht Lüneburg

H, Best. Hann 80a Verfahrensakten (23 Verfahren, 1933-1943), vor allem betr. Abgaben und Wasserrecht, aus je einem Verfahren wegen Verhängung von Schutzhaft (1933-1934), Unterbringung im Arbeitshaus (1935-1937), PaBverweigerung (1938).

\section{Bezirksverwaltungsgericht Minden}

DT, Best. M 1 B A Generalakten (14 Bde, 1933-1948), Sammlung der Entscheidungen des Oberverwaltungsgerichts auf Berufungen gegen Urteile des Bezirksverwaltungsgerichts Minden (1932-1942), Sammelakten betr. Darlehen zur Arbeitsbeschaffung und für ländliche Siedlung und betr. Gwerbekonzessionen in den $10 \mathrm{Kreisen}$ des Bezirks (11 bzw. 75 Bde), Verfahrensakten aus Prozessen wegen Gewerbekonzessionen (71), Gastwirtschafts- und Schankerlaubnis (12), Wasser- und Deichangelegenheiten (21), Eintragung in die Handwerksrolle (11), ErschlieBungskosten und anderer Abgaben (19), gegen Polizeiverfügungen (11), in Kirchen- (Kirchbaulasten-) und Schulsachen (8), wegen Erteilung von Legitimationskarten (7).

Bezirksverwaltungsgericht Osnabrück

OS, Rep. 437 Akten aus fortgeführten Verfahren vor dem BezirksausschuB (14 Bde, 1925-1936, u. a. wegen Enteignung, Unterbringung im Arbeitshaus) und aus Verfahren (meist 1933-1939) wegen Wege- (18 Bde) und Wasserbaukosten ( 9 Bde), aus dem Gewerberecht (15 Bde) und aus anderen Rechtsgebieten ( 9 Bde, dabei auch Beamtenrecht).

Bezirksverwaltungsgericht Schleswig

Generalakten (55 Bde, 1933-1945), Verfahrensakten (ca. 750 Bde, fast nur 1938-1943). u. a. betr. Klagen gegen allgemeine Polizei-, gewerbe- und baupolizeiliche Verfügungen, Schul- und Kirchensachen, Erteilung von Wandergewerbescheinen. 
Bezirksverwaltungsgericht Sigmaringen

SIG, Best. Ho 247

Generalakten (14 Bde, 1933-1944), Verfahrensakten betr. Klagen gegen die Landesfürsorgeverbände Hechingen und Sigmaringen wegen Kosten für Armenfürsorge (34 Bde, 1933-1940), Verweigerung von Wandergewerbescheinen für Juden und Zigeuner (2, 1936-1937), wegen Schank- und Gewerbekonzessionen (32), in Wege-, Verkehrsund Wasserrechtssachen (8).

Bezirksverwaltungsgericht Stade

STA, Rep. 268 u. 269

Verfahrensakten (187 Verfahren, 1933-1941) vor allem aus Verfahren wegen Ereilung von Konzessionen, Abgaben, in Bau- und Wegerechtssachen, insbes. wegen Entschädigungsansprüchen aus dem Ausbau der Unterweser (1930-1939), auch wegen Beschlagnahme eines Verlags der SPD, Anordnung der Sterilisierung, Erteilung von Waffenscheinen, Orts- und Innungssatzungen.

\subsubsection{Seeämter}

Die Seeämter und als Berufungsinstanz das Reichsoberseeamt entschieden in Verfahren, durch die Schiffsoffizieren, Maschinisten und Steuerleuten das Patent zur Berufsausübung aberkannt werden sollte, und untersuchten Seeunfälle, wenn ein öffentliches Interesse vorlag. Folgende Bestände sind vorhanden:

Reichsoberseeamt, Hamburg

BA, Best. R 95

Generalakten (47 Bde bis 1935), vor allem betr. Personalangelegenheiten und Dienststellenverwaltung, Register über Selbstmorde und Verschwinden von Schiffspersonal (1926-1942), Akten aus 172 Untersuchungsverfahren (1933-1944).

Seeamt Bremerhaven

HB, Best. 4,32

Sammlung der Sprüche in Seeunfallsachen (1935-1944), Einzelfallakten (Reste, ab 1942 vollständig).

Seeamt Emden

AUR, Rep. 155

Sammlung der Sprüche aus 107 Verfahren (1935-1942) über Havarien und Unglücksfälle, an denen in 10 Fällen außer deutschen auch Schiffe unter fremder Flagge beteiligt waren; 6 Verfahren betreffen Folgen von Luftangriffen (1940-1942), 4 Schiffsverluste durch Minen und Torpedierung.

Seeamt Hamburg

HH, Best. 373-5 I

Sammlung von 1518 Sprüchen (24 Bde, 1933-1944), einzelne Entscheidungen des Reichsoberseeamtes, Akten aus 18 Verfahren $(1936,1939)$.

\subsubsection{Prisengerichte}

BA. Best. R 27

ZStA, Best. 30.20

Die Beschlagnahme von Handelsschiffen unter der Flagge von Feindstaaten oder Neutraler, die für diese bestimmte Fracht führten, und ihrer Ladung erfolgte nach der Prisenordnung in einem förmlichen Verfahren durch dafür bei Kriegsbeginn geschaffene Gerichte, vor denen der Anspruch des Reichs durch Reichskommissare geltend gemacht wurde. die der Oberbefehlshaber der Kriegsmarine berief. Überliefert sind folgende Bestände und Teilbestände: 


\section{Oberprisenhof}

Urschriften von Entscheidungen (ZStA, 2 Bde, 1940-1944). Handakten des Vizepräsidenten Dr. Hesse betr. Besprechungen und Personalangelegenheiten (1942-1945), unvollständige Urteilssammlung (BA).

\section{Prisenhof Berlin}

Sammlung von Beschlüssen und der Urteile über 74, meist sowjetrussische, Schiffe (BA, 4 Bde, 1942-1944), in Potsdam weitere Uneile und Beschlüsse (1940-1944) und Vorgänge zu Grundsatzfragen der Prisengerichtsbarkeit, zu einzelnen Prisen sowie zur Beschränkung des deutschen Handels (4 Bde, 1939-1941).

\section{Prisenhof Hamburg}

Generalakten betr. Organisation und Geschäftsverteilung (9 Bde), Prisenordnung und -verfahren (24 Bde, 1939-1943), ausländisches Prisenrecht (10 Bde), Kriegswirtschaft und -politik (34 Bde, davon 20 Bde Berichte des Kaiser Wilhelm Instituts für ausländisches offentliches Recht und Völkerrecht über wehrwirtschaftliche MaBnahmen des Auslands, 1939-1944), Materialsammlungen zu Einzelfragen (34 Bde) und Akten aus Verfahren über 398 feindliche, meist französische und englische, und neutrale, meist finnische und schwedische, Schiffe oder deren Ladung.

\section{Reichskommissar beim Prisenhof Hamburg}

BA-MA, Best. RM 15 Generalakten, vor allem Korrespondenz mit Marinedienststellen (90 Bde, Tätigkeitsbericht des Reichskommissars beim Oberprisenhof 1939 - 15. 12. 1944 ZStA) und Akten über 1356 einzelne Schiffe und deren Ladung, auch über Freigabe ohne Verfahren, ferner Sammelakten über beschlagnahmte Güter und deren Verwendung, Listen, Schiffspapiere und -tagebücher (ca. 250 Bde).

Lit: G. KRETSCHMER: Die deutsche Prisenrechtsprechung im Zweiten Weltkrieg. 1967.

\subsubsection{Finanzgerichte}

Die 1922 bei den Landesfinanzämtern eingerichteten Finanzgerichte wurden 1939 in Abteilungen für Anfechtungssachen auf dem Gebiet der Besitz- und Verkehrssteuern umgewandelt; deshalb ist nicht auszuschließen, daß ein Teil ihrer Überlieferung noch bei den Akten der Oberfinanzpräsidien oder bei den nach 1945 neu entstandenen Finanzgerichten liegt. Über Berufungen und Beschwerden entschied der

Reichsfinanzhof, München

BA, Best. R 37

Bisher wurden das Beschwerderegister (51 Bde, 1933-1945) über die dort geführten Verfahren, deren Urteile in Grundsatzfällen in den ,Entscheidungen und Gutachten des Reichsfinanzhofs“ (Bd. 33-51, 1933-1943) veröffentlicht wurden, und Akten des I. (ca. 3600), II. (ca. 2400), III. (ca. 3300 ), IV. (ca. 3400), V. (ca. 5300 einschl. Zollsachen), VI. (ca. 8500 ) und Großen Senats (45) übernommen, während sich die General- und Verwaltungsakten noch beim Bundesfinanzhof in München befinden.

Lit.: G. UFFELMANN: Die Rechtsprechung des Reichsfnanzhofs unter nationalsozialistischem EinfluB in den Jahren 1933-1943. 1948. 
Finanzgericht München

MSt

Generalakten über Organisation und Geschäftsbetrieb mit Richtlinien für einzelne Steuerarten und Steuervorschriften (ca. 60 Bde, 1929-1964).

\subsubsection{Arbeits- und Sozialgerichtsbarkeit}

\subsubsection{Arbeitsgerichtsbarkeit}

Die Arbeitsgerichtsbarkeit war organisatorisch mit den ordentlichen Gerichten für $\mathrm{Zi}$ vilsachen verbunden, jedoch so, daß vielfach für mehrere Amtsgerichtsbezirke das Arbeitsgericht bei einem davon zuständig war und auch nicht bei allen Landgerichten Landesarbeitsgerichte eingerichtet wurden; z. B. gab es im OLG-Bezirk Bamberg bei 57 Amtsgerichten nur 24 Arbeitsgerichte, im OLG-Bezirk Hamm sogar nur 21 bei 108 und Landesarbeitsgerichte bei 2 bzw. 5 der 7 bzw. 9 Landgerichte. Möglicherweise ist daher in Schriftgut mancher Land- und Amtsgerichte, das sich noch bei diesen befindet, die Arbeitsgerichtsbarkeit besser dokumentiert als in den wenigen bisher gebildeten Archivbeständen. Eine Ersatzüberlieferung bietet gelegentlich Material der örtiichen Rechtsberatungsstellen der Deutschen Arbeitsfront, die auch für die Publikation wichtiger Entscheidungen sorgte.

Lit.: DAF - Entscheidungssammlung. 1936-1944. - U. REIFNER (Hrsg):: Das Recht des Unrechtsstaates. 1981. - A. KRANIG: Arbeitsrecht im NS-Staat. 1984. - E. NOAM, W.-A. KROPAT: Justiz und Judenverfolgung. 1975. S. 84-100.

\subsection{Reichsarbeitsgericht, Leipzig}

ZStA, Best. 30.10

Der Bestand enthält insgesamt 4576 Akten aus einzelnen Verfahren vor dem 1927 beim Reichsgericht errichteten Gericht aus der Zeit bis Kriegsende, die alphabetisch nach den Namen der Kläger geordnet sind, und in geringem Umfang vorgelegte Einzelfallakten von Landesarbeitsgerichten, die noch unverzeichnet und nur über die Angabe der Vorinstanz zugänglich sind. Veröffentlichte "Entscheidungen des Reichsarbeitsgerichts" liegen in 16 Bänden (Bd. 12-27, 1933-1944) vor.

\subsection{Landesarbeitsgerichte}

Lediglich von den Landesarbeitsgerichten Freiburg (FR) und Hannover $(\mathrm{H}$, Best. Hann 171) sind Entscheidungssammlungen (1 Bd, 1936-1940 bzw. 6 Bde, 1939-1944) in den Akten der jeweiligen Landgerichte enthalten.

\subsection{Arbeitsgerichte}

Arbeitsgericht Aalen

LB, Best. FL 700/1

Ca. 900 Urteile und Vergleiche (1933-1940).

Arbeitsgericht Bad Mergentheim

LB, Best. FL 700/10

Prozeßregister (1927-1945), ca. 500 Uneile und Vergleiche.

Arbeitsgericht Balingen

SIG, Best. Wü $182 / 11$

Akten aus 198 Verfahren (1933-1941) und betr. Tarifverträge (9 Bde, 1927-1954).

Akten aus 21 Verfahren (1939-1945), vor allem gegen Behörden und Körperschaften. 
Akten aus ca. 60, überwiegend durch Vergleich abgeschlossenen Verfahren (1938-1.942).

Arbeitsgericht Erding

MSt

Protokolle und Urteile aus 30 Verfahren (1938).

Arbeitsgericht Esslingen

LB, Best. FL 700/5

Uneile und Vergleiche aus 109 Verfahren (1933-1940).

Arbeitsgericht Freiburg

FR

Akten aus 19 Verfahren (1938-1945) wegen Lohnforderungen, Widertuf von Kündigung, Herausgabe von Arbeitspapieren.

Arbeitsgericht Fulda

MR, Best. 275

Einzelne Generalakten, u. a. betr. DAF, Geschäftsübersicht.

Arbeitsgericht Hagen

Sammlung von Urteilen (ca. 40, 1943-1944).

Arbeitsgericht Hamm

Generalakten (7 Bde, 1933-1938), Urteile aus ca. 200 Verfahren (12 Bde, 1933-1945).

Arbeitsgericht Karlsruhe

KA, Best. 510

Register, Tabellen, Akten aus Verfahren (1933-1944).

Arbeitsgericht Kemnath

ProzeBregister (1935-1946).

Arbeitsgericht Landau

SP, Best. O 17

Besetzungsakten (4 Bde, 1933-1939), Urteile (1933-1938), Register.

Arbeitsgericht Lörrach

FR

Verfahrensakten (721 Bde, 1934-1945), z. T. mit Vertretung der Kläger durch die DAF.

Arbeitsgericht Lübeck

HI

Verfahrensakten (8 Bde, 1933-1934).

Arbeitsgericht Ludwigshafen

SP, Best. O 18

Besetzungsakten (2 Bde, 1927-1934), Uneile (1933-1941), Register und Akten aus 67 Verfahren (1942-1944), unter den Parteien Wachleute von Arbeitslagern.

Arbeitsgericht Neuwied

KO, Best. 608,1

Generalakten über Dienststellenverwaltung (4 Bde, 1927-1943), Akten aus 6 Verfahren (1938-1944), davon 1 mit einem jüdischen Kläger, 2 mit Revision zum Reichsarbeitsgericht.

Arbeitsgericht Nidda

DA, Best. G 29A

Sammlung von Einzelschriftstücken zu einzelnen Verfahren (3 Kästen, 1932-1944), meist wegen Kündigungen und Lohnforderungen in handwerklichen und landwirtschaftlichen Betrieben, auch Anfechtung der Betriebsratswahl bei Buderus in Wetzlar (1933). 
Arbeitsgericht Rastatt

KA. Best. 510

Akten aus 367 Verfahren (1935-1944, 1941-1943 vollständig).

Arbeitsgericht Rosenheim

MSt

Akten aus 75 Verfahren $(1933,1936,1937,1942)$.

Arbeitsgericht Schwäbisch Hall

LB, Best. FL 700/12

ProzeBregister (1927-1938), ca. 600 Urteile und Vergleiche (1933-1945).

Arbeitsgericht Traunstein

MSt

Urteile und Vergleiche in ca. 400 Verfahren (12 Bde, 1933-1944).

Arbeitsgericht Tübingen

SIG, Best. WÜ 182/11

Akten aus 39 Verfahren (1933-1941).

Lit.: Repertorien des Staatsarchivs Sigmaringen. 1975.

\subsubsection{Sozialgerichtsbarkeit}

Nach der Reichsversicherungsordnung von 1911 entschieden die für die verschiedenen Zweige der Sozialversicherung eingerichteten Aufsichtsbehörden (zu ihrer Überlieferung aus dieser Zuständigkeit vgl. Abschnitt 7.1.4.9) zugleich als Spruchbehörden über Klagen gegen Maßnahmen der Versichenungsträger im Einzelfall. Daraus resultieren bisher folgende Archivbestände:

\subsection{Reichsversicherungsamt}

BA, Best. R 89

Nachdem $95 \%$ der überlieferten Einzelfallakten als nicht archivwürdig ausgesondert und vernichtet wurden, enthält der Bestand für die Zeit von 1933-1945 die Spruchbücher und ProzeBlisten (ca. 180 Bde) und Akten über Entscheidungen, von denen die wichtigsten in den „Entscheidungen und Mitteilungen des Reichsversicherungsamtes“ (Bd. 33-51, 1933-1944) veröffentlicht sind, zu Rekursen und Beschwerden auf folgenden Gebieten: - Unfallversicherung (ca. 2500 Fälle, dabei einzelne Klagen von Kriegsgefangenen und Fremdarbeitern, spezielle Sammlung über Benufskrankheiten 1933-1935).

- Krankenversicherung (ca. 200 Fälle),

- Arbeitslosenversicherung (ca. 120 Fälle),

- Knappschaftsversicherung (ca. 200 Fälle),

- Angestelltenversicherung (ca. 100 Fälle).

Außerdem sind alle Verfahrensakten über die Aberkennung von Rentenansprüchen wegen politischer Unzuverlässigkeit (ca. 100 Fälle, 1937-1944, z. T. mit Unteilen aus Strafverfahren, die zur Begründung herangezogen wurden) vorhanden.

\subsection{Reichsschiedsamt beim Reichsversicherungsamt}

BA, Best. R 159

Aus der Tätigkeit des Amtes zur Regelung von Auseinandersetzungen zwischen Ärzten und Zahnärzten einerseits, den Krankenkassen andererseits vor allem über die Zulassung zur Kassenpraxis und Honorarfragen sind Generalakten (9 Bde, 1933-1945), die Sammlung der Entscheidungen (20 Bde, 1933-1944) - auch des Reichsgerichts und des Reichszulassungsausschusses bei der Reichsstelle der Kassenärztlichen Vereinigungen - und erteilte Auskünfte und Gutachten (12 Bde) überliefert. 


\subsection{Reichsversorgungsgericht}

BA, Best. R 116

Erhalten blieben die Generalakten in Personalangelegenheiten (ca. 80 Bde), über Organisation und Geschäftsverteilung (6 Bde), über das Reichsversorgungsgesetz und andere anzuwendende Vorschriften (ca. $60 \mathrm{Bde}$ ) und über Medizinalangelegenheiten (6 Bde). Nachdem alle Einzelfallakten bis 1940 bei einem Luftangriff 1944 vernichtet wurden, ist die Spruchtätigkeit nur durch Sitzungsniederschriften (8 Bde bis 1940), die Sammlung der $-z$. T. in den "Entscheidungen des Reichsversorgungsgerichts" (Bd. 10-14, 1933, 1936-1940) veröffentlichten - Leitsatz- und Grundsatzentscheidungen (3 Bde, 19291929), Listen (31 Bde, 1933-1939) und Akten aus 7 Verfahren (10 Bde, 1925-1944) in Rekursen gegen Entscheidungen von Militärversorgungsgerichten bei Oberversicherungsämtern dokumentiert, außerdem durch Eingaben zu Einzelfällen (5 Bde).

\subsection{Oberversicherungsämter}

Ein Teil des Schriftguts der Oberversicherungsämter, die entweder regional oder für bestimmte Versicherungsträger zuständig waren, könnte sich noch bei den nach 1945 entstandenen Sozialgerichten befinden. Bisher sind folgende Bestände vorhanden:

Oberversicherungsamt Augsburg

Umfangreicher Bestand von Akten über einzelne Berufungsverfahren in Auseinandersetzungen zwischen Versicherten und Versicherungsträgern (1933-1945).

Oberversicherungsamt Berlin

B, Rep. 58

Entscheidungen nach $\S 358$ Reichsversicherungsordnung (59 Fälle, 1934-1940) und in Streitfälen aus der Krankenversicherung (ca. 100 Fälle, 1930-1940), Akten aus 60 einzelnen Verfahren vor allem gegen Reichsversicherungsamt, Landesversicherungsanstalt Berlin und Berufsgenossenschaften (1941-1945).

Oberversicherungsamt Darmstadt

DA, Best. H 17

Akten aus 71 Verfahren (1936-1945, Mehrzahl ab 1943) gegen die Reichsversicherungsanstalt für Angestellte, die Landesversicherungsanstalt Hessen und die Allgemeine Ortskrankenkasse Darmstadt.

Oberversicherungsamt Detmold DT, Best. L 80 I b A Akten aus ca. 1000 Verfahren (1933-1944, z. T. auch in Best. D 25 A).

Oberversicherungsamt Konstanz

Akten aus 246 Verfahren (1933-1945) vor allem gegen Berufsgenossenschaften wegen landwirtschaftlicher und gewerblicher Unfallrenten.

Oberversicherungsamt Reutlingen

SIG, Best. Wü 184/2

Urteile und ärztliche Gutachten (20 Bde, 1935-1941), Beschlüsse über Festsetzung des Jahresarbeitsverdienstes in der Landwirtschaft (1943-1950).

Oberversicherungsamt Sigmaringen

SIG, Best. Ho 262

Sammlung der Entscheidungen (16 Bde, 1933-1938), Akten aus 248 Verfahren (19401943) überwiegend gegen die Landesversicherungsanstalt. 
Oberversicherungsamt Stuttgart

LB, Best. E 396

Entscheidungen in ca. 5600 Verfahren (1935-1943) überwiegend gegen Berufsgenossenschaften und Landesversicherungsanstalt, Akten aus 510 Verfahren (1935-1943) aus Ablieferung des Sozialgerichts Reutlingen ausgesonder (SIG, Best. Wü 184/1).

\subsubsection{Disziplinar- und Ehrengerichtsbarkeit}

Neben die herkömmliche Disziplinargerichtsbarkeit für Beamte und Richter und die Ehrengerichtsbarkeit der Rechtsanwälte, Notare, Ärzte und Apotheker traten ab 1933 neue Standesgerichte für Angehörige bestimmter Berufe, und zusätzlich wurde für die Mitglieder der NSDAP eine eigene Parteigerichtsbarkeit (vgl. unten 9.1.16) geschaffen. Die Überlieferung beschränkt sich auf folgende Bestände:

\subsubsection{Reichsdienststrafhof}

BA, Best. R 148

Als Revisionsinstanz war der Reichsdienststrafhof nach der Reichsdienststrafordnung von 1937 (ab 1941 als Teil des Reichsverwaltungsgerichts) für Verfahren gegen Reichsund Landesbeamte zuständig, während der Reichsdisziplinarhof, von dem der Bestand ebenfalls Schriftgut enthält, auf Reichsbeamte beschränkt war. Überliefert sind die Akten aus ca. 2500 Verfahren (1937-1945 mit Vorakten ab 1934), die zum Teil auch vom Vertreter der Obersten Dienstbehörde beim Reichsdienststrafhof stammen. Gründe für eine disziplinarische MaBregelung, überwiegend die Entfernung aus dem Dienst, waren neben den Fällen normaler Kriminalität vielfach politische Vorwürfe, u. a. das „fragwürdige politische Verhalten“ eines Landrats, Verweigerung des „Deutschen Grußes", Nichtbeteiligung an einer Wahl, Betätigung als Ernster Bibelforscher, mehrfach Umgang mit Juden oder Hilfe für diese bei der Auswanderung durch Zollbeamte, ferner strafrechtlich nicht verfolgte Abweichungen von Moralvorstellungen wie Ehebruch oder Konkubinat, "Schuldenmacherei“, auch Verletzung der Amtsverschwiegenheit und "Verletzung der Kameradschaftspflicht" durch einen Ministerialrat. Grundsätzliche Urteile sind in den „Entscheidungen des Reichsdienststrafhofs“ (3 Bde, 1937-1941) veröffentlicht.

Für Disziplinarverfahren gegen richterliche Beamte und Notare, seit 1937 nur wegen Vergehen ,in oder bei Ausübung der Rechtspflege“, war der Dienststrafsenat beim Reichsgericht zuständig. Akten aus den dort durchgeführten Verfahren sind nur im Zentralen Staatsarchiv Potsdam (Best. 30.15, ca. 700 Bde) überliefert.

Lit: W. JUBELIUS: Beamtenpflichten und Disziplinargewalt unter der Herrschaft des Nationalsozialismus. 1985.

\subsubsection{Oberste Disziplinargerichte der Länder}

\subsection{Preußisches Oberverwaltungsgericht GStA, Rep. 184}

Von den zeitweise sechs Dienststrafsenaten sind Entscheidungssammlungen (30 Bde, 1934-1942) und Akten aus ca. 1800 Einzelverfahren (überwiegend 1935-1941) vorhanden. 


\subsection{Dienststrafsenat München}

MSt

Akten aus 455 Verfahren (1933-1944), darunter zahlreiche aus politischen Gründen (meist 1934-1936), z. B. wegen falscher Angaben über politische Tätigkeit vor 1933, Beleidigung Hitlers, auch wegen gesellschaftlichen Verkehrs mit Juden und Rassenschande.

\subsection{Dienststrafsenat Karisruhe}

KA, Best. 240

Akten aus 32 Verfahren (1933-1937), davon etwa 10 aus politischen Gründen, u. a. gegen den Polizeipräsidenten von Karlsruhe.

\subsection{Dienststrafhof Stuttgart}

LB, Best. E 136

Akten aus einzelnen Verfahren gegen Beamte von Gemeinden sowie auch vor der Reichsdisziplinarkammer Stuttgart (1933-1937).

\subsection{Disziplinarhof Hamburg}

HH, Best. 221-6

Generalakten betr. Organisation und Statistik (4 Bde, 1933-1936) und 29 Urteile (19331937).

\subsection{Disziplinarhof Bremen}

HB, Best. 3-D.7.

Generalakten (9 Bde, 1933-1937), u. a. betr. Gnadenrecht des Reichsstatthalters, Wiederaufnahme von Verfahren gegen Nationalsozialisten aus der Zeit vor 1933, Mitwirkung des NSLB bei Verfahren gegen Lehrer, Akten aus 58 Verfahren (auch erstinstanzlich vor der Disziplinarkammer, überwiegend 1933-1936), darunter gegen den ehemaligen Oberbürgermeister von Bremerhaven, je einen ehemaligen Senator und Staatsrat wegen ihrer Amtsführung vor der NS-Herrschaft.

\subsubsection{Dienststrafkammern}

In der Überlieferung der 1937 bei den Verwaltungsgerichten errichteten Dienststrafkammern ist z. T. auch Schriftgut der Reichsdisziplinarkammern und der erstinstanzlichen Disziplinargerichte der Länder enthalten. Folgende Überlieferung ist, mitunter in Verbindung mit Akten von Bezirksregierungen und Verwaltungsgerichten, vorhanden:

Disziplinarkammer Ansbach

Akten aus 31 Verfahren (1933-1945), von denen nur ein kleiner Teil politisch begründet war, in der Überlieferung der Regierung von Mittelfranken.

Lit.: E. FRÖHLICH in: BAYERN in der NS-Zeit VI. 1983. S. 170 ff.

Dienststrafkammer Aurich

AUR, Rep. 16/1

Nur Reste von Generalakten und Vorgänge über einzeine Verfahren gegen Lehrer und andere Beamte (1933-1944).

Dienststrafkammer Berlin

B, Rep. 31

Generalakten betr. Dienststellenverwaltung (8 Bde, 1932-1944), Einrichtung der Dienststrafkammern in Kärnten und Steiermark (1939), Urteilssammlung (2 Bde, 1934 1935), Verfahrensakten (ca. 800, 1933-1945), darunter gegen zwei ehemalige Bezirksbürgermeister, 7 Professoren, zwei Ministerialräte, je einen Ministerialdirektor, Re- 
gierungspräsidenten, Senatspräsidenten, Richter am Oberverwaltungsgericht, sonst gegen viele Lehrer und Polizeibeamte.

Reichsdisziplinarkammer Bremen

OL, Best. 150

Akten aus ca. 120 Verfahren (unverzeichnet, ab 1933), möglicherweise auch vor der Dienststrafkammer Oldenburg.

Reichsdisziplinarkammer Hamburg

HH, Best. 221-8

Sammlung der Entscheidungen (54 Bde, 1933-1937), Handakten der Vertreter der Anklage und andere Verfahrensakten (39 Bde).

Polizeidisziplinarkammer Hamburg

HH, Best. 221-9

Akten aus 13 Verfahren (1933-1937), darunter Entlassung wegen Beschädigung der Synagoge in Cuxhaven (1934), Ermittlungen wegen früherer Zugehörigkeit zu SPD und KPD, Auseinandersetzung mit einem SS-Führer (1935).

Dienststrafkammer Hamburg

HH, Best. $221-10$

Einzelne Generalakten und Akten aus ca. 250 Verfahren (unverzeichnet, 1933-1945, bis 1937 nur gegen Landesbeamte).

\section{Dienststrafkammer Hannover}

H, Best. Hann 180a

Generalakten (8 Bde, 1923-1937, mit Urteilssammlung 1935-1937), Akten aus 124 Verfahren (überwiegend 1933-1934, einzelne bis 1944) vor allem gegen Bürgermeister, Polizeibeamte und Lehrer.

Disziplinarhof für lübeckische Beamte 、 $\mathrm{HL}$, Neues Senatsarchiv, III $14 \mathrm{G} 2$ Akten aus 4 Verfahren (1933-1934).

Dienststrafkammer Schleswig SL. Abt. 312 Urteile (1932-1944), Verfahrensakten (8 Bde, 1933-1961), weitere aus 36 Verfahren gegen Beamte aus Altona im Staatsarchiv Hamburg (Best. 421-5), aus 28 Verfahren der Reichsdisziplinarkammer Schleswig ebenda (Best. 221-8).

Dienststrafkammer Sigmaringen

SIG, Best. Ho 261

Generalakten (3 Bde, 1932-1935) und Akten aus Verfahren gegen 3 Kommunalbeamte, je einen Lehrer und Gendarmeriewachtmeister (1933-1935).

\subsubsection{Seedisziplinargerichte}

Die Rechtsprechung der 1941 für die Bestrafung von Dienstvergehen der Angehörigen der Handelsmarine eingerichteten Gerichte ist in folgenden Beständen dokumentiert:

Seedisziplinarhof

BA, Best. R 95

Generalakten (7 Bde, 1939-1945, mit Weisungen und Statistiken), Akten aus 24 Verfahren (1941-1944), davon 16 gegen Kapitäne und Offiziere, u. a. wegen Verbrechen nach 175 StGB, tätlichen Angriffs auf Vorgesetzte, Wachvergehen, „Untergrabung der Manneszucht" mit Vorakten der Seedisziplinarkammern Bremerhaven, Danzig, Flensburg, Hamburg und Stettin. 
Seedisziplinarkammer Hamburg

$\mathrm{HH}$, Best. 222-7

Akten aus 53 Verfahren (1941-1944), davon 11 wegen Unzucht, 9 wegen militärischen Ungehorsams, 4 wegen Fahnenflucht, 2 wegen verächtlicher Äußerungen über Hitler, je eins wegen Unterstützung der KPD und Defaitismus.

\subsubsection{Ehrengerichtshof für die deutschen Rechtsanwälte, Leipzig} ZStA,Best.30.05

Neben einer geringen Anzahl von Generalakten zum Dienstbetrieb (ca. 10 Bde, 1914/1933-1945) ist eine sehr umfangreiche Überlieferung über ca. 4000 Einzelverfahren vornehmlich bis 1939 vorhanden.

Unterlagen und Entscheidungen aus den erstinstanzlichen Verfahren vor den Ehrengerichten bei den Anwaltskammern befinden sich möglicherweise noch bei den heutigen Kammern; vereinzelt sind Unterlagen darüber auch in Akten von Oberlandesgerichten enthalten (z. B. OLG Düsseldorf und OLG Hamm, vgl. oben 3.2.1.3).

\subsubsection{Reichsehrengerichtshof}

ZStA, Best. 30.11

Das Gesetz zur Ordnung der nationalen Arbeit vom 20. Januar 1934 sah bei „gröblichen Verletzungen der durch die Betriebsgemeinschaft begründeten sozialen Pflichten“ durch Arbeitgeber wie durch Arbeitnehmer ein ehrengerichtliches Verfahren vor, in dem als Höchststrafen die Aberkennung der Fähigkeit zur Führung des Betriebes bzw. die Entfernung vom Arbeitsplatz verhängt werden konnte. In letzter Instanz entschied darüber der Reichsehrengerichtshof; von ihm sind Akten aus 14 Berufungsverfahren (1940-1945) überliefert, die offenbar nicht mehr abgeschlossen wurden.

Unterlagen über erstinstanzliche Verfahren waren nur in Akten des Arbeitsgerichts Karlsruhe und der Staatsanwaltschaft beim Landgericht Essen (2 Verfahren gegen Betriebsführer, 1936-1938) zu ermitteln. In veröffentlichten Sammlungen arbeitsrechtlicher Entscheidungen sind auch Urteile von Sozialen Ehrengerichten enthalten (vgl. im übrigen Abschnitt 9.4.1).

Lit.: A. KRANIG: Arbeitsrecht im NS-Staat. 1984. S. 89-100, mit 5 Ureilen.

\subsubsection{Ehrengerichtsbarkeit einzelner Berufszweige}

Die Ehrengerichtsbarkeit der gewerblichen Wirtschaft ist in Akten der Reichswirtschaftskammer (Abschnitt 6.2.4) dokumentiert, der Ehrengerichtshöfe für Patentanwälte in Akten des Reichspatentamtes (oben 3.1.3), des Pressegerichtshofs und der Berufsgerichte der Presse beim Reichsverband der deutschen Presse (unten 4.6.2.4) und des Ehrenrats und Ehrengerichts des Reichsnährstands in dessen Überlieferung (unten 6.1.6). Bei Organen (Kammern) der nach dem Krieg neu begründeten Selbstverwaltung vor allem der freien Berufe könnten Unterlagen aus Verfahren vor den Ehrengerichten für Ärzte (Deutscher Ärztegerichtshof, München), Tierärzte (Deutscher Tierärztegerichtshof), Apotheker (Apothekergerichtshof) und des Handwerks (Ehrengerichtshof beim Deutschen Handwerks- und Gewerbekammertag) erhalten geblieben sein. 
